Portland State University

PDXScholar

1985

\title{
The use of humor in the social construction of role relationships in a behavioral treatment setting
}

Daniel D. Martin

Portland State University

Follow this and additional works at: https://pdxscholar.library.pdx.edu/open_access_etds

Part of the Counseling Commons, and the Sociology Commons

Let us know how access to this document benefits you.

\section{Recommended Citation}

Martin, Daniel D., "The use of humor in the social construction of role relationships in a behavioral treatment setting" (1985). Dissertations and Theses. Paper 3577.

https://doi.org/10.15760/etd.5461

This Thesis is brought to you for free and open access. It has been accepted for inclusion in Dissertations and Theses by an authorized administrator of PDXScholar. Please contact us if we can make this document more accessible: pdxscholar@pdx.edu. 
AN ABSTRACT OF THE THESIS of Danial D. Martin for the Mastar

of Science in Sociology presented December 5, 1985:

Title: The Use of Humor in the Social construction of Role Relationships in a Behavioral Treatment Setting.

APPROVED BY MEMBERS OF THE THESIS COMMITTEE:

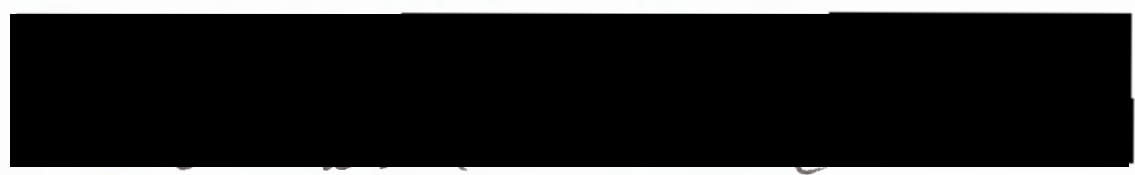

Dr. Charles D. Bolton, Chairman

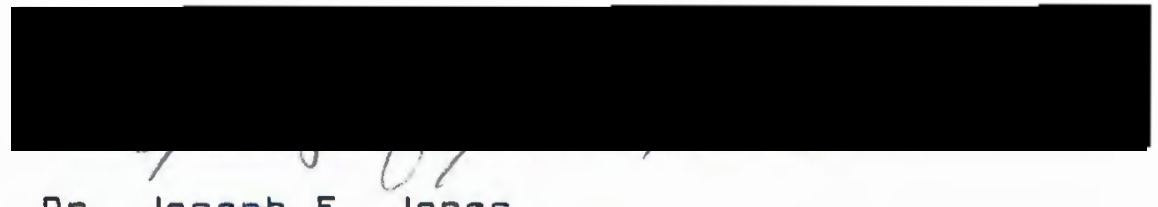

Dr. Joseph F. Jones

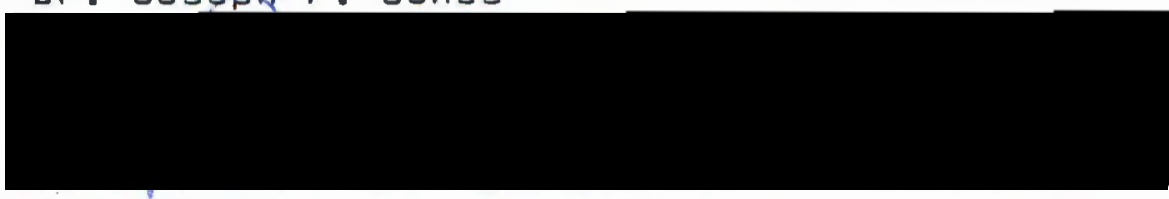

Dr. Robert W. Shotola

This study examined the use of humor between workers and managerial personnel of two different treatment teams within a residential treatment center for emotionally troubled youth. Three primary questions guided the research: (1) What indigenous types of occupational humor will be found within the treatment teams?, (2) How will the use of humor vary between front and back regions of treatment work?, and (3) How does occupational status affect the way in which team members target one another to be the "butt" of jokes and 
other humorous remarks?

Utilizing Erving Goffman's concepts of "front region" lwhere role-players attempt to give a performance which "embodles certain standards"), and "back region" (whera performers typically "let their hair down" and relax their performance)-- and " a study by Gary Traylor whose findings indicated that joking patterns in a workgroup follow dimensions of status-- the study presented three hypotheses:

Hypothesis I: The use of ridicule, sarcasm and invectives as a form of humor will more frequently occur in the back region.

Hypothesis II: The frequency with which a member of the group is the target of person-focused humor will be an inverse function of his/her status within formal or frontstage settings.

Hypothesis III: When the focus of humorous remarks is of superordinate status, humor/jokes will occur more frequently in the back region.

Observational data were gathered during staff conferences and on-line work of both groups, and at a local pub where members of both groups soclalized after their shift.

The findings appear to conform only partially to the 
hypotheses presented. Team performances in the staff conferences, given for the benefit of outside professionals, tended to support hypothesis I. That is, ridicule, sarcasm and invective as forms of humor were not present when outside professionals attended the staff conferences, but, rather, a concerted effort was made by the participants to create an impression of professionalism.

The appearance of outside professionals was also observed to produce a social transformation of the setting from a back region to a front region. While Goffman indicated that different physical locales are used by social actors for different types of performances, the present study found that the same locale (a confarence room) was socially transformed according to the desired impression that treatment team members attempted to create le.g., "we are all professionals" or "we can all relax now").

Hypothesis II appeared to conform only partially to the findings. It was observed that the distribution of person-focused humor assumed a hierarchical pattern lsuperordinate group members "joking down" to subordinates without subordinate group members reciprocatingl only when superordinates were defined as "functionally legitimate" by subordinates (i.e., when superordinates were judged to possess both technical competence and human relations skills). When superordinate group members were seen as not possessing adequate tochnical competence or human relation skills, hierarchical patterns of humor did not appear. The 
frequency of jokes or humorous remarks about the supervisors was greater in the back region of work (on-line) than the front region (staff conference). The findings, however, do not appear to support hypothesis III, even though jokes directed at the supervisors were greater in frequency in the back region. (Other superordinates, such as family therapists, were the focus of humarous remarks more frequently in the staff conference than on-line.\}

It was found in the present study that patterns of humorous exchange are thus mediated by both the setting of the interaction and dimensions of status. The findings also suggest that both status dimensions and patterns of joking which accompany these dimensions, may be relativized if particular office-holders come to be defined as functionally illegitimate. 
THE USE OF HUMOR IN THE SOCIAL CONSTRUCTION OF ROLE RELATIONSHIPS IN A BEHAVIORAL TREATMENT SETTING

by

DANIEL D. MARTIN

A thesis gubmitted in partial fulfillment of the requirements for the degree of

\author{
MASTER OF SCIENCE \\ in \\ SOCIOLOGY
}

Portland State University

1985 
TO THE OFFICE OF GRADUATE STUDIES AND RESEARCH:

The members of the Committee approve the thesis of Daniel D. Martin presented December 5, 1985.

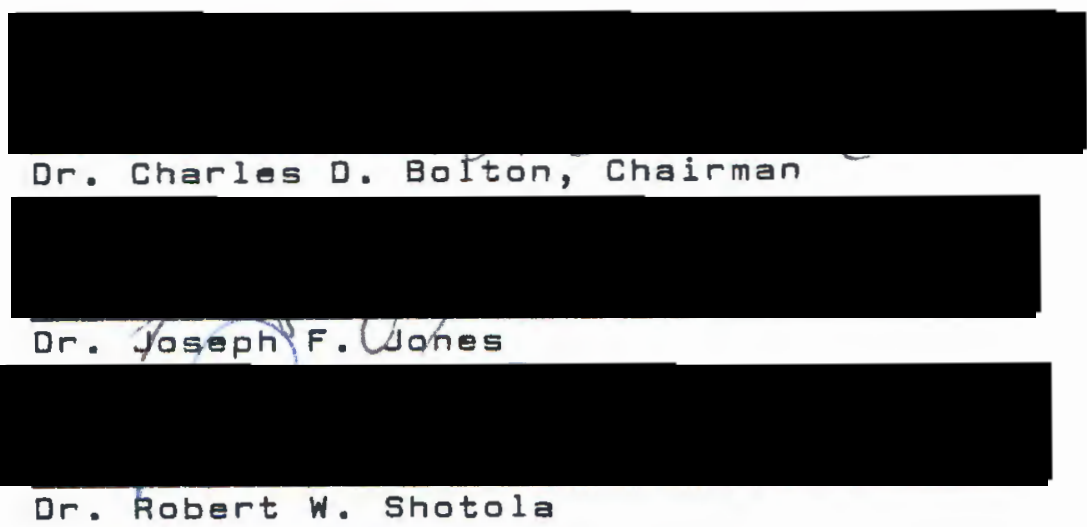

APPROVED:
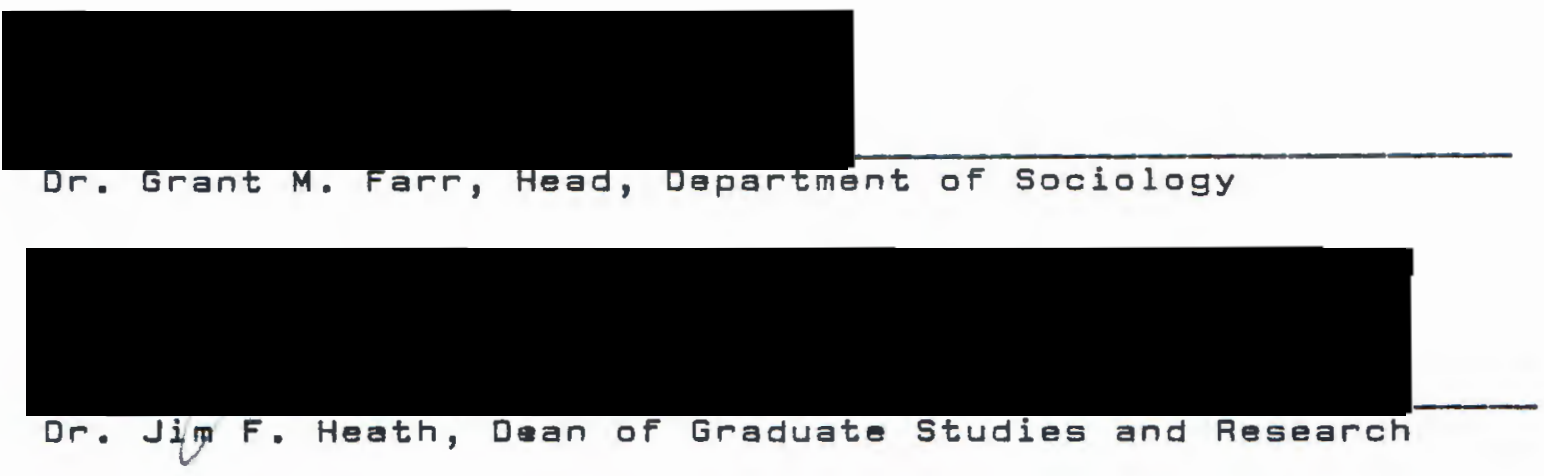


\section{ACKNOWLEOGEMENTS}

While contemplating exactly how I should word the following acknowledgements I have come to the realization that my own blunderings in writing style will probably hinder the true expressions of heart-felt appreciation I would wish to render. I shall thus be brief.

I would especialiy like to thank, of course, the members of my thesis committee. Dr. Bolton's theoretical comments throughout the whole writing process have been of great help, as well as his continual support and concern--these have been of inestimable value. I am in great debt to Dr. Jones who directed me toward key areas of the literature. I am especially indebted to Dr. Jones for his help with grammatical form and theoretical precision. Our chats and sharing of humor and cartoons during the course of this project helped provide a needed relief from the struggle of putting the paper together. I would like to thank Dr. Shotola for his availability and candid questions regarding my methodology; and for our talks about standards of ethics in social research. I would venture to say that Dr. Shotola has provided a lot more help than ho probably realizes, and, along with Drs. Bolton and Jones transformed the whole writing process into a learning experience-rather than simply a set of "hoops" to. jump through.

In acknowledging both friends and family I would like to 
express appreciation to both the Martin and Shepard families, whose love and support has helped sustain me through the whole endeavor. I cannot nearly say thank you enough save I write another chaptar. I would equally like to express my gratitude to both Mr. Kim Scott and Dr. Martin Abbott, and their families, for both their comic perspectives and their faith as friends--their support has been stalwart throughout this whole process.

Glancing over numerous other theses it appears that many of them are "joint efforts" typed out by spouses. This present work falls into that category. I would here like to express my love and appreciation to my wife and to God--both of whom I have, at times, probably tested to the limits of their patience and endurance. It is to my wife Jan I dedicate this endeavor.

$$
\text { D.D.M. }
$$




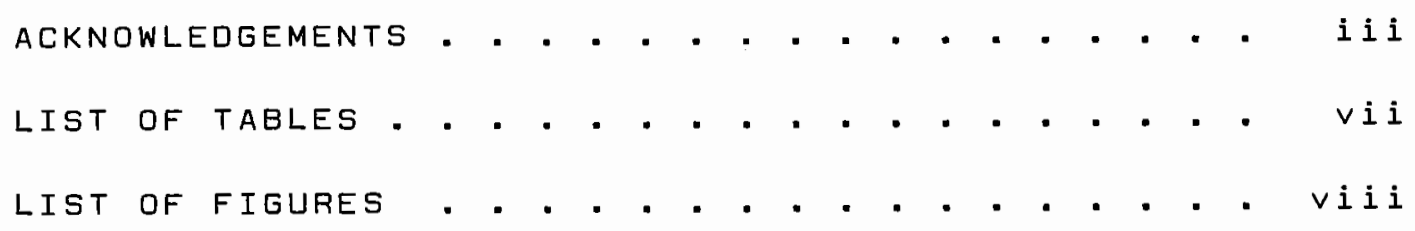

II Work Settings, Authority Structures and Humor . . . . . . . . . . . 69

The Staff Conference and On-Line Work as Stage Settings 
Work Routines and Stage

Workgroup structure and AuthorityRelations

Formal Organizational Structure

Authority, Status-Boundaries

Problems with Data Collection

Functional Legitimacy of Managerial Personnel

"Greenrooming:" Humor at the

\section{Problems and Implications for} Future Research 


\section{LIST OF TABLES}

TABLE

PAGE

I FRONTSTAGE HUMOR DISTRIBUTION • • • • • • • 116

I INVECTIVE, RIDICULE AND SARCASTIC HUMOR • • 119

II PERSON-FOCUSED HUMOR: STAFF CONFERENCE - . 121

IV STATUS AND PERSON-FOCUSED HUMOR

RANKINGS . . . . . . . . . . . . 122

$\checkmark$ CODED HUMOR HITHIN STAFF CONFERENCES . . . 125

VI BACKSTAGE HUMOR DISTRIBUTION (ON-LINE) • . 131

VII PERSON-FOCUSED HUMOR: ON-LINE $\cdot \cdot \cdot \cdot \cdot \cdot \cdot \cdot 136$

VIII HUMOROUS RIDICULE: DISTRIBUTION BY REGION • . . . . . . . . . . . . . . . 139 


\section{LIST OF FIGURES}

FIGURE

PAGE

1. TRANSITION OF STAGE SETTINGS . . . . . . . . 79

2. Formal structure of the treatment teams - • 86

3. Stage SetTings: PeRson-Focused humOR . • . . 98 


\section{INTRODUCTION}

\section{STATEMENT OF THE PROBLEM}

The study of humor has received theoretical attention from an assortment of quite divergent philosophical and intellectual positions. Vis-a-vis the vast array of other paradigmatic approaches to the study of humor (psychological, anthropological, philosophical, theological and physiological to mention a fewl, sociological theories have predominantly focused on humor as a communicative act which is symbolically constructed and serves a multiplicity of social functions (Barron 1950; Coser 1959; Emerson 1975; Obdrilk 1942). While much of the functional analysis of humor within sociology resembles anthropological work done on "joking relationships" (Apte 1983; Bradney 1957; Radcliffe-Brown 1952; Sykes 1966), the salience of sociological contributions to the study of humor hag been in delineating how human relationships are both molded by, and provide an experiential base for, humorous expression. Such analyseg have typically sought to explicate the integrative functions served by humor for social structures las well as its conflict and control functions).

Much of the soclological research on humor within complex organizations, industrial settings and work-groups has attempted to delineate how humor is used between role-occupants rolative to different status arrangements. 
Such research suggests that person-focused joking within work-groups reflects the social boundarieg derived from these status arrangements: specifically, while persons in superordinate roles are able to "joke down" to occupants of subordinate roles, persons in subordinate roles are not likely to reciprocate (Bradney 1957; Lundberg 1969; Traylor 1972). Other research has suggested that humor is an emergent part of group culture; fostered within work-contexts by social relationships in which participants license each other to breech the normative expectations which otherwise govern the situation (Handelman 1976; Handelman and Kapferar 1972; Roy 1959). These joking relationships themselves, however, may be transformed according to the different "stage" or setting within the organization in which humorous interaction occurs. Rose Laub Coser (1960), for example, indicated that the nature of staff conferences within a hospital setting provides an occasion for the deinstitutionalization of role-relationships, and a decrease in social distance between role-occupants, because of emergent norms of reciprocity which often accompany conference banter. Still other studies have attempted to reveal how professional functionarios are able to utiliza humor in problematic araas of role-relationships. According to Joan Emerson (1975), physicians and other medical professionala are able to sustain medical definitions of reality by using humor to "neutralize" the sexual 
connotations implicit in gynecological examinations.

The specific theoretical interests within this study focus on the different forms (as well as "group-specific" content) of humor that are to be found within two different treatment teams of a residential treatment center, the occasions and manner in which humorous episodes are symbolically constructed, and the social conditions and social relationships which mediate different humorous interaction. The general scope of this study includes how specific settings within the residential treatment center mediate variations of certain forms of humor, how person-focused humor is affected by status-position as well as the legitimacy of organizational role-occupants, and how participants of the treatment teams use humor to mitigate pressures considerad detrimental to group life.

In rather truncated fashion, two major conceptualizatione of humor are discussed in an attempt to discern the theoretical uniqueness of a sociological conception of humor. To qualify this apparent theoretical excursion, it may be suggested that in order for one to understand what a sociological conception of humor "ig" one must understand what it "is not." To this end, the following cursory presentation of two other conceptualizations, those of psychology and philosophical-anthropology, is made. After a fairly extensive review of the literature, it is felt that these perspectives reprasent major orientations to humor 
from which anthropologists and sociologists have historically "taken their cue."

THEORETICAL ORIENTATIONS TO HUMOR

\section{Psychological Approaches to Humor}

Psychologist Paul McGhee (1979) noted that the present meaning of the word "humor" (comical or amusing) originated from the archaic Latin word "humor," which meant "fluid" or "moisture." According to McGhee this classical conception of humor emerged from medieval and renaissance physiology which saw four basic bodily "humors" or fluids as playing a "major role in a person's temperament, mood or general disposition" (1979:5). The composition of the four humorg included:

1. Choler or yellow bile; was thought to be produced by the gall bladder-- an excess of choler led to irrascibility and proneness to upset or anger.

2. Melancholy or black bile; secreted by the kidneys or splean-- caused gloominess, dejection or depression.

3. Sanguine; excess of blood-- characterized by confidence, hopefulness and cheerful spirit.

4. Phlegm; referred to as cold, moist mucus producing "phlegmatic" temperament-- slugishness and apathy.

These four suppositions emerged from a conceptual 
body as a composition of four basic elements-earth, air, fire and water; each element associated with a specific temperature and degree of moisture (Cecclo 1978).

McGhee indicated that the predominant psychological view of humor has tended to focus on the importance of humor as it faclititas the release of emotional and psychological tension for the individual. That is, humor "performs dynamic: functions for an individual, mainly as a result of the laughter that usually accompanies humor" (McGhee 1979:3). Present discourse on humor within both psychology and the medical field have noted the cathartic effects produced by humor and laughter in the discharge and relief of emotional and physiological stress (Scheff 1979). Gary K. Laak (1974), in a report on the "Effects of Hostility Arousal and Aggressive Humor on Catharsis and Humor Preference," indicated that persons experimentally subjected to a hostility-arousal condition and then allowed to read aggressive wit jokes experienced a reduction in aggression/hostility towards the original source of arousal. other professional and paraprofessianal fields have also espoused the cathartic effects of humor and laughter. The notion of "Laughter as the Best Medicine" has long received popular attention from lay-journals such as the Reader's Digest. Other publications, such as Norman Cousins' (1976) "Anatomy of an IIIness," in which Cousins reported that he cured cancer with humor and laughter, have also attracted 
popular and professional attention. This growing attention is evidenced, too, in the emergence of "laugh clinics:" i.e., seminars which seek to educate persons on "how humor affects mental and physical health, how it can be used to relieve tension and stress, and how to find it in unexpected places" (Richards 1985). As a form of therapy humor has become a popular way of dealing with the stress, frustration and anxiaty usually associated with the occupational demands of one's profession. Specifically, humor has been suggested as an effective measure for use in the prevention of "burnout." Humor has been lauded not only as a healthy form of release for both emotional and psychological stress, but also for physiological stress-- which may approximate the gtages of an actual physical injury. One of the therapeutic benefits attributed to laughter, for example, is that it is a respiratory activity which dramatically oxygenates blood and thereby helps to alleviate physiological stress (Climo 1985). Perhaps the most pivotal psychological theory of humor was that of sigmund freud in which "wit" and "humor" were viewed as responses seated in the desire to escape the moral, rational and logical demands of society-- foremost, as a means of release by persons whose instinctual urges had been repressed by society. Freud viewed "wit" as a form of relaase of sexual-instinctual and aggressive impulses (primarily in the use of sarcasm). Humor, however, was viewed as a medium which served several functions: viz., as a 
socially legitimate means of releasing frustration and anxiaty, as a "defense mechanism," and as a source of gratification and pleasure (Freud 1905, 1938). While such an abbreviated comment on Freud's work can in no way indicate the importance of his contribution, such concepts have remained central for sociological as well as psychological inquiries into humor.

\section{Humor as Philosophical-Anthropology}

Max Scheler, expounding upon Immanuel Kant's metaphysics, sought to theoretically ground "man" as an object of study for the social sciences within the philosophical parameters of the "essence" or "essential conditions" of man (scheler 1958:1). By the term "philosophical-anthropology," scheler referred to

a basic science which investigates the essence and essential constitutions of man, his relationships to the realms of nature (organic plant and animal lifel as well as the source of all things, man's metaphysical origin as well as his physical, psychic, and spiritual origins in the world, the forces, powers which move man and which he moves, the fundamental trends and laws of his biological, psychic, cultural and social evolution, along with their essential capabilities and realities (Scheler 1958:65).

Scheler viewed the fundamental task of such a science as being an investigation into the relationship between the existential condition of humans and their ability to exercise a reflexive consciousness with regard to that condition. 
Scheler posited several kinds of knowledge which have emerged as specific historical doctrines or perspectives (e.g., history, sociology and philosophy). Insofar as he saw these "historical doctrines" as constituting distinct perspectives on man, scheler presented them as particular types of anthropologies. The significance of scheler's conception of philosophical-anthropology for a study of humor lies in a conceptualization of humor as one of the "essential conditions of man." classical philosophical theories of laughter, as noted by Arthur Koestler in Insight and Outlook (1949), have dealt with laughter as a source of ridicule and distantiation in human relationships. As Koestler indicated, in Aristotle and Plato's "theories of degradation' laughter was "closely linked with ugliness and debasement". Likewise for cicero, "the province of the ridiculous...lies in a certain baseness and deformity; for Descartes laughter is a manifestation of joy but a joy mixed with surprise or hate or sometimes with both" (1949:54). Finally, Koastler mentions Thomas Hobbes' theory (Leviathan) as a similar conception of laughter related to degradation. Citing Hobbes...

The passion of laughter is nothing else but sudden glory arising from a conception of some eminency in ourselves by comparison with the infirmity of others, or with our own formerly (Koestier 1949:56). [sic]

Other philosophical discourse on humor and laughter has 
focused on humor as a mechanism of cognitive and emotional transcendence, allowing persons to "rise above" the conventionality and suffering inherent in human experience. That is, humor is viewed as a symbolic transformation of life-experience into a metaphysical structure which relativizes both the finitude of man and human tragedy, such philosophical notions being typified as "liberation." Horace Kallen noted the association of "laughter and liberation" in the following:

The cheerful democritan laugh purports to be a laugh at them both-at the invincible nature of things and at deluded mankind waging its foredoomed war against the invincible nature of things; the laugher frees himself also from the suffering of its coercion and hurt, and he laughs again; his laughter at once his liberation and liberty. Such laughter is transcendent (1968:65).

Victor Frankl in The Doctor and the Soul (1957) also commented on the "transcendent" character of humor in the use of psychotherapy; the therapeutic utility of humor lying in what Frankl termed "rationalizing irrational fear." Frankl thus suggested an implicit metaphysical dimension in which comedy and tragedy were coetaneously interwoven into the fabric of human Iifo:

The humorous approach which we have suggested to him, which we have taught him to pretend, makes this easier for him-- for all humor makes it easier for people to put themselves ABOVE A SITUATION. In fact, humor is that sense of Iife, that "attunement" (Heidegger), which represents the unnecessary antithesis to the "tragic" mood, to the neurotic's anxiety 
about life-- just as, incidentally, humor represents the antithesis to that underlying mood of metaphysical anxlety which dominates in one-sided and rather arbitrary fashion Heidegger's existential philosophy (1957:207). (Emphasis added).

Comedy and tragedy, as a cosmic dualism in the classical works of shakespeare and others, represent a philosophical lineage ever-present in philosphical-anthropological discourse on the "nature of man." Philosophlcal-anthropologies offered by Peter Berger (1961,1970) and Jackson Lee Ice (1973) deplct humor as both part of man's "essential nature" and as a mechanism used by humans in dealing with the stark realities of their awn finitude (both Berger and Ice's works are more accurately described as "theological anthropologies"). Ice's treatise, titled "Notes Toward a Theology of Humor," conceptualized humor as a "prototypical human gesture" which allows humang to cognitively organize the universe or "cosmos" into some kind of logical structure. According to Ice, the cosmological importance of humor lies in its propensity to "force a journey from the constructions of the commonsense language world to the world that is beyond convention" (1973:397). While the implications for Ice's theological arguments are obvious, so, too, are the tenets of phllosophical-anthroplogy: viz., that humor plays an inherent part in humans experiencing their world and conceptually organizing it into a "meaning-structure." Or, as Ice stated: 


\begin{abstract}
Humor is a mode of encounter, one of man's transformational systams, which aids in ordering his psyche and mental respanses for insight and cantrol. It is a component of the psychic matrix man possesses for racycling his life forms toward importance. Like all man's modes of encounter it is rooted in being and hence reflects, while enhancing and transforming, the world and his experience of it $(1973: 394)$.
\end{abstract}

For Berger (1961), tragedy and comedy are two different aspects of the same "social drama" which comment on "human finitude." That is, tragedy perceives the "entrapment of man and accepts it" while comedy "questions the entrapment" (Berger 1961:212). Humor thus has a liberating effect on its creators. Harry Mindess positad, in Laughter and Liberation, that humor and laughter are sources of "freedom" from the "entrapment" of human lifa in that they "can enabla us to survive both failure and success, to transcend both reality and fantasy, to thrive on nothing more than the simplicity of being" (1971:21). According to Mindess, humor provides liberation from the routinization of everyday mundane reality, entrenched within modern consciousness. For Mindess, "the comic spirit is an embodiment of the spirit of disruption. It breaks us free from the ruts of our minds, inviting us to enjoy the exhilaration of escape" (1971:23). Mindess, moreover, asserted that humor also provides release or cognitive emancipation from conformity, inferiority and marality.

Humor has also been postulated as a symbolic 
construction which "liberates" persons from entrenched patterns of cognition (closed mindedness) and their own subjectivity: "the person who can appreciate the humor in his awn situation is liberated from the dominance of his own emotions, and so has a more objective view of himself" (Morreall 1983:106). That is, humor is posited as creating psychological distance from one's own personal problems or preoccupation with oneself, thereby fostering objectivity. such distance or "liberation," by individuals from a particular repertoire of interpersonal responses or "transactional role" is viewed as having potentially positive effects. In light of the subjective attachments that persons may develop to problematic roles, humor has been suggested as a therapeutic mechanism in interpersonal relationships in that "joking reflects the ability of role partners to achieve some distance from the conflict by laughing at themselves and each other" (Jacobson and Hermann 1966:95).

Finally, in a philosophical-anthropological essay on religion, Berger set forth the proposition that comic discrepancies are ultimately derived from the "discrepancy between man and the universe" (1970:70). Berger asserted that "it is this discrepancy that makes the comic an essentially human phanomenon and humor an intrinsically human trait" (1970:70). For Berger, one of the most important functions of humor is that it allows participants to relativize "discrepancies of the human condition," one of 
these discrepancies being power. While the "serious" reality of power-differentials may lead us to pity its victims, humor, according to Berger, allows us to relativize the situation. Humar "turns the tableg" as it were, implying that "the one to be finally pltied is the one who has the lllusion"..."power is ultimately an illusion because it cannot transcend the limits of the empirical world. Laughter can-- and does every time it relativizes the seemingly rocklike necessities of this world" (Berger 197ø:71).

While the thearetical orientation of philasophicalanthropology implies that humor is able to relativize many social conventions (and points to its cosmological dimensions), the framewark does not explicate exactly "how" humans use humor to achieve this. That is, the propositions offered remain philosophical propositions which do not readily lend themselves to empirical testing. This present study proposes to examine some of the sociological properties (e.g., the relativization of gocial conventions) derived from this framework.

\section{Huumor as Incoongruity}

One of the fundamental theories regarding the "binary" character of humor posits that particular kinds of communications are humorous because they establish "incongruous relationships (meaning) and presents them to us with suddenness (timing) that leads us to laugh" (Berger 
1976:113). That is, humor, tout court, "primarily regults from a situation associating two generally accepted incompatabilities" (Van order Smith and Vinackle 1951:69). Such a conceptualization is represented as early as 1819 by Schopenhauer, wherein humor was postulated as the "sudden perception of incongruity between an object and the abstract concept under which it is subsumed" lcited in, Wilson $1979: 11)$

Perhaps the most salient contribution to the incongruity theory of humor was proffered by the French philosopher Henri Bergson (1956), in which a comic situation was viawad as one which solicited an interpretation from two mutually exclusive meaning-structures. As Bergsan stated:
A situation is invariably comic when it belongs simultaneously to two altogether independent series of events and is capable of being interpreted in two entirely different meanings at the same time (1956:123).

For Bergson, the comlc situation is epitomized by occasions in which the gestures and movements of the human body "remind us of a mere machine" (1956:79). Such a duality, according to Bergson, produces an expression "which gives us, in a single combination, the illusion of 1 ifo and the distinct impression of a mechanical arrangement" (1956:105).

In hig theory of "bigociation" (1949), Koestler presented a similar conception of humor as incongruity. Koestler argued that humar is a product of dual association 
in which a logical assertion is "simultaneously associated with two habitually incompatible contexts" (1949:37). The potential for humor to be perceived within this cognitive process arises from the presence of what Koestler termed "operative fields." By the concept "operative fields," Koestler referred to "logical chains and streams of associations, raasoning by analogy, or by induction or deduction, syntax and grammar, thinking in terms of this or that"; those processes, in toto, which come to be routinized into a "pattern of thinking" (1949:39). Koestler posited that humor emerges from mental patterns or cognitive structures, which habitually "appear as incompatible; not necessarily a pattern that is logically incompatible" [1949:37]. A similar conception is offered by John Morreall who viewed laughter as the result of a "pleasant psychological shift...emanating from unexpected stimulation" (1983:4ø-41); ("psychological shift" referring to a shift from one mode of thinking, or conceptual system, to another). While humor arises from the apparent incongruities between conceptual systems, laughter is "the physical activity which is caused by, and which expresses the feelings produced by, the shift" between these structures (Morreal1 1983:39). In a phenomenological discourse on humor and joking, sociologist Anton C. Zijderveld (1968), also presented humor as a form of "psychological shift;" this shift, however, having direct implications for analysis of every day life. Consideration 
will be given to some of these implications in the following. Húmor, Language and Social Reality

Ag Zijderveld noted, the relevance of sociology

(gpecifically a phenomenological sociology) to a study of jokes 1 ies in the fact that joking is first and foremost a social phenomenon: "In order to joke and laugh, we need the company of at least one partner; it is very much a matter of social interaction" (Zijderveld 1979:101). Such humor is, as it were, the "social grease" lubricating both conceptual machinery and the stream of human interaction from which it draws its content. If only temporarily, humor allows us to "leave the functional realm of daily routine and its chores," to "enter a make-beliave world in which in principle everything is possible. In humor, the values of social life are turned upside down, the norms of social hierarchies violated, the rules of language (grammar, syntax) and of logic suspended" ( $z i j$ derveld 1979:1ø1).

According to Zijderveld, what humor has in common with sociology is the "rolativization of our taken for granted world" (1968:287). Preclsely, what we take for granted in the natural attitude of everyday lifo-- and its "pragmatic motive"l-- becomes temporarily abandoned for an alternative perspective (viz., a humorous one). This temporary abandonment being, as Alfred Schutz contended, a transition from one "finite province of meaning" or "meaning structure" to a different one (Schutz 1962:23ø-232). That is, humorous 
episodes are situationally transacted by persons who have "jumped" from one particular "cognitive style," or "texture of consciousness" (that style being serlousness, or the "pragmatic motive"), to a different one...humor. Zijderveld, however, suggested that humar creates a "specific accent of raality" by relativizing "institutionalized meanings." The uniqueness of humor as both a cognitive process and grammatical form, according to Zijderveld, is that humor relativizas institutionalized meanings at the same time that it suggests that this relativization, itself, is not to be taken seriously:
At least for the duration of the laughter elicited by jokes, the meanings that had been played with aro rolativized. Meanwhile, laughter turns out to be a very adequate response: it defines this play with institutionalized meanings as samething not to be taken seriously; it communicates the fact that the legitimacy and plausibility of the meanings is not really affectad, that reality still is what it has been before (1979:102).

In his analysis of "Jakes and their Relation to social Reality," Zijderveld defined joking as the "conscious or unconsclous transition from one institutionalized meaning structure to another, without changing much of the original role behavior and logic" (1968:290). That is, a joke results from the evocation of an institutionalizad meaning-structure from which it then departs: in essence, a linguistic "set-up" which plays upan the comman-sense, taken-for-granted attitude of its hearer. This departure from the expected manifests a 
novelty from which jokes "draw their power" (zijderveld 1969:291]. As "deviations" from ingtitutionalized meaning structures, Zijderveld offered four categories of jokes and their respective techniques (1968:299-3ø1):

Categories of Joking

1. As deviations from the meaning of socio-cultural and political life at large

2. As deviations from the meaning of language

3. As deviation from traditional logic

4. As deviations from traditional amotions

\section{Technique}

Imitation of everyday

existence, stylization of our taken-for-granted way of lifa, and the emphasis upon unconsiously accepted "normal life."

Play in word order, syntax and grammardeviations from the standards of language.

(a) Transports normal logic into the absurd (b) Deviates from normal logic by hypar-cunning inteligence.

sick-humor jokes; jokes encompassing such ultimate human facts as death, birth, sexual intercourse, fatal diseases, love, faith, atc.

Humor, as a form of communication, shares with other locutionary modes a symbolic organization with which either actual or potential experiences can be expressed or anticipated. That is to say, humor is symbolically constructed and then related to othars within a world of previously constructed meanings. Quite simply, humans Iive within a social-symbolic world which arises from their 
ability to construct meanings not simply an "environment" which is a repository of stimuli, eliciting rasponses from humans-- humor is thus a departure from these routinized meanings. While the functional aspects of humor are those which may relieve both psychological or structural stress for participanta, humor is a communicative episode which is symbolically constructed-o oftentimes a product of individuals fitting together their communicative "lines of action" In a concerted effort to situationally construct humor.

As Zijderveld indicated, jokes, like other communicative modes, "are essentially empty forms which can be filled up with totally different meanings, dependent on specific people in specific situations" (1968:294). That is, old joke-forms are modes of communication which, still, are situationally constructed and hence can only be understood in terms of the "socially organized actual occasions of their use" (Garfinkel 1967:3). Humor is thus a symbolic expression whose meaning can anly be "indexed" from the interaction-episodes from which it emerges; $1, e .$, it may be understood as Garfinkel has proferred-- as an "indexical expression" (Garfinkel 1967:11). In much the same way, Charles Winick (1976) suggested that not only do jokes permit persons to volce feelings for which there is "no socially acceptable or easily accessible outlet," but that jokes which prevail in American sociaty can only be "indexed" or understood in terms of the larger 
cultural context.

While humorous episodeg are symbolically constructed in concrete situations, this construction is gestural as well as linguistic. The utilization of linguistic forms of humor, however, often allows one to objectify or "actualize" experiences for both others and oneself. The use of language in symbolically constructing humor not only makes socially available for others one's own experiences, but potentially objectifies those experiences in a manner which cognitively or emotionally disarms them. Thus, one can mitigate actual experiences faced as threats in one's biographical past, or disarm future or potential threats, by conjuring up and objectifying an Imagery given humorous form. For example, one can "disarm" an intimidating personnel director during a job interview by imagining him wearing nothing but underclothes; or make socially available one's own biographical experience, relating the toughness of one's neighborhood, the poorness of one's family, etc., as caricaturas of a subjectively experienced reality (which then becomes symbolically as well as temporally disarmed). Put differently, not only is language "capable of becoming the objective repository of vast accumulations of meaning and experience which it can then preserve in time" (Berger and Luckmann 1967:37), but as a repository it also holds the potential to modify this experience, a la humor, every time such experiences are communicated to others. As is often the 
case, some subjective experiences actually seom to gain objective facticity, becoming "larger than life," after they have been told and ratold to others. Thus, the temporal dimension or "distance" from one's own prior experiance also helps facilitate a redefinition of the situation. Murray 5. Davis suggested that the use of humor and comedy actually allows persons to symbolically distance themselves from the actual or potential disorganization of their social world: "They back off from what they fear is falling apart, so that the instability of their external world does not threaten tha stability of their inner psychological world" (1979:167). Hence, social gituations which are initially very problematic come to be seen as humorous once the danger has been either temporally neutralized (distance in time), symbolically neutralized (redefined in meaning), or both.

Humor may also be uged to neutralize ongoing threatg to reality, emergent in immediate interaction-situations. Such a process may be molded, also, by the general nature of language. As Edward Sapir positad, language "actually defines experience for us by reason of its formal completeness and because of our unconscious projection of lts implicit expectations into the field of experience" (Sapir 1964:128). As indicated by others, the construction of reality is "an operation that takes place within the linguistic system and the meaningfulness of experience is realized only when the received language is applied to it" 
(Homan 1981:219). Roger Homan noted the importance of language in establishing a consensual definition of the situation within one's own group:

In spheres of experience which are not neutral

to the dominant group the usa of the group's particular language is critical to the definition of the situation since it carries "correct definitions" of the perceived reality $(1981: 220)$.

Joan Emerson explicated how physicians and other medical professionals are able to employ the technical terminology of their field in an effort to simultaneously sustain medical definitions of reality during gynecological examinations, along with counter themes which tend toward personalization and the semblance of intimacy. As Emerson stated, at the same time the patient's "self must be eclipsed in order to sustain the definition that the doctor is working on a technical object and not a person" (1975:335), "failing to acknowledge another person is an insult. It is insulting to be entirely instrumental about instrumental contacts" (1975:336). Thus, the physician must symbolically organize the situation in a way that will allow him to "carry off the performance." As mentioned, a special language is employed in staff-patient contacts in an effort to depersonalize and desexualize the encounter. While communication between physician and patient must occur for technical reasons (e.g., gauging the presence of pain, etc.), the physician must avoid explicit technical terms as well as dodge common everyday 
language-- which would bring the symbolic ediflce of the whole situation crashing down. Emerson specifically noted changes in syntax whlch helped accomplish this feat:

\begin{abstract}
Substituting dictionary terms for everyday words adds formality. The definite article replaces the pronoun adjective in reference to body parts, so that for example, the doctor referg to "the vagina" and never "your vagina."

Instructions to the patient in the course of the examination are couched in language which bypasses sexual imagery; the vulgar connotation of "spread your legs" is generally metamorphosed into the innocuous "let your knees fall apart" (Emerson 1975:334).
\end{abstract}

While a variety of events threaten the definition of the situation as a "medical situation" which calls for a "matter-of-fact stance," (e.g., a patient's embarrassment, signs of sexual arousal, etc.), such events are actively redefined by medical staff whose "foremost technique in neutralizing threatening events is to sustain a nonchalant demeanar" (Emerson 1975:338).

The use of humor in gynecological examinations provided the medical staff with a very important maans of sustaining a medical definition of the situation. As Emerson observed, humor may be used to both discount counter-definitions of the situation, proffered by the patient, at the same time that it provides a "safety valve" for all of the role-players in the given performance. As Hugh D. Duncan stated, "comedy upholds as well as regigts authority by making ridiculous, absurd or laughable whatever threatens social order" (1962:377). 8y 
symbolically constructing both implicit and often overt concerns into a humorous form (joke, pun, etc.) medical personnel and patients were able to express these concerns "without taking the responsibility that a serious form of the message would entail" (Emerson 1975:338). Humor thus neutralized elements of the examination which threatened the definition of the situation by discounting implications which would be deragatory in another setting. Mary Douglas in an article "The Soclal Control of Cagnition: same Factors in Joke Perception" (1968), delineated other situational factors which mediated the construction of humorous episodes. By her term the "social control of cognition", Douglas meant that for joke-forms to occur a certain configuration of both social experience and social conditions must bo, a priori, constructed. That is, there are certain social conditions which permit a joke to be perceived and initiated. Douglas' major proposition is offered below:

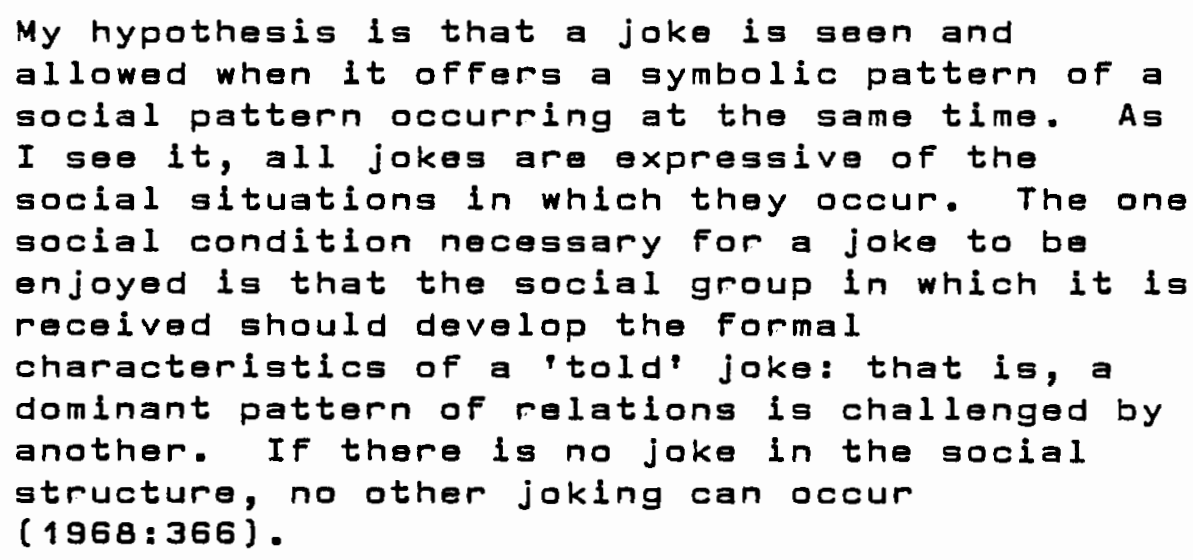

Humar In the form of jokes only arises to the degree 
that jokes are perceived or interpreted as such. Such a perception, according to Douglas, only takes place if the joke corresponds to some form of social experience. Dworkin and Efran, for example, noted in their study on anger and humor that "people respond more strongly to humor stimuli which in some way parallel or relate to their currant cognitions" (1967:236). Douglas, however, posited that "the experience of a joke-form in the social structure calls imperatively for an explicit joke to express it" (1968:368). Douglas suggested that the "joke experience" is a "fourfald perception of the congruence of a formal pattern." This pattern consists of congruence between the symbolic organization of the joke and a configuration of social, physical and mental experience leach conceptualized as a matrix which, when aligned with the others, produces a release of subconscious energy). Douglas' conception of the "joke experience" is reminiscent of Parsons' theoretical work on the relation between systems in the "Cybernetic Hierarchy of Control" (Parsons 1961:30-38). Note the similarity between Douglas' structure of the joke experience and Parson's model of informational control:

(Douglas) Joke Experience as Congruency Among Structures:

Joke Structure (symbolic)

social structure

Physical Experience
(Parsons) Systems of Informational Control:

Cultural System

Social system

Personality system 
Subconscious Enargy

Organismic system

While, admittedly, Douglas offered the analysis in a cursory manner, the analysis failed to indicate which specific social and experiential elements in the total configuration align with one another to produce the "situational effect" of humor. These considerations seem to have been more generally addressed in Handelman and Kapferer's analysis of "joking frames," which are presented below.

Handelman and Kapferer (1972) indicated that humor is situationally constructed according to the set of contextual rules which govern the joking activity. They refer to both these rules and the context, in toto, as "joking frames." Joking frames or joking activity has elsewhere been referred to as a "form of play" (Wilson 1979). William Difazio, for example, noted the inclusion of such "play" by denizens of the "Hiring Hall Community:"

Joking behavior consists of paper throwing, hair messing, head rapping, insults, joke tolling, etc.. To an outside observer, this behavior would be interpreted as hostile and overtly aggressive behavior, not as behavior that contributes to group solidarity (1984:63).

According to Handelman and Kapferer, before individuals are able to organize their interaction in terms of such joking they must "receive a 'Iicense to joke' from the persons toward whom their activity is directed" (1972:484). 
This "license to joke" constitutes the "rules of the frame" such that some frames may be governed by rules "rooted in the mutual past experience of participants and therefore does not necessarily have to be negotiated at the onset of each new joking sequencell (Handelman and Kapferer 1972:484). Joking is viewed as a process which is both molded by the "form" of the activity and conditioned by the soclal context in which it initially emerges.

The sequences presented by Handelman and Kapferer constitute two different types of joking frames, those which are "setting-specific," and those which are "category-routinized." "Setting-specific" joking frames represent a particular joking activity in which its initiation depends upon "locally derived cues proffered by and to potential participants" (1972:485). The "time-depth" of setting-specific joke frames tends to be very shallow, relying upon specific persons and identities in the given social setting. Because these frames are situationally constructed and have not been routinized, either in terms of specific roles or specific cues in the joking activity, such frames are easily susceptible to "subversion." That is, "participants are rarely able to sustain the original definition of the frame in the face of attempts to end the joking discourse" (1972:485). Subversion of the setting-specific joke frame most readily occurs when participanta are confronted by the reality-invoking 
statements of others. As Handelman and Kapferer stated:

Rules of the frame and joking behavior emerge interdependently through the course of joking and generally affect one another. It is therefore axiomatic in setting-specific joking that the establishment of a joking frame also plants the seeds to its own destruction or the transformation of its original rules (1972:496).

While setting-specific joke frames are relatively unstable and therefore easily altered, "category-routinized" frames tend to be more resilisnt and able to sustain the original definitions of the joking activity for a longer period of time. Category-routinized joking is joking behavior that is "anchored in the common recognition that particular categories of persons can joke with one another" (Handelman and Kapferer 1972:497); (e.g., friends, on-line workers, managers]. One of the implicit assumptions of category-routinized joking is that normative prescriptions which govern the context of joking, the category of the person permitted to joke, and even the content of the joke, have been consensually valldated by all of the participants. Handelman and Kapferer point out that one of the most important functions of such a joke frame is that it allows the social identities of the participants to be playfully (and temporarily) redefined in derogatory ways. That is, the "derogatory redefinitions are meant to be treated nonseriously by the mutual consent of the participants, and the serious meaning of redefinition is disattended to" 
(1972:5ø2). Reclprocity of this redefinition within such frames is typically one of the social items which makes routinization of the frames possible. "Reciprocal rights" to target another as the focus of the joking activity is, in fact, essential for the activity. Those who initiate the joking, or select the target lperson towards whom the joking is directed) run the risk of being selected as a target, in all possibility, by the person at whom they aimed their comments (Handelman and Kapferer 1972:5ø2). The initiator of the joking actually sets her/himself up as a potential target since the target of the joke may be supplied with sufficient influence to redirect the joking back towards the initiator target (the entire frame may be subverted if the "target," in fact, refuses to be the target).

Handelman and Kapferer offer a conception of joking activity which has two primary implications for a sociological study of humor: (1) as social relationships vary In their degree of formality, intimacy, time-depth and social contexts of occurrence, so do the normative expectations which accompany them; and (2) while humor is situationally constructed, like other human activities its construction follows the normative expectations which infuse these social situations.

The general intent of this study is to understand such relationships in an organizational setting-- specifically that of a social service agency. While this study proposes 
to research the emergence of humor within such a setting, much of the literature on humor in work-groups and organizations has provided a substantial theoretical basa, focusing on its use within staff meetings and "on-line" work and as a form of communication mediated by formal status arrangements between role-occupants. Such concerns, however, exceed the framework thus far presented. 


\section{HUMOR AS PART OF WORKGROUP CULTURE}

In much the same way that culture has been represented as an "adaptive mechanism," or "design for living," (Kluckholn 1949), used by humans in molding their natural environment, similar conceptions have been employed in analyses of the workplace. (The cultural items of workgroups have often been discussed in terms of providing a "solution to the elemental problem of 'psychological survival'i) (Roy 1959:158). Andrew M. Pettigrew delineated the concept of organizational culture "as a system of such publicly and collectively accepted meaning operating for a given group at a given time," within the workplace (1983:93). According to Pettigrew, "this system of terms, forms, categories and images interprets a people's own situation to themselves." Gary Alan Fine has proffered a similar conception within the theoretical framework of small-group analysis-- specifically, that of "idloculture." By "idioculture," Fine refers to "a system of knowledge, beliefs, and custom which are particular to a group to which members can refer and employ as a basis of further interaction" (Fine 1977:315). The concept of culture, generally expressed as a system of knowledge, represents, too, the establishing of a "symbolic universe" which supplias explanations of the group's existential condition, tradition and origin. The cultural life of workgroups may thus be seen as representing a symbolic 
subuniverge within the total life of the organization. That is, within the symbolic "subuniverses of meaning" workgraups may socially construct and/or maintain an identity which is somewhat independent of the organization's offical function. This identity may be sustained, in part, through the use of "collective representations" (Durkheim, 1965). Quite simply, workgroups themselves may symbolically designate particular traits of their groups for others, or themselves, through the collective identification (or "shared sentiment") with certain sacial items, which then serve as symbolic referents for the group (see Appendix A).

It is proposed here that every workgroup exhibits its own particular "idioculture" and that one cultural item within conceivably all occupational groups is humor. Martineau (1972) posited that humor within different structural settings serves two primary functions: (1) as a means of social facilitation, and (2) as a means of social control. According to Martineau, humor fosters consensus ano group integration by facilitating the development of social relationships, esteeming the group life of the in-group, or by disparaging those in the out-group. The functions performed by humor, however, are always predicated upon its phenomenological status i.e., how the utterance or cue comes to be intersubjectively defined by the denizens. As Martineau stated, "humor initlated in an intergroup situation functions within the group depending upon how it is judged by 
the group members" (1972:116).

Joking Relatianships

Much of the research on humor within the workplace has focused on joking relationships as a cultural aspect of workgroups. These studies have indicated that such humor serves as both a saurce of play and entertainment for participants and also reflects the normative expectations which are woven into workgroup culture. One earlier analysis (discusged below), which provided the theoretical framewark for some of these studies, was done by A.R. Radeliffe-Brown. In hig seminal work on humor within group life, A.R. Radcliffe-Brown in Structure and Function in Primitive Society (1952), axplicated how familial and trlbal joking relationghipg promoted integration within small social

systems. By the term "joking relationships," Radcliffe-Brown referred to "a relation between two persons in which one is by custom permitted, and in some instances required to take no offense"t (1952:9ø). The joking between tribal members, according to Radcliffe-Brown, represented an alliance which increased social solidarity. Radcliffe-日rown also indicated that these relationshlps were often stratified gerontocratically. In several tribes lojibwa Indians of North America, Clinga of Uganda, Zigua and Zarama tribes of East Africa), for example, children were not allowed to joke or tease their own parents-- thereby maintaining the 
appropriate degree of deference-- but commonly formed joking relationships with their grandparents. According to Radcliffe-Brown, both grandparents and grandchildren were on the periphery of participation of social life (grandchildren entering into full participation as grandparents are leaving it). Such social transitions in tribal lifo permitted the usual status differences within the tribe to be situationally relativized; allowing children an "exchange relationship" with grandparents that wauld otherwise be considered socially inappropriate.

One of the more significant aspects of joking relationships presented by Radcliffe-8rown, was that of directionality. That is, joking relationships were classified as either "symmetrical" (both persons engaged in mutual exchange), or "asymmetrical" (one person accepting the joking of another without "retaliating," or by returning only a minimal teasing response). By the concept of symmetrical/agymmetrical exchange, Redcliffe-Brown thus referred to humorous exchanges as they were related to status positions within the tribal and familial social structure.

Peter 8. Hammond (1964) analyzed joking relationships within Mossi tribal society, observing that joking served as an "adjustive mechanism," which established a social context conducive to intermarriage between "descent groups" within the tribe. Prior to such marriages, separate family or "lineage" groups within the tribe associated with one another 
in part through "joking alliances." While joking alliances promoted a high degree of amity between descent groups, the occurrence of marriage was accompanied by different norms of joking behavior. These newly acquired normative prescriptions delimited the type of joking remarks and insults persong outside of the marriage arrangement could otherwise engage in. In the following, Hammond described the transformation of joking behavior due to new social relationships produced by marriage:

Once such marriage is contracted, however, Ego and his wife must take care that their joking insults are directed only at younger kinsmen of the other and that insulting remarks are personal. It would, for example, be acceptable far Ego to call his wife's sister a disreputable shrew but dangerous to call her a slave (a term of disrespect used frequently in jaking between sibs\}. To refer to her as a slave would cast unflattering aspersions on her entire kin group, including her mother and father, with whom, in their new status as parents-in-law Ego may no longer joke (1964:266).

One function of joking alliances, mantioned by Hammond, is that they provide a context in which intergroup grievances can be expressed and resolved. The joking relationship, likewige, allowed for the expression of aggressive feelings which reduced frustration between group members and thus served indirectly to "perpetuate the amicable aspect of the relationship in which it occurs" (Hammond 1964:264).

Utilizing Radcliffe-Brown's theoretical framework, both Pamela Bradney (1957) and A.J.M. Sykes (1966) studied humor 
within the workplace. Bradney's study examinad joking relationships within a sales department of a large department store. Her report indicated that such relationshipg helped facilitate cooperation and cohesion between personnel in a structural context which promoted conflict and competition. Disruptive social elements such as interruption by other workers, competition between sales personnel, and social distance between staff members, was mediated, according to Bradney, by a relationship which allowed frustration to be vented in a socially acceptable manner. While potential conflict between store personnel soemed inevitable upon occasion, it was pracisely on such occasions that a joking relationship developed. As Bradney posited, "the 'social conjunction' between the assistants-- because they are working for the same organization, on the success of which their livelihood ultimately depends-- makes essential the avoidance of strife in the department, and it is at this point where conflict is most likely to arise that the joking occurs" (1957:183).

The joking within the department store included a wide variety of subjects by staff personnel. Such joking entailed "a jovial manner of passing the time of day or commenting on the weather or some other matter of topical interest; mutual teasing about personal habits, appearance, love experience, morality, and, in particular, work and the methods of work; telling funny stories about members of the store and telling 
other funny stories in some way relevant to the subject of conversation" (Bradney 1964:183). The joking, however, was not necessarily confined simply to relationships between personnel of equal status within the store. While joking relationships tended to be symmetrical between participants of similar gtatus (1.e., personnel of similar status participatad equally in jocular exchangel, asymmetrical joking tended to occur between members of different status (i.e., higher-status personnel "aimed" their joking at subordinates who did not reciprocatel. Symmetrical joking relationships formed irrespective of status, however, when members of low status...

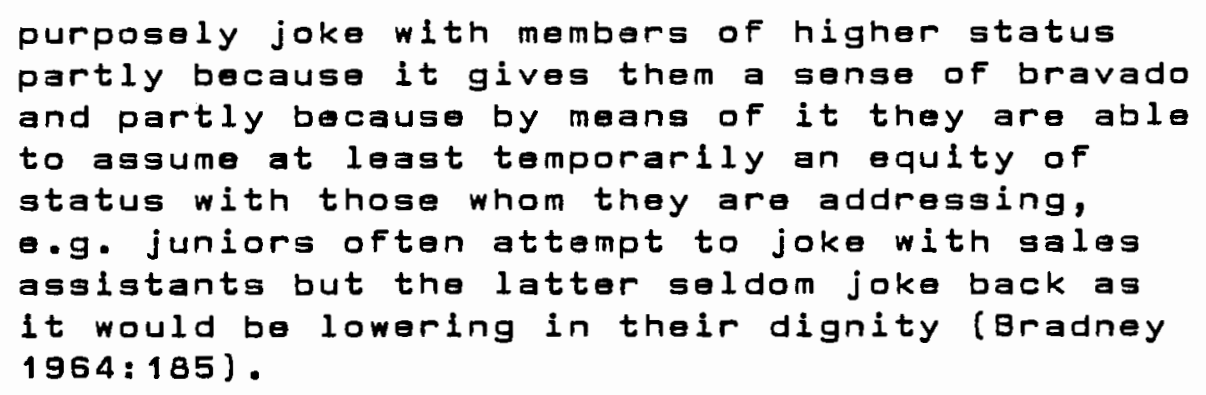

Research by A.J.M. Sykes on "Joking Relationships in an Industrial Setting" (1966) observed how joking relationships between workers in a print shop were mediated by variables of participant age and sex. The findings of sykes study suggested that while norms of modesty among young female and male workers typically delimited the usual type of profane banter permitted in the workplace, "immodesty in behavior was restricted to those who were not potential sexual partners" 
(1966:193). Participants in the study were designated as belonging to one of four different categories: old and young male, and ald and young female. The placement of persons in these categories depended upon the following factors: (a) age--the "young" categary included persons age 15 to approximately age 25 , and in some cases up to the age of 30 ; (b) personal choice--in some instances a person could determine his or her age classification by assuming a role in the joking relationship that was appropriate to that age le.g., a person, age thirty, who maintained the role of a young person might still be accepted as young: once one was accepted as "old," however, there was no changing back to a "young" classification); (c) marital status--a married person was typically regarded as old and normally assumed the role of an "old" person in the joking relationship (1966:189-19ø). While all workers in the print shop were abserved to engage in "serious" conversations on such topics as union activities, work, etc., sykes primarily focused on the presence of obscene banter between warkers. The joking relationships between both old and young men, and old men and women, tended to be very similar. Persons in these categories exchanged a great deal of obscene banter, exhibiting a symmetrical joking relationship (i.e., one in which oither party could initiate the jokingl. Specifically, while axplicit comments of a "suggestive" nature were never made, persons of either sex "could Initiate obscene 
axchanges." The joking relationship between young men and old women in the print shop, howevar, proved somewhat different: participants in both categories were permitted to exchange obscene remarks, but the banter was almost always initiated by the women. (Such exchanges "stopped at banter; physical contact, horseplay or petting between young men and old women was never observed") (Sykes 1966:19ø). Analysis of the joking relationships between old men and young women, and, young men and young women revealed quite divergent findings. The "old men" in the print shop were permitted "gross obscenity," in their joking relationships with young women; "almost anything could be said as a joke without causing offanse" (Sykes 1966:19Ø). Sykas stated that in this relationship "old men were permitted a great deal of license in public touching, kissing and petting the young women. The women rarely made any objection and in fact 'led the men on" (1966:19ø). The apparent tolerance for this type of joking behavior, according to sykes, must be understood in the total complex of normative prescriptions which govern print shop activities. While the old men were able to sustain profane conversations with young women in a joking manner, they were not pormitted any kind of physical contact ("petting") in private. Indeed, such behavior received severe sanctioning from all members of the work-group. By contrast, the joking relationships between young men and women, within the print shop, appeared to be the only context in which a social 
relationship, aside from their work relationship, was publicly permitted (sykes mentioned that even serious conversations involving usual work topics were not present). The joking relationship between young males and females differed from the others, however, In that "open obscenity was not permitted." sykes offers the following description:

The pattern usually followed was that the young men would initiate the conversation, if they were slow to do so the young women would lead them on but in such a way as to preserve the illusion that the initiative lay with the men. The young men would make suggestive remarks very thinly disguised, at this the young women would pretend to be shocked or not to understand. Though the remarks were often suggestive they were never openly obscene and any serious reference to sex was not permitted. Conversations would thus largely consist of suggestive remarks by the young men to which the young women would reply with insulting remarks about the men, and, occasionally, with suggestive remarks of their own. The convention that open obscenity was shocking to the young women was maintained in spite of the gross obscenity that the old men uged towards the young women (1966:191).

While petting in public between young men and women was strictly disallowed (occasional attempts receiving heavy sanctions), so, too, were attempts to make sexual innuendo through humor and joking la form of humor which had been included in the joking relationship between old men and young women). In contradistinction to their joking relationship, however, "it was known that heavy petting was carried out in store rooms and various odd corners of the works" (sykes 1966:191). Thus, joking relationshipg were the only form of 
communicative relationship publicly available to young female workers and their male counterparts.

While joking relationships have received a great deal of attention within anthropological (especially enthnographic) literature, few--if any-of these have attempted to discern the precige conditions which give rise to such relationships. Rather, analyses of joking relationships have generally represented these relationships as established patterns of social interaction, characterized by "permitted disrespect" (Radcliffe-Brown 1952) and, notably, as a unique form of "play." As a form of play, it has been suggested that humor plays an intricate part in the cultural life of the group, solidifying the social bonds between group members (Fine 1977). Discussed in the following section, humor as a form of play or "game," often provides personnel in otherwise mundane workplaces with a source of entertainment.

\section{Joking and Humor as Forms of Play}

In a study of a Newfoundland seal fishery, Jahn R. Scatt researched the "idiographic" forms of entertainment within the culture of the seal industry. The basic forms noted by Scott at the soal fishery wore play, song and story sessions, and pranks or practical jokes. (Play, pranks and practical jokes all included a variety of humorous episodes which "mocked" the disparaged living accommodations of the sealers: "By making them the subject of humor, the sealers could cope 
with these conditions better than if they succumbed to swearing at them," scott 1974:279). Tho utility of humorous play found among sealers was that it facilitated cooperation among crew members of the sealing ships by providing "diversions:"

The need for diversion was perhaps not critical when the work was going well, but one of the major problems of the industry was that the ships, with very few exceptions, did not have ice-breaking capabilities. This meant that they were often jammed in the ice, unable to find a concentration of seals or to go home. In these situations, diversion was critical, and the spirit of cooperation was tested to its fullest extent $(1974: 277)$.

As forms of humorous play, pranks and practical jokes served several important functions-- foremost, they provided participants with a source of entertainment (1.e., like other forms of humorous play, the jokes provided diversions for participants). At the same time, however, the play also created a socially acceptable way of releasing hostility in a setting (the close quarters of a sealing ship) which promoted social friction.

In a study which included participant observation within a "small workgroup of machine operatives," Donald F. Roy observed how... "one group of operators kept from igoing nuts" in a situation of monotonous work activity..." (Roy 1959:158). While preliminary observations of joking, made by Roy, appeared as "occasional flurries of horseplay so simple 
and unvarying in pattern and so childish in quality that they made no strong bid for attention," subsequent abservation revealed the "structure" of the interaction. Participants whin the work setting developed patterned disjunctions in their work-routine by episodically constructing informal, humorous interactions. Not only did these episodes parady "those common fractures of the production process known as the coffee break, the coke break, the cigarette break," but the interactions "appeared in daily repetition in an ordered series of informal interactions" (Roy 1959:162) [sic]. Roy referred to these (humorous) interaction-episodes as "times," i.e., periods of brief "rest" and "physical refreshment." The exchange content of these interactions centered around the sharing and consumption of food lcoffee time, peach time, banana time, fish time, Coke time, lunch time, etc.). While these "times" often provided workers with the opportunity to engage in "serious" discussions, they also vere occasions for "entertainment" for the participants:

Banana time followed peach time by approximately an hour. Sammy again provided the refreshments, namely, one banana. There was, however, no four-way sharing of sammis banana. Ike would call out, "Banana time!" and proceed to down his prize while sammy made futile protests and denunciations. George would join in with mild remonstrances, sometimes scolding sammy for making so much fuss. The banana was for consumption at lunch time; he never did get to eat his banana, but kept bringing one for lunch. At first this theft startled me. Then I grew to look forward to the daily seizure and the verbal interaction whlch followed (Roy 1959:152). 
The workday of the machine operatives was also fraquented by what Roy termed "themes." Aside from the ritualized play constructed within the interactional frame of "times," themes were comprised of "kidding," joking and pranks which were recurrent, but were not routinized as were "times." (That is, joking themes were "fillers," emerging between the ritual occurrences of "times"). Utilizing a different conceptual framework, Don Handelman suggested that the order and content of "times" and "themes" represents the "symbolic integration" of the workplace. By establishing "symbolic matrices of reciprocity, mutuality, and solidarity for interaction," and discounting the "seriousness" of oppositional "times" (permitting the expression of conflict), humorous play and communication constitutad an "integrative frame of meaning" (Handelman 1976:438-442). Moreover, Handelman indicated that the ritual aspect of humor, within the workgroup, enabled participants to experience both work and "play" as zones of experience phenomenologically bridged by humor. As Handelman posited...

The order and content of "times" and "themes" constituted a template of symbolic meaning which enabled these occassions to be integrated experientially in a comprehensive way and which permitted the dual realities of work and play to compliment one another in a manner that integrated all behavior within the setting (1976:438). 
symbolic process in which participants "transitioned" from "the reality of work to that of expressive behavior." That is, participants ritually transformed the otharwise mundane and drudging work into a routine which included entertainment; this transformation resulted from participants' active construction of humorous episodes. In a study on interaction within tavern culture, Kenneth Read (1980) similarly observed how ritualizad jocular performances between denlzens of a homosexual tavern symbolically portrayed their shared consciousness of a deviant status:

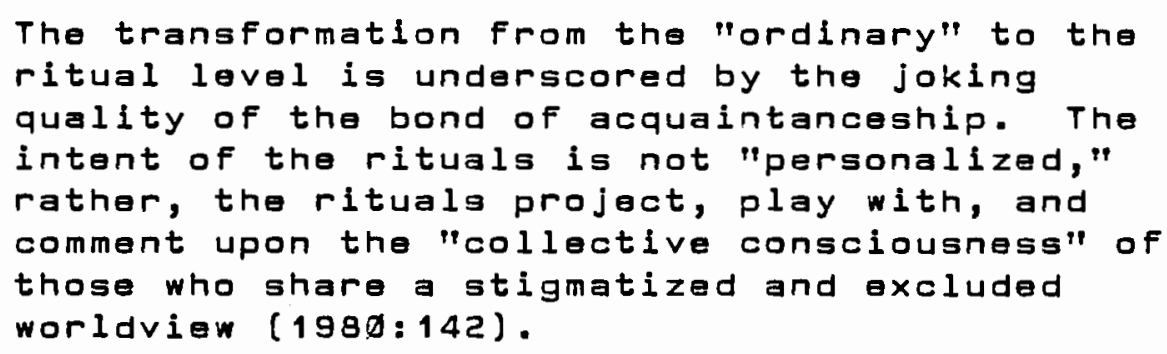

While Roy separated the humarous episodes occurring in the machine shop into two different analytical categories, all of these episodes represented a "time out" from the usual expectations of work. In a study on "Drunken Camportment," Craig MacAndrew and Robert B. Edgerton (1969) suggested that disinhibition is a learned social behavior. Such behavior represents a "time out" from the usual norms of propriety which are culturally ganctioned. As MacAndrew and Edgerton stated, "the state of drunkeness is a state of societally sanctioned freedom from the otherwise enforceable demands 
that persans comply with the conventional proprieties" $(1969: 89)$

The conceptual Framework developed by MacAndrew and Edgerton seems to fit well with the types of humorous play described by Roy (1959) and Handelman (1976). The humorous play found in a variety of work settings and professions suggest that participants do, indead, create "time outs" for entertainment which serve as a needed detour from dull and mundane work (this will be documented in research reports of several staff meetings in chapter $V$ J.

Humor as Social Control

In several sociological analyses of humor lincluding some of those cited earlier) a moderate amount of theoretical attention has been given to humor as social control. An early work by Antonin J. Obdrilk (1942) postulated that humor used as a means of social control against the Nazi's served two primary social functions: (1) it strengthened the morale of the oppressed, and (2) it had disintegrative effects upon the morale of those to whom it was directed (1942:7ø9). Obdrlik termed such types of humor as "gallows humor." In studying such humor, Obdrlik's general theoretical concern was with the social psychological functions humor served for "those innocent victims of the aggression of the dictators" lspecifically, the use of humor among the czechoslovakian citizenry subjected to the Nazi invasion of World War IIJ 
(1942:7ø9-71Ø). The significance of such humor was its

"transcendent" character. That is, such humor represented an objectivation of collectively shared sentiments. obdrik

indicated that the symbolic importance of the humorous ridicule of the Nazis was that it provided citizens with a sense of reassurance. Obdrik stated:

\begin{abstract}
People who live in absolute uncertainty as to their i ives and property find refuge in inventing, repeating and spreading through the channels of whispering counterpropoganda, anecdotes and jokes about their oppressors. This is gallows humor at its best because it originates and functions among people who literally face death at any moment... These people simply have to persuade themselves as well as others that their present suffering is only temporary, that it will soon be all over, that once again they will live as they used to live before they were crushed (1942:712).
\end{abstract}

One of the interesting theoretical issues implicit in Obdrlik's analysig is haw social actors usad such humor in cognitively constructing a sense of control. Obdrlik posited that gallows humor was both a "psychological escape" and a "psychological compensation" providing its users on tha symbolic level with a sense of control-- even thaugh, objectively, they were relatively powerless. This calls into question, however, Obdrlik's own premise of gallows humor as a specific form of social control, and a more fundamental

theoretical issue (indeed, one apprehended by Marx's conceptualization of "false consciousness"): viz., the phenomenological disjuncture between participant's sense of 
control or power, at the level of consciousness, and contral shared by participants as an objective reality. While obdrlik seemed to indicate that negative sanctions were incurred upon the oppressars in the farm of lowered morale, he did not indicate how this "sanctioning" actually manifested any change on the level of concrete social action. Indead, the kind of social control obdrlik alludes ta is more aptly described in one of his footnotes:

Ridicule also has been used effectively as a social sanction among the primitives. The Eskimos, for instance, use ridicule against thievery. Instead of punlshing the thief, they laugh whenever his name is mentioned, which, judging from the fact that stealing is almost unknown among the Eskimas, is probably a more effective means of social control than fining or imprisoning offenders (1942:718).

As evidenced from obdrilk's study and others, one of the most common forms of humor employed as a means of control is humorous ridicule. Other research on ethnic jokes and social boundaries has reported simllar findings (Davios 1982;

Stephenson 1951). Richard Stephenson (1951) asserted that humor used in the development and perpetuation of sterootypes is but only one of the "control functions" of humor. As a means of control, ridicule, satire and eritique (qua humor) may be used as specific sanctions to preserve sacial distance between roles (1.e., preserve the prevaliing status system). Humor may also be used to ameliorate social differences and Impose sanctions upon those who appear to deviate. In 
particular, Stephenson posited that within American "stratification jokes" (e.g., jokes which depict laborers as "characteristically lazy" and seeking to "avoid work;" business persons as "overbearing and of doubtful veracity;" the rich as "idle, tightfisted and vain;" and, the poor as "lazy, ignorant and stupid") (1951:57ø), the control function of humor is aimed at a "leveling offensive."

Although a consciousness of occupational and aconomic differences is demonstrated in stratification jokes, this is neither the focus nor the point of the humor. Rather, the tendency is to minimize these differences and their effects on social structure and to maximize the expression of American values as embodied in concepts of equality, ambition, initiative, opportunity, enterprize and the like. There is a general propensity to ridicule the top and bottom of the hierarchy in a kind of leveling offensive consistent with American values. It is significant to note, however, that although ridicule is aimed at the top and the bottom, it is selective even at these extremes (stephenson 1951:571).

In a general theoretical comment, Hugh Daziel Duncan (1953) suggested that laughter may be a form of social control insofar as it disarms "threatening group members"... "We can laugh at them and thus destroy their possible power within the group...as lang as we can kap him from serious acceptance by our own group, we can keep him from power" (1953:5Ø). Robert D. Rassel observed humor as a form of control within a gmall group experiment, similarly noting that participants interjected humor into group discussions when the "discussions" threatened "to undermine the order of 
the group by geriously drawing existing realities into questian" (1981:2ø6).

Humor has also been seen as serving as a means of social control within the workplace. Bruce Kapferer (1969) in a study of humorous exchanges and other communications among a group of African coal miners observed how participants employed name-calling (humorous and otherwise) as a means of social control. Primarily these transactions occured in on-line production work and served as negative sanctions for those workers involved in "rate-busting." Mentioned previously, Pamela Bradney's ethnography of humor within a large department store also avinced humor and joking as a means of social control. In Bradney's study, humorous riducule was directed at personnel who had assumed an erroneous status of moral superiority (i.e., had "put on airg"l). Bradney indicated the efficacy of this method of sanctioning within one of the sales dapartments in the following:

One of the assistants said that in her department whenever someone was sent to help or to work there who was rather "snobbish" and wauld not talk to them, they all mada a point of joking at her continuously in a good humorad way and she saon "came off it." The activity which this department adopted in making a newcomer take a hall-fellow-well-met attitude had thus become to some extent formalized (1957:186).

Bradney auggested, moreover, that joking relationships within the department store were governed by several types of 
sanctions, which she referred to as positive and negative informal sanctions, and "automatic sanctions." (Bradney's outline of these sanctions are presented below):

(Positive Sanction)

1. Those who joke readily attain more popularity than those who do not, evidenced by...

(a) They are approached more often by other members,

(b) They elicit a more favarable reaction from othars when they "make an approach," and

(c) They are never seen to sit alone during their meal breaks.

(Negative Sanctions)

2. Particular departments in which infrequent joking occurs come to be defined as less fun, too serious, and a place "they would not cara to work," by other employees.

3. Informal negative sanctioning of both departments and individuals who do not joke typically takes the form of obvious patterns of avoidance by other emplayees.

\section{(Automatic Sanctions)}

4. Social contact made with the "correct" type of "joking attitude" achleves the purpose of the contact more quietly and easily (and tends to be repeated in future contacts).

(a) If the personnel'g attitude in making the approach was not correct, the fact that it elicits a rather less satisfactory reaction "automatically" discourages $\mathrm{him} / \mathrm{her}$ from repeating this type of approach in future contacts.

(b) Mental and physical pleasure also provides automatic sanctioning for joking behavior CBradney seems to indicate here the positiva onjoyment of joking as simpla reinforcement for 
the behaviorj.

One of the crucial issues emergent from these studies, and of particular relevance for the present study of humor is the phenomenological status of the social actors towards whom ridicule, sarcasm and other forms of "conflict humor" is directed. That is, what are the intersubjective meanings and definitions of the actor shared among those constructing such types of humor?

Humor and Structural Stress Within the Organization

A multiplicity of studies on the use of humor, within organizational settings, have attempted to explicate how humor alleviates stress upon the structure of social situations and social groups. Lewis Coser suggested that "the need for safety-valve institutions lncreases with the rigidity of the social structure, that is, the degree to which the social system disallows expression of antagonistic claims where they occur"l (1956:45). Coser noted the conceptualization of such institutions in the work of Margaret Mead and Gregory Bateson on Balinese culture:

In Bali, where the social structure is highly stratified and rigid, great attention is paid to the etiquette of rank and status, the theatre specializas in paradies of rank. These "skits of status" consist, for example, of dances in which people stand on their heads with feet doing duty as hands and with masks on their pubes. "This freedom of theatrical caricature...concentrates on the points of stregs in the system, 
AND SO PROVIDES CONTINUAL RELEASE IN LAUGHTER."

It is suggested that the Balinese theatre

drains off latent hostilities which are bred in

thig rigidly stratified society and thereby

allows its continued functioning--although the

authors do not produce evidence sufficient to

demonstrate this (1956:44). (Emphasis added).

In a general overview of other organizational functions served by humor, Joseph Ullian (1976) delineated several of its uses. One of the more significant aspects of humor within the organizational context, posited by Uliian, is that joking-forms serve as an index of social conditions. That is, joking behavior is an indirect mode of organizational communication in situations where the "prescribed hierarchical procedures" are found ineffective. Jaking, then, not only allows persons to express and rectify grievances but, too, may serve the purpose of defusing latent discontent. Ipso facto, humor (especially banter) often stablizes an organizational structure by accommodating participantg with an alternative means of expressing discontent. While Ullian initially observed how participants "targeted" each other to be the "butt" or "focus" of the jokes, within the workgroup, he also observed how humor was used as a protective device. Humor may potentially shed the joker of responsibility for the "serious" content or implications of the joke. Where persons are the focus of the joke, and the content of the joke is rather direct, the humorous form of the communication legitimates the exchange. 
That is, though the recipient may attempt to subvert the joking frame and call into question the "meaning" of the content, the initiator may retreat, taking refuge in the assertion that the remark was, again, only meant in jest. As Gregory Bateson (1955) suggested, the interactional form of the exchange communicates that "this is play" thereby suspending the normal rules which govern the situation. Ulian, moreover, made the observation that, "in many of the situations joking was elicited upon the introduction of certain types of messages" (1976:131]. These messages contained information which disrupted the routine operation of the workplace. Specifically, the introduction of the new information provided a context in which those who received it (i.e., those whose usual work routines would be disrupted by it), were situationally licensed to target the sender as the focus of a joke. Thus, persons having breached the routine expectations of the work schedule by introducing new information received jocular sanctioning. While Ullian suggested that such humor mitigated stress upon the structure of relationships within the workplace, no indication was made of how-- if at all-- such exchanges are mediated by status differences (a concern this study will attempt to deal with in following sections].

Although Ulilan made no reference to Goffman's analysis of "face-Work," Ullian's observations of joking upon the introduction of new information aptly corresponds to 
Goffman's concept of "cooling the mark out" (Goffman 1952). In Goffman's essay, "marks," or "suckers," were "helped" to redefine the discrepant definitions of the self after beling swindled by con-artists ("operators"). By use of various techniques provided by a confederate of the operator lcalled the "cooler"), marks were offered the consolation prize of an altarnative status-- i.e., "marks" were supplied with an apologetic framework which offered suitable rationalization for "being taken," and which helped them to "save face." The utility of Goffman's theoretical framework thus lies in explicating how humor, as a potential "cooling out" technique, alleviates stress generated within the structure of the workplace. Uliian's study consequently indicated that a very effective way of "cooling out" individuals whose work-routines have just been altered because of information just given them, is to permit (as Goffman indicated) a "full vent of the Initial shock." As indicated previously, such episodes serve several functions: (1) they allow for a release of stress within relationships, via permitting persons to "vent;" (2) the ritual "targeting" in jocular interaction allows the "mark" (who is powerless to change the mandate of the new information) to "save face" by targeting the sender; and, (3) the sender, even though the target of the humor, can permit this quasi-profanation, qualified by the "not to be taken seriously" form of the communication which thus insulates the self. One of the residuals of the 
interaction, Ulian speculated, is that the humorous interaction may be laced with themes which suggest accountability:

often the aim of the joker is simply to implant the consideration of a socially risky intention in the mind of the target wlthout being attacked. While the uncertainty about the existence of an ulterior intent in joking protects the joker, the consideration of the intent even as a possibility by the target of the joke accomplishes the joker's aim. Repeated joking can reinforce the suspicion that the possible intent is real while the joker still remains under the aegis of humor. These two aspects of joking-ambiguity and intricacy-are often put to use in social interactions (1976:13ø).

Research within hospital settings has analyzed the "organizational structural stress" emergent in the interaction-gituations between medical personnel and between medical personnel and patients (Coser 1959). ["Organizational structural stress" referring to stress "emanating from the necessity of being part of a goal oriented group and facing internal conflicts in human relations within the organization" Gross 197ø). Burling, Lentz and wilson (1956) examined how humor and joking alleviated stress within the operating team once the major task of the surgery had been accomplished. Coser (1959) observed how patients, by cloaking their complaints in the garb of humor, promoted cohesion within the structural setting of the hospital. While many standard jokes exist about Iife in the hospital le.g., "the nurse who wakes you up 
to give you a sleeping pill" coser 1959:176), the "jacular griplng" of patients "ls based on shared experience, it unites the group by allowing it to reiniarprat together an experience that previously was individual to each" (Coser 1959:178). Coser stated:

Unlike the joke which calls for a listener, the jocular gripe calls for a participant. It transforms a personal experience into a collective one; by generalizing it and making it the property of all, the individual sufferer is "dispossessed" of his own suffering. This type of behavior stresses the equality of all patients within a social structure otherwise characterized by its rigid hierarchy; it brings about consensus and strengthens group identification among persons whose relationships are only transitory (1959:179).

As mentioned previously, one of the significant social aspects of humorous play and joking is that participants may often, very creatively, construct eplsodes which serve as a release of stress upon the entire structure of activity of which they are a part. Soth Roy (1959) and scott (1974), for example, indicated that within the setting of the machine operatives and that of the seal fishery (respectively), joking behavior prevented the ossification of workgroup structure by interspersing work with humorous play.

While a variety of studies have dealt with the use of humor in industrial, hospital and other settings, few have been concerned with residential treatment settings. It seams that an equaliy small amount of research has been done on nonverbal humor; although Emory s. Bogardus' article, 
"Sociology of the Cartoon," was publiahed in 1945.

In line with the aforementioned studies, it was found that the organizational structure of a residential treatment center (which was the site of data collection for the present research) was infused with a wide variety of different types of humor; both verbal, gestural and written communications. One of the more prevalent activities among team members, not found in these other studies, tended to be the distribution of "literature." Not only did this activity provide "release" within a setting which promoted both individual psychological stress, and stress upon the structure of group relations, but oftentimes humorously critiqued the bureaucratic vicissitudes of the profession.

As will be gvidenced in this study, such forms of humor rarely emerged in the setting of staff conferences. Rather, these exchanges tended to be shared between staff members in the course of the usual work routine. As previously indicated, much of the sociological research on humor in the workplace has studied how social actors use or construct humor within a specific social context. No analyses, however, could be located which concerned how different settings within the workplace le.g., the staff conference versus on-1ine work) mediate variations in the particular forms or types of humor which participants actively construct. Such an analysis, thus far, seems to have been eclipsed by a more general theoretical interest: viz, how the 
cultural aspects of humor are functional for the integration of a social system (specifically, the workplace). The particular concerns of this study, which deal with the setting of humorous interaction, as mell as the status of the role-occupants, are addressed in the following sections.

\section{Humor in Staff Conferences}

In his analysis of staff conferences within a psychiatric hospital, William Caudill (1958) examined the frequency of speaking by different status-holders on a medical staff. Caudill's findings indlcated that "higher status persons tend to participate more heavily in group discussions" (1958:245). Caudill specifically observed that while senior staff members talked the most, residents talked the second most and other (lower-status) personnel, specifically the nurses, talked the least. Palola and Jones (1965), in a study of "Contrasts in Organizational Features and Role Strains Between Psychiatric and Pediatric Wards," noted variations in conference behavior between the two wards. They indicated that "variations in conference behavior were related, as was the distribution of role strain, to the contrasting organizational social structuras between these two services" (1965:147). A greater "task-orientation," for example, was observed in conference behavior of the pediatrics ward, which also exhibited a high rule emphasis and "authority differentials" as well as low 
individual freedom and autonomy (Palola and Jones 1965:145). One significant theoretical interest generated by these studies concerns how status-arrangements and other characteristics of the organization portend variations in patterns and forms of communication between staff. Findings by Ridgeway, Berger and Smith (1985) in research on

"Nonverbal Cues and Status," guggest that gestural cues guch as eye-gaze, and vocal cues, are patterned in the interaction, on the basis of the participants' ralative status in the given situation. (The study noted, for example, the relation between the speed with which a person in a group responded to the assigned group task-- by beginning to verbalize-- and the known status of the person.] Homans, much earlier of course, analyzed the Bank Wiring Observation Room, wherein he presented the hypothesis that: "a person of higher social rank than another originates interaction for the latter more often than the latter originates interaction for him" (1950:145). The relevance of all of these studies to an analysis of humor, lies in the nature of humor as a form of communication, subject to the same social influences as other communicative forms. Specifically, humor as a communicative mode, is mediated by the setting in which the transaction takes place, as well as the status of the role-occupants between whom it occurs. Research by Goodrich, Henry and Goodrich (1954), studying the use of humor in weekly psychiatric staff 
meetings, revealed that such laughter primarily seemed to release tension and promote group integration. The two predominant forms of humor found within the conferences were incongruity (violation of mores, play on words, violation of objective reality), and disparagement (disparagement of self, others, or another's opinion). While the content of the humor focused on a variety of topics and persons within the hospital (the most common were patients, physicians, nurses, peychoanalysis, children, death, old age and sex), one of the most prevalent forms was disparagement humor. In fact, $35 \%$ of all laughs observed by the researchers were at remarks which disparaged others. of these, $58 \%$ belittled physicians while $29 \%$ belittled patients and $3 \%$ belittled children, death, nurses and psychoanalysis. Goodrich, Henry and Goodrich noted that such humor increased as the conference wore on, with 110 out of 144 such humorous remarks occurring in the last half hour of the staff metings. Besides reducing the tension produced by occasional crises which occurred on the ward and, hence, vicariously within conference discussions, laughter after dissension in the meetings also "reintegrated" the group. That is, common participation in the guffaw solicited cohesion from group members who, earliar, had been involved in conflict over particular issues.

In a similar study of humor among staff in a mental hospital, Rose Laub Coser posited that "social barriers, such 
as those of status, temporarily are lowered because to laugh with atherg presupposes some degree of common definition of the situation" (196ø:81). As Tom Burns cogently stated:

In all societies, the joke is the short cut to cansensus. And it is the characteristic double understanding of the joke relationship that permits the maintenance of two status positions through the same unit of social action, through the performance in the same role (1953:557).

Coser observed the differential use of humor between role-occupants of different status positions within staff conferences. One of her findings indicated that women staff members participated in humorous episodes within informal settings but deferred to their male counter-parts within the staff conference. Coser thus proffered two general observations regarding this variation: the cultural prescriptions for the role of women are those of subordination-- "passive and receptive, rather than active and initiating"-- and, these expectations were superimposed upon their already subordinate status as "junior members" in the staff conference:

The junior members at the staff meeting had a role in some respects similar to that of women in the culture: they were supposed to learn, to "recelve" knowledge and to "accept" the intellectual superiority of the senior members. Too much humorous behavior on their part would be socially interpreted as questioning the teacher-student relationship (Coser 196Ø: 84-85 \}. 
Coser's examination of person-focused joking within the staff conference revealed that "humor tends to be directed againgt those who have no authority over the initiator" (1960:85). That is, humor was directed in a manner which met the "requirements of the authority structure." Thus, while senior staff members frequently joked "down" to junior staff members, the latter did not reciprocate but, rather, directed humorous remarks towards those "below" them le.g., the patients and their relatives), or against themselves. The hierarchical social structure of the hospital according to Coser, dictated the direction of humorous remarks (viz., in a "downward" pattarn). Mareaver, this downward pattern symbolically represented the power-differentials between role-accupants. As Coser mentioned, junior members less frequently interjected humor into the proceedings of the staff conference than senior members because "it would hava been construed as a challenge to the conduct of the meating" (196ø:86). By proffering humarous remarks junior members may actually subvert control of superordinates within the authority structure...this proffering is a "riaky tool" in that it induces "seniar members to give up, for the moment, their control of the meeting and to follow the juniors' guidance" (Caser 196ø:86). Hence, the subardinateg who offer humorous remarks are "more likely to be tolerated if thay offer the diversion in the guise of, an aggression upon a specifically mentioned and legitimate target-- a patient or 
the self" (Coser, 1960:87).

Reduction in social distance between senior and junior staff members within the staff conferences tended to be the exclusive privilege of senior staff members, who, in superordinate status-positions, were able to control the degree of social distance between themselves and subordinates. Coser, furthermore, argued that, via self-disparaging humor, junior-status personnel were able to weaken the prevaliling status structure by ingratiating themselves with senior members la phenomenon referred to in "Iay" tarminology as "boot-licking," "apple polishing," or "brown-nosing"). Not only was this action by junior members considered as a sign of anticipatory socialization by Coser, but, it was also suggested that such action promoted cohesion by "playing across" status 1ines. Several partinent considerations, however, seem to have been omitted in coser's analysis. While humorous interplay between role-occupants of differential status may appear to temporarily relativize these status differences, Coser indicated that such relativization typically occurred through a process of self-ingratiation. In such a process, however, it was the subordinate role-occupant whose humor deferred to those "at the top" of the authority structure, who solicited this relationship. At the same time that humor used between superordinate and subordinate roles symbolically constructed the semblance of status equity, it also reaffirmed the 
authority structure which circumscribed them. That is, the humor of subordinates in the conference was actually deference to authority, and the practical outcome of this deference was to reinforce the superordinate-subordinate role-relationship. Ultimately the symbolic deference to authority (i.e., to the "power-holders") through the humorous targeting of self reaffirms the taken-for-grantad status of roality of authority-relationships.

Jayca 0. Hertzler, in an analysis of humor and laughter in role performances, suggested that laughter may serve as a "social equalizer," or "lever," to the degree that it fosters communication between subordinates and superordinates. Although person-focused humor generally strengthens role-relationships and maintains status differences, according to Hertzler, it can also be used to reduce social distance. The important point to note (indeed, one gleaned by Hertzler), is "who" initiates such exchanges. Hertzler stated:

\footnotetext{
The initiative in the use of humor to reduce social distance (or in some smaller measure to contribute to equalization) is usually by the senior or "superior" members in the hiararchical system; in fact, initiation by the status-superior seems to be expected (1970:129].
}

Kaplan and Boyd (1964) similarly oxamined the use of "hostilo humor" (a.g., ridicule and sarcasm) by patients on a psychiatric ward. The presence of hostile forms of humor was 
most notable upon occagions where the patients, qua patients, assisted with presentations to representatives from other public organizations (ugually concerning methods of psycho-therapy). Kaplan and Boyd suggested that such humor, because it attacked the "conventional" knowledge of the extra-hospital population, displayed during presentation and question sessions, ameliorated the social distance between patients and outsiders from the view of the patients. They state:

Such humor again appears to function so as to
decrease the social distance perceived between
the patients and extra-hospital populations.
By ridiculing the behavior of the "normal"
population, the patients deny any significant
difference between themselves and the outside
world and justify their future return to the
latter. This serves to alleviate their their
anxieties concerning the social stigma being
attached to being a mental patient and at the
game time reinforcing the solidarity of the
patient group (1964:510).

Experimental studies of humor within small group settings have attempted to discern how the use of humor by persons contributes to their overall informal status within the group. Goodchilds (1959) found that two different types of humor exhibited by persons mediated their postion in the social gtructure of the group. While persons who interjected sarcastic witticisms were observed to have power to influence others, but ware not popular among group members, persons who "clowned" were, conversely, observed to have popularity but little power to influence others. Scogin and Pollio (1980) 
examined humorous remarks exchanged between individuals in six different group settings. The findings of their research indicated that "in groups which have a gustained character, (i.e., where group members know one another and where there is an expectation the group will continuel, humorous remarks were directed at one another or target another in approximately $2 / 3$ of the cases" (Scogin and Pollio 1980:847). That is, personal one-to-one familiarity provided a license to joke across status boundaries. In both short-term and "enduring" groups it was found that depreciating humor, rather than serving to solidify social relationships, constituted a means of social control. As a mechanism of social control the humor which depreciated others not only "established hierarchies," but also allowed "for an expression of feelings in a somewhat less threatening manner than direct confrontation" (Scogin and Pollio 1980:848). Finally, O'Quinn and Aronoff's (1981) research on humar in a study using a bargaining paradigm, provided support for their primary thesis that "verbal humor laads to greater compliance." Humar used as an experimental manipulation in which subjects ("buyers") were to negotiate a bargain with researcher confederates ("sellers") evidenced findings which indicated that... "humor was equally effective as an influence technique when used by both sexes, and when directed toward both sexes" (o'Quinn and Aronoff 1981:354). An examination of research of humor within both staff 
conferences and small group settings suggests a variable relationship between the structure of social relationships and emergent forms of humor within those social relationships.

That the use of humor is subject to status arrangements seams to be readily apparent. Formal status arrangemonts (i.e., status arrangements which are a part of the institutional order), however, may be a bit more ambivalent than suggested by initial appearance especially if those in superordinate roles come to be perceived as illegitimate holders of office. Thus, hierarchical role-relationships within an organization may be temporarily relativized by participants who, for whatever reasons, segk to cognitively mitigate social boundaries between themselvas and others, using humor. In introducing such claims, this study seeks to test some of the propositions implicitly suggested within this "ambivalance" framework: viz., (1) that legitimation and dalegitimation processes at work within an organizational authority structure portend differential outcomes on the types of humor that participants activaly construct, and ( 2 ) that differences in organizational "stage settings" mediate a differential usage of humor between organizational participants. 
III. WORK SETTINGS, AUTHORITY STRUCTURES AND HUMOR

The Staff Conference and On-Line Work_as Stage Settings

The daily duties of participants observed in this study took place within a residential treatment center for emotionally troubled children. While a more detailed analysis of the organizational setting is presented in a following section, it is the intent here to lay out the general theoretical framework utilized throughout the remainder of this study. As indicated in other analyses Coser 196ø; Goodrich, Henry and Goodrich 1954; Palola and Jones 1965; Caudill 1958), the typical routing within a variety of social service organizations is often segmented between performances in what are potentially a multiplicity of settings. One of the more significant nuances of this study concerns how the same area of the workplace can be both front region and back region for given performances, depending upon the immediate presence (or absence) of certain social elements...and, specifically, how lines of action fitted together into humorous episodes are themselves relative to these two different settings. The two settings that are of concern in this study are the staff conference and on-line "unit" work. Participants habitually vary their performance in accordance with the compartmentalized expectations accompanying the activities in each setting. Central to the theoretical framework used in the present analysis is Erving Goffman's (1959) work on "gtages" or 
"regiong" of behavior, whero actors routinaly modify their performances in the course of everyday life.

Goffman defined "ragion" as "any place that is bounded to some degree by barriers to perception" (1959:106). These regions, according to Goffman, represent specific settings for interaction within which persons stage their performances. Performances within the ragion are bounded by time as well as physical partitions-- which serve to insulate the interaction from the view of all. As Goffman trenchantly stated:

The impression and understanding fogtered by the performance will tend to saturate the region and time span, so that an individual located in this space-time manifold will be in a position to observe the performance and will be guided by the definition of the situation which the perfomance fosters (1959:106).

Goffman specifically differentiated between the "front region", or "front stage", setting, and the "back ragion", or "back stage" setting. "The performance of an individual in a front region may be sean as an effort to give the appearance that his activity in the region maintains and ambodies certain standards" (1959:1ø7).

\section{The Staff Conference}

It is posited here that the staff conference (one of the sites of observation within this study), constitutes a frontstage setting. Such a premise is qualified by several 
factors. First, staff conferences represent a portion of the participants' workday which adheres to strict time boundaries. Of the two different treatment teams abserved during the period of this research, one team met for a two hour weekly staff meeting while the other met for three hours. The time boundaries of the canferences contributed to the formality of the setting by restricting dialogue (most of the timel to the pragmatic issues at hand, most notably, the problems of the clientele. A frequently large volume of information disseminated to staff members regarding cases and case planning often promoted a strict "no-nonsense" demeanor wthin the conference. The presence of other significant social elements also fostered "decorous" behavior on the part of participants. That is, performers adhered to a set of standards while in the "visual or aural range of the audience" which engendered both polite manner and a professional appearance. Precisely, performers constructed a "peraonal front" commensurate with the formality of the occasion. This front Goffman referred to as part of the "decorum" of the setting:

While decorous behavior may take the form of showing respect for the region and setting one finds oneself in, this show of respect may, of course be motivated by a desire to Impress the audience favorably, or avoid sanctions, etc.. Finally, it should be noted that the requirements of decorum are more pervasive ecologically than are the requirements of politeness. An audience can subject an entire front region to a continous inspection as 


\begin{abstract}
regards decorum, but while the audience is so engaged, none or only a few of the performers may be obliged to talk to the audience and hence to demonstrate politeness. Performers can stop giving expressions but cannot stop giving them off (1959:1ø8).
\end{abstract}

Personal attentiveness to one's own performance within the staff conference was reinforced by the presence of extra-agency personnel. While the "core group" of the meetings typically was composed of the unit supervisor, childcare workers and family therapists, the meetings were frequently attended by teachers, caseworkers and other administrators. "Case-presentations" (in which treatment team members presented information about the cliont to teachers, social workers, play therapists, etc.l proved to be occasions, par excellence, in which team members held fast to masks of "professionalism". As Goffman suggestad:

When one's activity occurs in the presence of other persons, some aspects of the activity are expressively accentuated and other aspects, which might discredit the fostered impression, are suppressed. It is clear that accentuated facts make their appearance in what I have called a front region....(1959:111).

The need to pull off a performance of professionalism was crucial in that such performances helpod insure crediblity with those professional functionaries who ultimately held power in key decisions. These decisions included: (1) placement of the clients in other settings (such as foster homes, residential treatment centers, group 
homes, etc.), (2) programming and (3) policy formation. Not only did one need to pull off the performance if personal credibility and professional integrity were to remain intact (i.e., if one were to have "any say" in the decision-making process), but one's performance, too, reflected the credibility and competence of the team. As Goffman stated, "Service personnel, whether in profassion, bureaucracy, business, or craft, enliven their manner, with movements which express proficiency and integrity, but, whataver this manner conveys about them often its major purpose is to establish a favorable definition of their service or product" (1959:77). Thus, individual performance in the staff conference was also the property of the collectivity: i.e., it served as a symbolic representation of the team's credibility and competence. Tout court, presentations made to professional functionaries from outside of the treatment teams, and from outaide of the agency, demanded cooperation in "gtaging a single routine" if both the team, and the agency, were to retain credibilty lGoffman referred to such collective cooperation as the "performance team").

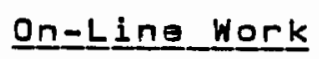

In contrast to the frontstage setting of the staff conference, on-line work provided a context where team members could "let their hair down," drop the "front" and relax their performances. It is in this sense that on-line 
work represents Goffman's concept of "back region". Goffman defined the back region or backstage as:



sinco the back region is typically out of bounds to members of the audience, the formality of relations between participante exhibited in the front region is dropped for relations of familiarity. This change in the performance of participants who, in the front region, wear the mask of proficiency and professionalism was evidenced by one worker who stated:

I like working the p.m. shift because you don't have a supervisor looking over your shoulder.

That is, the performance given for a very significant audience (one's own boss) required the situational construction of a personal front. Such performances, however, ara contingent upon a number of intervening 
variables, including the degree to which participants ara able to protect the back region from "territorial invasion" (i.e., from intruders).

The "language of behavior" in back regions also exhibits a distinctive character which stands in contradistinction to that in the front region las Goffman elaborates in the following):

The backstage language consists of reciprocity first naming, cooperative decision-making, profanity, open sexual remarks, elaborate griping, smoking, rough informal dress, "sloppy" sitting and standing posture, use of dialect or sub-standard speech, mumbling and shouting, play aggressivity and "kidding," inconsiderateness for the other in minor physical self-involvements such as humming, whistling, chewing, nibbling, belching, and flatulence. The front stage language can be taken as the absence (and in some sense the oppositel of this. In general, then, backstage conduct is one which allows minor acts which might easily be taken as symbolic intimacy and disrespect for others present and for the region, while front region conduct is one which disallows such potentially offensive behavior (1959:128).

\section{Work Routines and Stage Transitions}

It should be noted that while both morning and evening workers were observed las well as other team members such as family workers, and supervisors) within the workplace, only the evening workers were observed attending the "revival meetings" at the local pub. Indeed, such organized activities after work did not appear to be even an occasional 
event for A.M. workers; there wera, however, reports of very small coteries (two or three persons) gatting together outside of the workplace for occasional lunch-dates, shopping, and other leisure activitiea. The usual work routine for A.M. workerg began at 6:3ø A.M. or $7: 0 \emptyset$ A.M. and

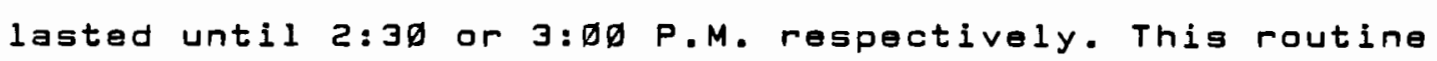
remained intact throughout the work-week except on the day of the staff meeting-- all morning treatment workers left the "unit," i.e., the living quarters for the group of children, to go to the staff conference which began at $1: \emptyset \emptyset P . M$.

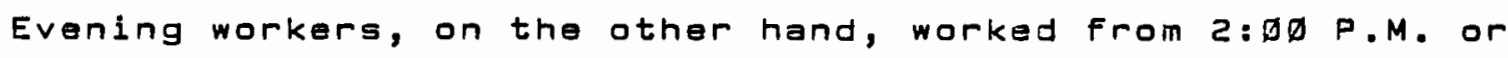

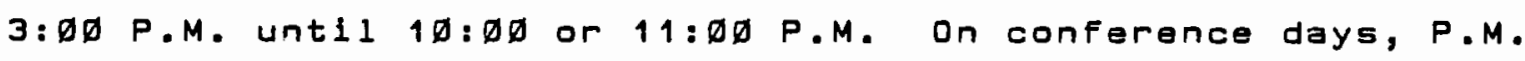
workers arrived early ( 1 : Ø P.M.) for the conference and proceeded to go to on-line work at the conclusion of the conference. That is, the childcare workers would exit from the front region of the staff meating into the back region of on-line work, which demanded neither the technical locution nor style of presentation of self found in the former. Morning workers, on the other hand, moved from the back stage setting of on-line work to the frontstage setting of the conference. The precise period of transition was often shared with P.M. workers who had just entered the agency; both shifts of workerg collecting notes, papers and other props which were to be used in sustalning their performance and the definition of the situation as "professional" within the conference. 
The nature of the audience within the staff conference manifested collective as well as individual frontstage performances and upon occasion a relative retreat into the "back region" by the team. This transformation of the setting from front region to back reglon by the team accompanied the departure of outsiders (i.e., other professional functionaries such as caseworkers) who had attended the conference in an officlal capacity. The transformation, while evidencing a team performance, did not permit the removal of "masks" by individual participants. Rather, the transition often proved to be an admission by all of the performers that constituent members must mutually reinforce, or validate, the performance of each other if decisions by particular state workers were to be influenced. As suggested by Goffman...

\footnotetext{
Each teammate is forced to rely on the good conduct and behavior of his fellows, and they, in turn, are forced to rely on him. There is then, perforce, a bond of reciprocal dependence linking teammates to one another. When members of a team have different formal statuses and rank in a social establishment, as is often the case, then we can see that the mutual dependence created by membership in the team is likely to cut acroas structural or social cleavages in the establishment and thus provide a sense of cohesion for the establishment. Where staff and line statuses may tend to divide an organization, performance teams may tend to integrate the divisions (1959:82).
}

This team performance was observed on several occasions during case-presentations made to CSO (Children's Services 
Division) warkers which supposedly supplied the cso workers with information crucial for the future planning of the "case" (child). After the CsD workers had left the conference, the absence served as a time to vent frustrations about conflicts with particular CSD workers, CSD planning for children, and intra-group issues which might otherwise destroy carrying off the performance as a credible team. Joking and humbrous remarks were less frequent in that case-discussion was viewed as "serious business." It was observed, however, that in circumstances where particular cso workers initiated humoraus episodes, thereby licensing others to do the same, team members (at least temporarily) would join In the activity and implicate the "front."

While team performances evidenced a social

transformation of the setting from front to back region, individual performances in the conference ware raraly given in a way that would indict the credibility or competence of the performer. The mask of professionalism was worn, and worn well. Ag indicated in figure 1., the performance of individual team members varied in accordance with the formality which accompanied each setting. The performance thus reflected the presence of a particular audience and the presence (or absence) of authority roles. This transition for workerg, from particular areas of work, represented a specific change in cognitive style. Disengaged from the setting of the staff conference, workers returning on-line 

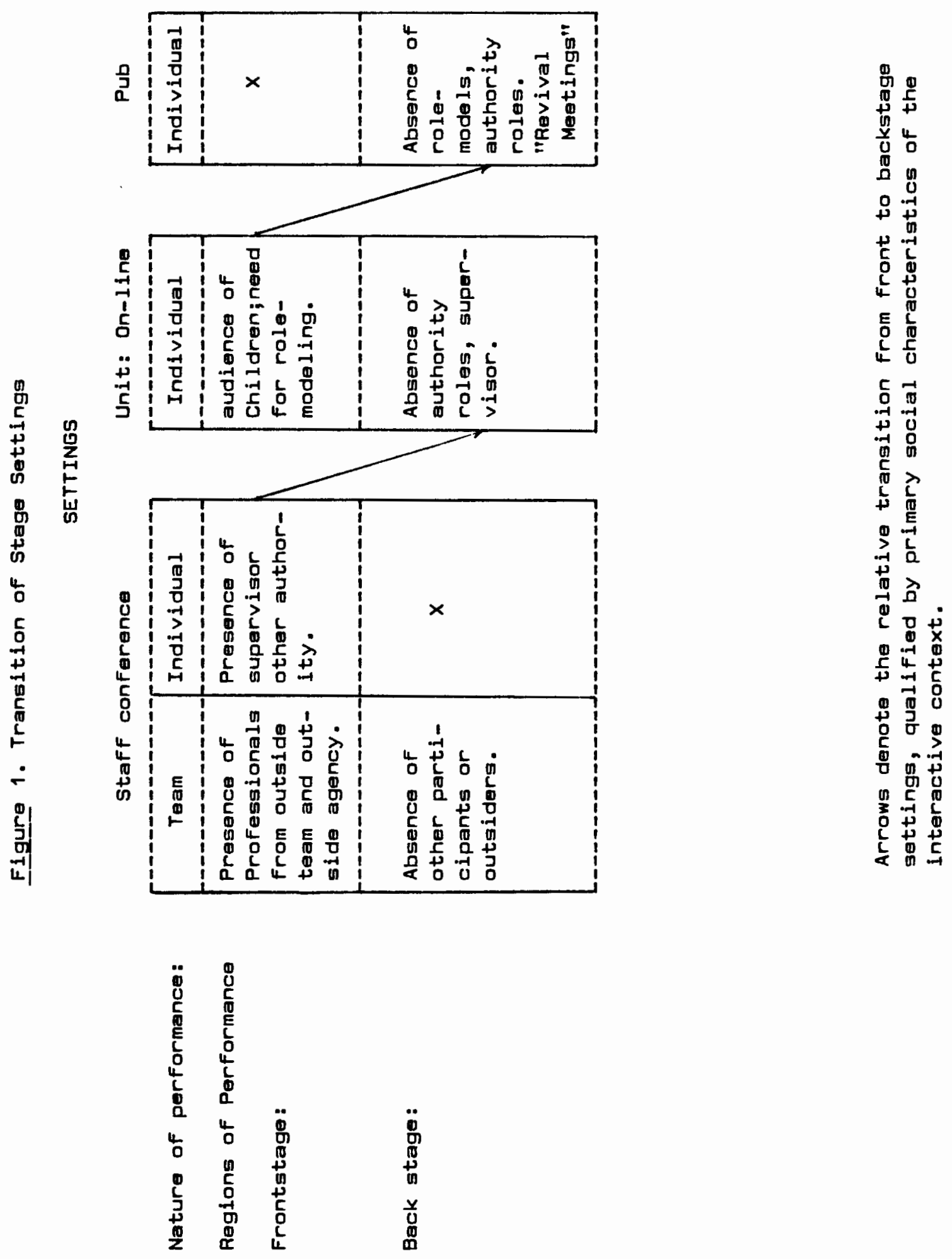
(back to the unit) could "let their hair down." Backstaje on the unit, workers could discuss lalbeit, in a somewhat "coded" fashion so that identities in the conversation remained anonymous to the children) the comments and action of other team members in the conference, and what they really thought of administrative decisions.

Concurrent with the relative absence of authority roles on the unit, however, participants' behavior was subject to scrutiny by another key audience-- the children. This is to suggest the sheer relativity of stage performances with regard to changes in audiences. While on-line work, compared to the formality of the conference, was backstage for workers, it also demanded that workers orchestrate a performance for the children. Such perfarmances themselves represented a front region in that the childcare workers were expected, as a matter of good treatment, to role-model correct bahavior for the clientele. That is, childcare workers routinely demongtrated the proper way to interact for the children: this included correct (as opposed to profane) language, table manners, problem-solving and other behaviors. While unit-work demanded that a definitive performance be given for the benefit of the clientele, workers often creatively constructed a simultaneous back region. This was done in several ways. As mentioned previously, a coded version of previous discussions in the staff conference could be carried on in front of the children who, ignorant of the 
meaning of the esoteric symbolism, were prevented from gaining otherwise privilegad information. Another form of symbolic manipulation used in carving out a back region while on-line was evidenced in the following conversation between workers:

M: Have you heard some of the jokes fred tells?

F: He acts so serious...like the other day, he came up to me and said, "F, I need to talk to you out in the hallway for a minute!" He was so serious, I thought something was wrong. Then he told me that joke...ohhhh!

As evidenced in the dialogue, a hallway adjacent to one of the units readily supplied workers with a backstage relative to performances given by workers on the unit. The symbolic edifice which was constructed immediately prior to moving backstage-- one which created the impression something was wrong-- allowed staff to veil their communications from unwanted listeners by providing the necessary justification for the excursion.

The Revival Meeting

Compared to work on the unit, the "revival meetings" at the local pub provided an opportunity for workers to really step backstage. Indeed, relative to the workplace, the pub represented a "GREEN ROOM" for workers; that is, it was a place where workers as performers could "relax before, after 
or between appearances" (Webster's New Collegiate

Dictionary). gy utilizing the pub as a private enclave, the workers could voice their true sentiments with the assurance that such bravado would be sheltered from official scrutiny. Not only was the "revival" marked by the conspicuous absence of any authority roles (supervisors and the like), but the setting also provided an occasion for the "seamy" side of the profession. Gossip, profane banter and humorous caricatures of other staff members, administrators and clientele, infused the conversation. One could finally let down the front without fearing official retribution, and vent the day's frustrations.

While variations in the types and differential usage of humor are influenced by differences in stage settings, they are also influenced by persons' relative positions within the prevailing authority structure. As Coser's findings indicated, "humor tends to be directed against those who have no authority over the initiator" (196ø:85). One of the theoretical concerns of the present study, however, is how the perceived legitimacy (or illegitimacy) of office holders-- apart from the authority of office-- produces variations in parson-focused humor within these different stage settings. 
Workgroup structure and Authority Rolations

Max Weber, in The Theory of Social and Economic Organization, defined power as "the probability that one actor within a social relationship will be in a position to carry out his own will despite resistance" (1947:152). Weber further elaborated the theoretical relevancy of the definition to group enterprise by use of the term "imperative control." Ey "imperative control" Weber meant "the probability that a command with a given specific content will be obeyed by a group of persons" (1947:152). When the exercise of such control (or power) comes to be accepted as the legitimate right of the power-holder by other members of the group, according to Weber, it is normally routinized into an "Imperative control of action," which formidably rests upon the control of an administrative staff.

The treatment teams in this study, while functionaliy different in terms of the different kinds of services they provided, both approach Weber's model of "legal authority with a bureaucratic administrative staff" (1947:329-340). By "legal authority," Weber indicated that the basis of legitimacy of the social order rested upon "rational grounds." That 1s, persons are vested with power in accordance with the "lagally established impersonal order." Authority is vested in the offlce-- and any exercise of that authority must adhere to "the scope of authority of the offlce" (Weber 1947:328). Although Weber's tranchant 
analysis of authority and bureaucracy contains a plethora of theoretical observations, of concern to this study is the phenomenological dimension of legitimation which undergirds his analysis. The specific concern of the present study is the degree to which participants' definition of power as legitimate or illegitimata influences emergent patterns and forms of humor lthase patterns observed among the treatment team workers, both within the staff conferences and on-line work, and in the interaction between staff members of differant statuses].

\section{Formal Organizational Structure}

The express purpose of the treatment teams within the residential treatment center was to traat (i.e., modify the behavior of emotionally disturbed children, as well as provide their parents with training which would be needed upon the child's return home. The residential setting, which was the site of the data collection for this study, generally approximated an "open setting" (Maluccio and Marlow 1972). While the children and parents within the agency were often mandated clients (1.e., the children were wards of the court), the residential center was not designed as a lock-up facility. The agency, in fact, espoused a minimal intervention policy towards its clients, having as its general aim the return of the children to their homes. While these characteristics generally depict the 
orientation and goals sought by both of the teams in this study, a glight variation in the structure and composition of each treatment team axisted during the period of this research (presented in figure 2). Team A was composed of a program manager, family therapists, lead childcare workers (i.e., childcare worker, level IV-- CCW IV), and (unit) childcare workers, level III (CCW III). The services provided by Team A included the daily care and behavioral treatment of children ages 8 to 13 within the setting of the residential canter. The team utilized behavioral modification as its primary treatment modality, and worked with the children during the week lall of the children went home on the weekends). While family therapists worked with both parents and children in weekly therapy sessions, the program manager facilitated coordination of all taam members and was ultimately responsible for the smooth operation of the program. The manager's respongibilities ranged from training staff and development of overall unit "programming," to assisting in the admission of children to the program-- as well as a varied assortment of other organizational duties. Childcare workers were responsible for the immediate supervision of children "on-line" and other duties subsumed under the general category of "treatment coordinating" or "case-coordinating". These included developing individualizsd treatment plans (identifying specific issues children needed to work on, such as appropriate peer 
Figure 2. Formal Structure of the Traatment Teams

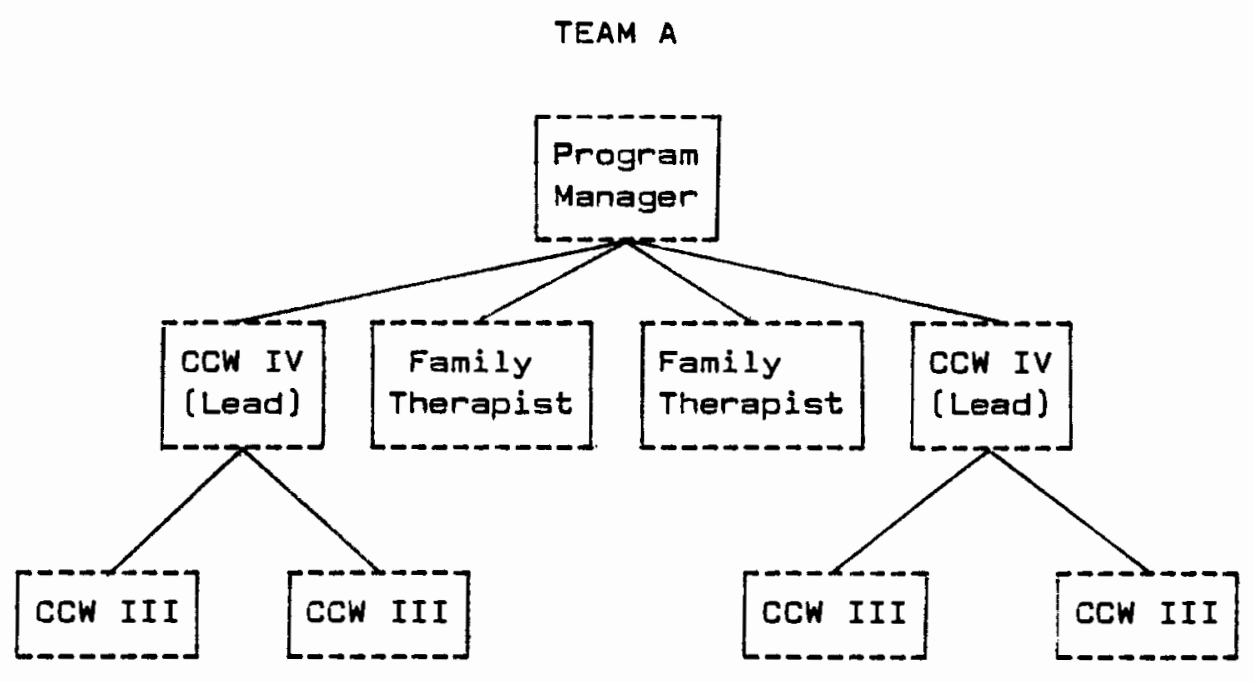

TEAM $B$

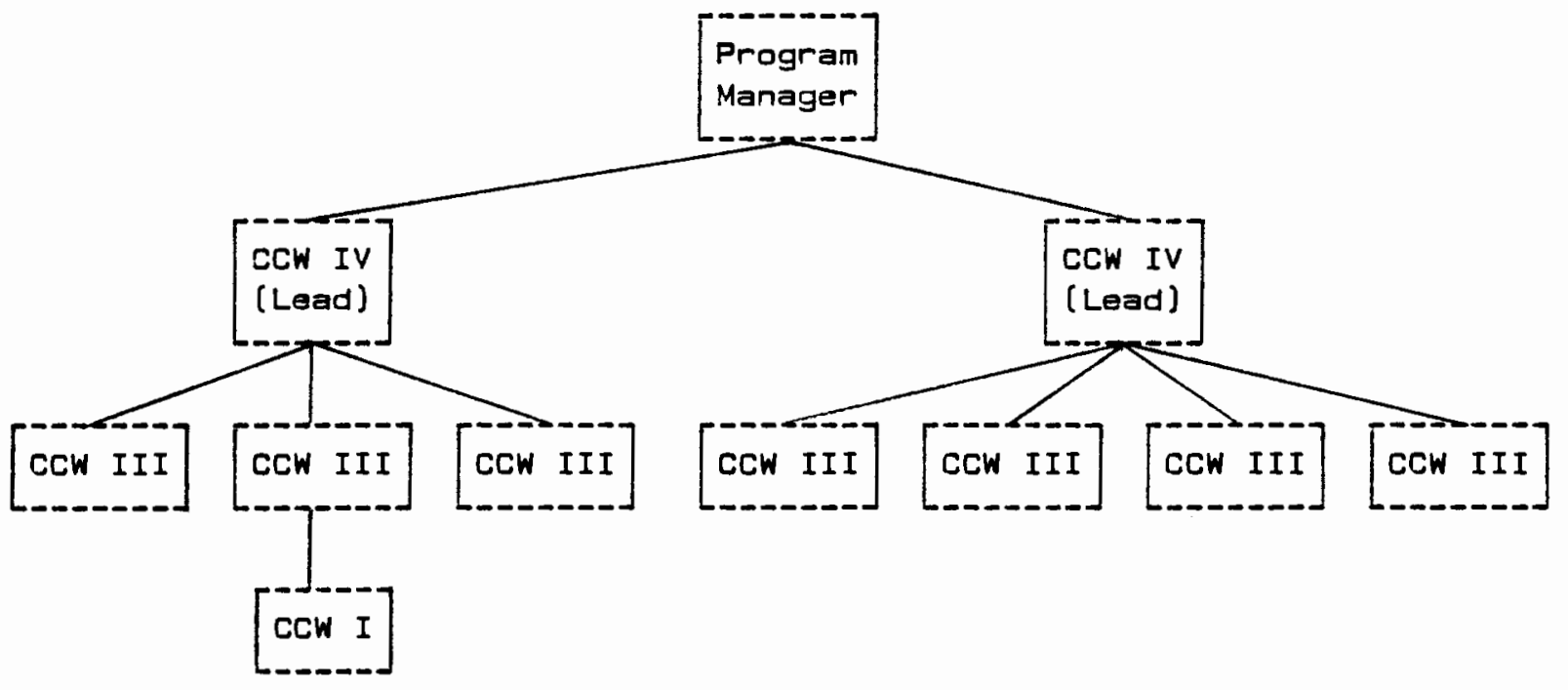

Group Composition

(Number of persons in Role)

\begin{tabular}{lcc} 
Occupational Role: & TEAM A & TEAM B \\
Program Manager & 1 & 1 \\
Family Therapist & 2 & $\emptyset$ \\
Childcare Worker IV (Lead) & 2 & 2 \\
Childcare worker III & 4 & 1 \\
Childcare worker I & 0 & 11 \\
\hline Total $N=$ & 9 &
\end{tabular}


interaction), coordinating school plans and writing up "treatment reviews," or "discharge summarieg," which were sent to the state CSD offices. In addition to the normal responsibilities of childcare work, lavel IV warkers performed managerial duties in conjunction with the program manager. This is represented below in a statement issued by the agency:

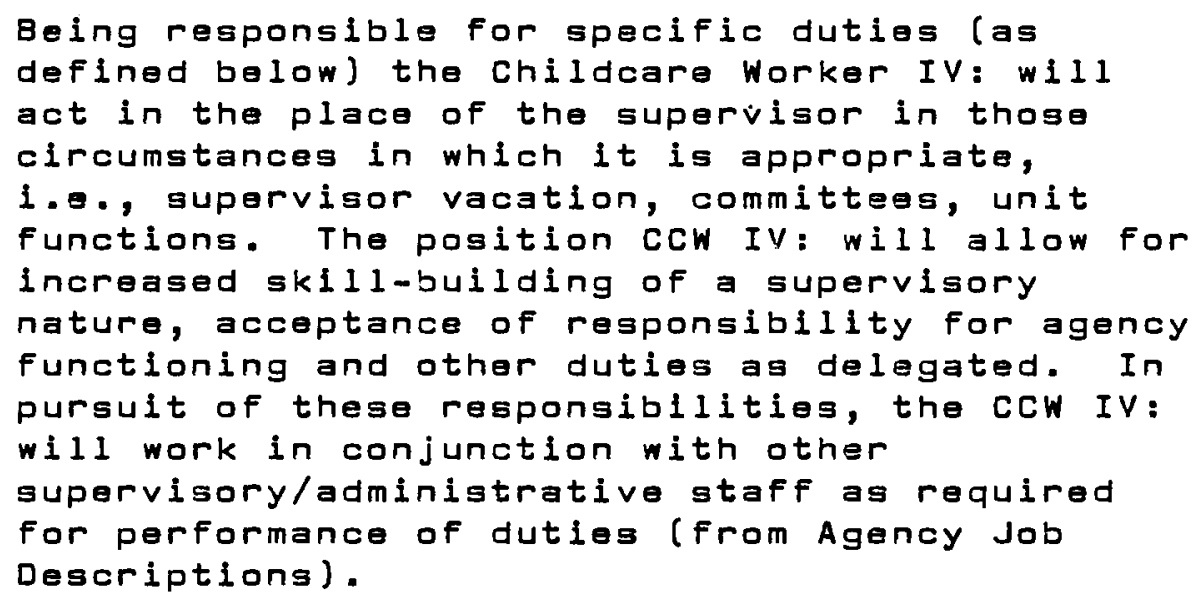

While the duties of workerg of both programs were very similar, Team B catered their gervices to a qualitatively different population of children. The clientele serviced by Team A normally stayed at the agency for approximately one year; those of Team B, however, generally stayed less than four months. In fact, the length of stay prescribed by the nature of the program for Team 8 was only 6 d days. In general, the kind of care provided for the children was, in fact, more custodial and less "treatment" oriented than thet of Team A. A significant structural difference was the 
relative absence of family workers on Team $\theta$. This related directly to the short stay of the elientele and the fact that the purpose of the program was to provide emergency relief and care for children (as wall as providing behavioral assessments of the children to the statel, as opposed to long term treatment. Another significant structural element las indicated in figure 2), was the presence of CCW I on Team $B$. This addition of another worker had apparantly been due to the relatively low staff to client ratio, and the subsequent magnitude of the work-load. While CCW I's assumed the same daily duties as the other childcare workers, the responsibilities of case-planning and subsequent behavioral assessments presented to the state cso offices were not included in their job descriptions. Thus, the total number of team members (including the program managar) for Team $B$ was 11 and for Team A, 9 persons.

One of the basic assumptions made in thls analysis is that the structure of authority relations (i.e., power to determine the kind of programming, use of time and other resources, and the mode of "treatment" employed) was ultimately determined by the office of the program manager [i.e., the supervisor]. This assertion is qualified by several factors. First, the program manager alone was responsible for all review processes pertaining to both family workers and childcare workers (whether the review process was for a "merit" increase in salary ar disciplinary 
action). Second, the office of supervisor was responsible for hiring, firing and training personnel. Third, although substantial bartering took place, the content of conference discussion was contingent upon the issues ultimately thought relevant by the gupervisor, and it was he/she who was normally responsible for conducting the conferences-frequently this meant insuring that team members stuck only to the pertinent issues at hand and did not deviate from the agenda. Fourth, the structure of the unit (i.e., the rules, regulations, planned activities, daily routines which involved the children), while actively constructed by the workers, ultimately reflected the policy decisions of the program manager as well as the agency in general. Fifth land most important], $\exists 11$ of these activities within the treatment teams were ultimately sanctioned by the office of the program manager through either formal or informal channels. As evidenced in observations made during the period of this research, formal sanctions ranged from official commendations which went on one's personal record to official termination. Informal sanctions tended to be circumscribed by the interpersonal ralationg between the manager and the treatment team member and included personal expressions of appreciation as well as those of dissatisfaction.

It would be a conceptual fallacy, however, to regard superordinates within an organization as the sole possessors of bureaucratic power. Conceivably, lower organizational 
participants may be as much empowered by the bureaucratic ruleg which regulate their work as they are subjugated by them. That is, bureaucratic rules may actually protect workers from arbitrary decision-making insofar as such directives may fall outside of the normative expectations of their work, i.e., the "job description" (Gouldner 1954). Others have also pointed out that the strategic location of Lower participants within the organization, along with other processes, also results in particular power for on-line workers (Mechanic 1962).

It should be noted, too, that managerial personnel need not simply exercise the authority of their office to influence decisions made by subordinates... "instead, they may attempt to exert influence in the desired direction through education, persuasion or advice" (Goss 1959:47). such influence may result from the fact that lower organizational participants are cognizant of the authority of the superordinate who implements thege alternative means of influence. As Dennis Wrong posited:

The intentional control of others is likely to create a relationship in which the power holder exercises unintended influence over the power subject that goes far beyond what he may have wished or intended at the outset (1979:4).

The significance of these processes for the study of humor lies in understanding how participants of different formal statuses symbolically portray role-relationships 
through their use of humor, how role-relationships themselves may be symbolically transformed by participants, and how the situational construction of such humor is relative to "stage sattings" within the workplace.

\section{Authority, Status-Boundaries and Humor}

In a study on linguistic forms of address and status differences, Roger Brown and Marguerite Ford (1960) explicated how the use of a person's name in conversation symbolically portrays his or her position in status arrangements. According to Brown and Ford, the presence of status differences in the organization studied was accompanied by patterns of "nonreciprocal address." Persons of high status within the organization were addrassed by a title used with their last name. Subordinates, however, were typically addressed by their first name. This pattern was maintalned even in situations where the person of superior status was younger than the person of subordinate status. In observations remiscent of earlier hypotheses presented by Homans (195ø), Brown and Ford observed that:

When there is a clear difference of status between the two, the right to initiate the exchange unequivocaliy belongs to the auperior-- to the elder, the richer, the more distinguished of the two. The gate to linguigtic intimacy is kept by the person of higher status. (1960:381) 
in delineating how linguistic forms correspond to the formal relations between persons in the organization. It has been suggested that humor, as a linguistic form, also symbolically represents the relationship between persons as they come to be located in a particular place within the production process. Craig C. Lundberg (1969), for example, researching patterns of joking within workgroups of an electric repair division, noted that the relative prestige of the work group corresponded to the importance of the tasks they performed. Moreover, the pattern of exchange in joking observed by Lundberg indicated that while high ranking workgroup members could typically "joke down" to persons of low-ranking status, the latter did not appear to "joke back." Lundberg consequently stated that "in the context of stable human organizations, person-focused joking incidents seem to fulfill a social function; namely that joking defines and redefines the differentiated social grouping, reinfarces the ranking of group members both within and between groups, and clarifies the status of one group to anothar" (1969:28). In a similar study, Gary Traylor (1972) researched the use of person-focused humor among memberg of a petroleum exploration party in Alaska. Traylor's findings supported his hypothesis that "the frequency with which a member of the group is the focus of person-focused jokes originating with other group members w11l be an Inverse function of his status" 
A primary theoretical interest within this present study concerns the kinds of social conditions that produce patterns of joking other than the hierarchical patterns abserved by both Lundberg (1969) and Traylor (1972). One such condition proposed by the present study occurs when the "functional legitimacy" of specific office holdars (i.e., his/her technical competence and skills in human relations) comes to be defined as waning by subordinates. In Max Weber's masterful work on types of authority, Weber differentiated between power vested in the characteristics and subjective qualities of the person (charisma) and those vested in office (legal-rational). More contempory analyses have utilized Weber's conceptualization in studying organizational authority in hierarchical organizations. Charles R. Hollowman, oxamining managerial and supervisory positions, differentiated between "the static positians of headship and the dynamic process of leadership" (1968:38). By "headship" Hollowman referred to the mere appointment of a person to office who may exercise power and influence decisions by virtue of the legitimacy of office-- not by virtue of their own personal qualities. This exercise of power presupposes an unidimensional declsion-making process which stands in contradistinction to a true leadership process. As Hollowman asserted, "Where there is no choice, there is domination, the antithesis of leadership" (1968:40). Leadership, according to Hollowman, "is a characteristic of the functioning of 
groups resulting from the interaction of leader, group and gituation" (1968:38). According to Hollowman this entails a democratization of the decision-making process whereby the leader is able to influence group members to achieve organizational goals via voluntary cooperation. Other key differences between headship and leadership offered by Hollowman are presented below (1968:41):

Headship-Leadership Differences in Hierarchical organizations HEADSHIP LEADERSHIP

1. Exercised by: Appointed Head Natural Leader

2. Means of

Assuming Role:

Appointed

Group Acceptance

3. Source of Authority:

Delegated From Above

Accepted From Below

4. Basis of Authority:

Lega 1

Porsonal/

Competence

5. Authority Legitimated by:

Values Institutionalized in Legal Contract and Cultural Ideologies

6. Relationship of superior to

Domination (Unidirection-

Recognition of Contribution to Group Goals. Subordinates: al)

Personal Influence (Group Directional)

7. Responsible to: Superiors Superiors \& Subordinates

8. Extent of control:

Limits of Lagal Authority

Bayond 1 imits of Legal Authority

9. Social Gap: Wide Narrow 
10. Behavioral

Authoritarian Democratic

Patterns:

While supervisors and managerial personnel are typically hired on the basis of their administrative qualifications and technical expertise, such skills may be only of partial relevance to work-group members. Indeed, as Hollowman indicated, elements within the interpersonal relations between supervisor and worker may be just as significant as formal authority if the supervisor is to achiave a significant degree of organizational efficacy. Hollowman identified the more important aspects of this relationship in the following:

\footnotetext{
However he emerges into the leadership role, he must be perceived by the group as a means to the achievement of some recognized desired goal. Group members willingly accept his direction because they believe that through following him they can satisfy their own personal needs as they achieve group goals. Regardless of the validity of their judgement, the person in the leadership role derives influence because the group believes that he can help them (1968:39).
}

In prior research of organizational authority within public service organizations (a police department, welfare office and elementary school), Robert L. Peabody (1962) similarly differentiated between "formal authority" and "functional authority." Pabody stated that "the bases of 'formal' authority-- legltimacy, position, and the sanctions 
inherent in office-- need to be distinguished from the source of 'functional' authority, most notably, professional competence, experience, and human relations skills, which support or compete with formal authority" (1962:465-466). Essentially, the issues identified by Peabody, subsumed under the general label "functional authority," are those which Hollowman later associated with leadership. Peabody posited that functional authority is the legitimacy gained by superordinates because of their technical knowledge and expertise (usually through professional training or specialized graduate education) and also from experience "gained from day-to-day confrontation of problems" (1962:47ø). Functional authority is also derived from one's own person... "be it charisma or routinized human relation skills" (Peabody 1962:472).

In a much earlier theoretical analysis of the "screening function" of rules, Alvin Gouldner delineated how bureaucratic rules served "as substitute for the personal repetition of orders by a supervisor" (1954:164). The screoning function of rules preserved the authority of the supervisor, according to Gouldner, by warding off contestations that might otherwise call it into question. As Gouldner gtated:

The screening function of the rules would geem, therefore, to work in two directions at once. First, it impersonaliy bolaters a supervisor's claim to authority without compeliing him to employ an embarrassing debatable legitimation 
in terms of his personal superiority.

Conversely, it permitg workers to accept managerial claims to deference without committing them to merely a personal submission to the supervisor that would betray their self-image as "any man's equal" (1954:166).

One managerial behavior mentioned by Gouldner, which led to supervisors being defined by workers as functionally "illegitimate," was close supervision. Primarily, "close supervision violated norms of equality internalized by workers, and they responded by complaining that the supervisor was 'just trying to show who is boss'" (Gouldner $1954: 161\}$

The relevance of these analyses for the present study is in delineating the differences in types of humor emergent from the structured relations between those who hold differential power (i.e., managerial personnel) in the workgroup and their subordinates. As previously mentioned, one of the basic assumptions whlch undergirds the present study is that the authority structure of the workgroups (specifically, the treatment teams) is to a very large degree contingent upon the programming carried out by the program manager. By utilizing both Goffman's concept of stage-settings, and a conceptualization of functional authority derived from Weber, Hollowman and Paabody, a typology of person-focused humor may thus be constructed. 
Figure 3. STAGE-SETTINGS: PERSON-FOCUSED HUMOR

Perceived Functional Authority of Superordinate:

\section{LEGITIMATE}

I LLEG IT I MATE
Front Region (Staff Conference) (On-Line/ Pub)

\begin{tabular}{|c|c|c|}
\hline LEGITIMATE & $\begin{array}{l}\text { Hiararchicaliy } \\
\text { Patterned Person- } \\
\text { Focused Humor } \\
\text { (Reinforcement of } \\
\text { Superordinate-sub- } \\
\text { ordinate Role- } \\
\text { Relationship) }\end{array}$ & $\begin{array}{l}\text { Playful cri- } \\
\text { tique of Sup- } \\
\text { erordinatel } \\
\text { Hierarchically } \\
\text { Patterned Hu- } \\
\text { mor }\end{array}$ \\
\hline I LLEG IT I MATE & $\begin{array}{l}\text { Mimicry/ "Coded" } \\
\text { Humor/ Private } \\
\text { Communiques }\end{array}$ & $\begin{array}{l}\text { Humor as } \\
\text { Profanation: } \\
\text { Invectives, } \\
\text { Ridicule, } \\
\text { Sarcasm }\end{array}$ \\
\hline
\end{tabular}

The typology in Figure 3 represents particular types of humor one might expect to find given the (above) specified conditions of interaction within the workplace. Specific hypotheses have thus been derived (some of them borrowed) from both previously mentioned theoretical frameworks (Goffman et. al) and exploratory observations made within the residential treatment setting. While the hypotheses presented in the following chapter are intergal statements of relations between phenomena, they should not be considered statements which are a part of a true statistical hypothesis testing mathodology. 


\section{METHODOLOGY}

\section{Theoretical Questions}

Humorous interaction between staff members of two different treatment teams within a residential treatment center were recorded during an approximately 3 month period of non-participant observation. Three primary questions guided the research:

1. What indigenous types of occupational humor will be found within the treatment teams?

2. How (if at all) will the use of humor vary between the front and backstage regions of treatment wark?

3. How does occupational status affect the way in which team members target one another to be the "butt" of jokes and other humorous remarks ( $i . \theta$.) how does status affect "person-focused" humor)?

\section{Definitions of concepts}

Both the guiding questions of this research, and the conceptual framework used in the analysis of person-focused humor suggest several key variables and concepts in need of more precise defining; these definitions have been presented below.

I. Humor/Joking/Jocular Interaction: Any behavior or communication engaged in by one or more persons to intentionally arouse laughter or a smile in others, and did. By defining humor in such a way, the researcher has attempted to delimit observations of humorous episodes to 
concrete interactions between participants. This excludes, a fortiori, situations which accidentally produce laughter. such an accidental production was best exemplified during one of the staff meetings when, in the midst of a relatively brief period of silence, a window slammed shut. Needless to say, the unexpected loud noise startled everyone, who, cognizant of their own reaction, broke into a group guffaw. Humar, as defined here, implies a particular intention on the part of social actors engaged in communication. It also denotes that communications are humorous only if BOTH parties involved define it as such. That is, the listener, or recipient, must perceive the communication as humor; it is not merely a product of the sender. The communication was classified as "intended to be Funny/humorous" only if the sender him/herself laughed or snickered after sending it.

II. Person-Focused Humor: Humor in which the focus or "butt" of the remark, joke, etc., is a person or group of persons to which an individual belongs.

Thus, one may make a joke about a specific childcare worker, manager or client, or a joke about auch people as a category. The predominance of riddles which can be readily adapted to accommodate any social grouping is avidenced, for example, in the form "How many sociologists does it take to screw in a light bulb?" In recording and analyzing person-focused humor the following definitions were also 
used:

A. Initiator: The person who starts the joking; e.g., begins telling the joke, initiates the prank, etc..

B. Recipient: The person or persons to whom the joking/humor is directly commmunicated.

C. The Focus (or "butt"): The person, group or category whom the joke/remark is about. The focus may be the recipient or the initiator if the initiator makes jokes/remarks about him/herself.

D. Audience: The term for group members beyond the Initiator and recipient who can gee and/or hear the humor.

(See "Appendix C" for the notational scheme used in recording the directionality of remarks observed during staff conferences and on-1ine work.J

III. Occupational status (operational definition): The rank standing for each member in the group based upon a composite score of the following items lon which members were ordinally ranked). This scale was adopted from Traylor's (1972) study of humor and status within an Alaskan pipeline crew. 
A. A person's formal authority as contractually defined: CProgram Managar=5; Family Worker=4; Childcare Worker IV (lead)=3; Childcare Worker III=2; Childcare Worker I=1).

B. The level of Formal Education Achieved: (Ph.D=5; $M A=4$; $B A=3$; Some college=2; H.5. grad=1).

C. Level of Salary (members ordinally ranked): The pattern for each group closely resembled figure 2. (presented earlierl, displaying formal authority relations. Among Childcare Worker III's, however, length of employment directly represented salary lovels gince merit increases were always received by mamberg of the two groups upon the one year anniversary of their initial employment. Thus, the actual ordinal ranking of team members on this variable was represented by Program Manager, highest; Family Worker, second highest; Childcare Worker IV, third highest; Childcare Worker III, ranked on length of employment relative to other CCW IIIs; and, Childcare Worker I ranked lowest. The primary reason for using the format was two-fold. First, the formal salary range for each position was known prior to the distribution of questionnaires; and, second, attempts to get some persons in the group to disclose anything about their present salary level would have been futile. 
check list developed by Laforge and Suczek (1957). Mean scores were obtained by dividing the total scora accumulated by the number of raters. The person accruing the lowest score (as prescribed by Laforge and suczek) was considered to have been afforded the most esteem. Such persons were ranked highest with others ranked gequentially (see "Appendix D"). One's status within the group was, thus, represented by the following formula:

Formal Authority + Education + Salary + Esteem = Status

As stated, each team member was ordinally ranked on each of these variables. These ordinal rankings were then combined to yleld a camposite score. After the composite score for each member had been computed (the composita score regarded as the index of member's overall status], members were then ordinally ranked highest to lowest (the highest score representing the person with the highest status]. The status structure derived from these operations typically (but not always) followed formal relations. The major difference occurred at the level of the lead childcare worker (CCW IV) where certain CCW IVs were ranked lower on the esteem scales then some CCW IIIs: Consequently, some of the CCW IIIs who had been employed longer had higher than expected gtatus within the group. 
IV. Functional Legitimacy: The authority of a person derived from his/her technical knowledge and expertise, as well as other skills in human relations. The supervisory Evaluation Questionnaire was used to measure workers' assessment of supervisor's technical knowledge as well as their human relation skilis.

The Supervisory Evaluation Questionnaire was a compilation of items from four different questionnaires concerned with managerial relations (Campbell 1956;

Fleischman 1953; Schmid 1967; Stogdil1 1955): many of these items appeared within all four of these questionnaires. The questionnaire was distributed to all team members in both groups and was used to compare differences in perceptions of supervisors between the two work groups (soe Appendix E). During the period of data collection, qualitative observations were made of participants' general evaluation of the supervisor. The richness of this conversational data, and the humor, is, in fact, reflected-- but not captured-- in the questionnaire data. Observations seemed especially plentiful during luncheons on "staff training days" while the supervisors were not present. The usual format used to "hustle information" from the participants (Prus 1980) began with "so...how do you guys like your new supervisor?" lboth program managers had been hired to their positions at almost the same time and were relatively new). The researcher then prodded group members to explain their initial responses. 
It wag found that all of the explanations generally focused on items included in the Supervisory Evaluation Questionnaire with workers commenting upon the personal characteristics of the supervisor lsuch as the supervisor's authoritarian or democratic style of management, how easy he or she was to get along with, etc.).

\section{Problems with Data Collection}

While a substantial portion of the data were collected through non-participant observation, two separate survey forms were also utilized: an Interpersonal Adjective Checklist developed by Laforge and Suzcak (1957) (see Appendix $D$ ) and the Supervisory Evaluation Survey. Several prablems encountered with the checklist by Laforge and Suzcek led the researcher to question its reliability. The primary problem was, in fact, voiced by the respondents that some of the characteristics could not be scored because the items did not represent a true continuum. Consequently, some of the items failed to capture the entire range of personal characteristics of the person being evaluated, according to the raters. This produced several incomplete surveys which, unless manipulated, would have been worthless. A post hoc realization by the researcher has been that the only redeeming value in using the scale by Laforge and Suzcek hag been an educational one attained in learning how to "patch up" a poor scale. This was accomplished with the incomplete 
surveys by taking the mean score of the completed items and multiplying it by the total number of items to achieve a projected total score. While the method is a quantitative "poetic license" at best, this researcher considered the data to be better than no data at all. After discovering these flaws, this researcher has subsequently run across measures which seem to be better suited for the task lsee for example, Jones 1962 ).

The Supervisory Evaluation Questionnaire was a composite of several different pretested questionnaires concerned with managerial relations (see Appendix E). By far, the singla greatest problem with the survey was that participants failed to respond. In fact, several of the participants posed the question that since the researcher "already knows how we feel, why should we fill this out?" some of the respondents lall of whom were informed that the survey was, of course, completely a voluntary exercisel thus declined to respond.

The total number of respondents for the supervisory quastionnaire was thus 6 out of 8 (Team A) and 5 out of 10 (Team B) group members. Since these samplas were so small the reader should be cautioned that representation of the "true" significance of sentiments observed in the communication between group members by the quantitative data alone may be suspect. Indeed, it is the richness of participant expression observed in interaction that probably best depicts workgroup reality. 
Besides the exceedingly small sample of the supervisory evaluation survey, several other problems related to the observation process plagued collection of the data. One of these was related to "instrument decay." specifically, the researcher qua data-collector found that his efficiency at recording observations was relativaly waak at the very beginning and at the tail-and of the project. This occurred bacause of two common processes at work during the actual data collecting: first, the recording techniques needed slight adjustment after the initial use of the observation sheet-- i.e., the researcher was learning the most efficient way to record as many observations as possible, in organized fashion; and second, as frequently occurs, boredom and fatigue began to appear during the tall-end of the study. since no other person was employed to simultaneously observe interaction (within staff conferences or on-1ine), the first and last week of observations were excluded from analysis of the quantitative data. This control was imposed specifically for the purpose of analyzing data which included the frequency with which persons were the focus of other's humor. Another problem during the data collection concerned "intragroup history." The period of observation for the study (approximately 3 months) was, in fact, shortened by several weeks after several staff members left the agency. Any further data collection would have thus been mislaading given the already small size of the group and, more 
important, the fact that group composition would have been altered significantly. During the first week of observation, a member of the same team had been promoted to another position within the agency and left the team. Since the position he vacated was a "lead" childcare worker position, the supervisor supposedly was left the onerous task of screening applicants for the position. The position was quickly filled, however, with another childcare warker from the same team. Thus, the group basically retaingd its initial compostion. This occurred in the first week of observation and was controlled insofar as the person-focused data for this weak was excluded from analysis.

One of the less visible yet important issues at work within the resaarch (at least in the very early stages) was that of "reactivity" (that is, behaviors of the subjects, or observed effects within the research that might have been the product of subjects reacting to the presence of the researcher and not a true representation of normal patterns). Since the researcher was actually a previous employee of the organization, and knew or was acquainted with most team members, integration into the workgroups was relatively quick and unproblematic. In fact, It would seem that had not the researcher been known to group members in a prior wark role much of the data collected would have been unavailable (this is attributed to the simple but crucial issue of "trust" which is evidenced in the research relationship). Reactivity 
to the mere presence of the researcher within the staff conferences seamed, initially, to have produced an effect in two distinct ways. Several group members pointed to the researcher's presence as a sign that they could now legitimately "cut up" in the conference. One of these episodes was, in fact, facilitated briefly by one of the supervisors in the vary first meating:

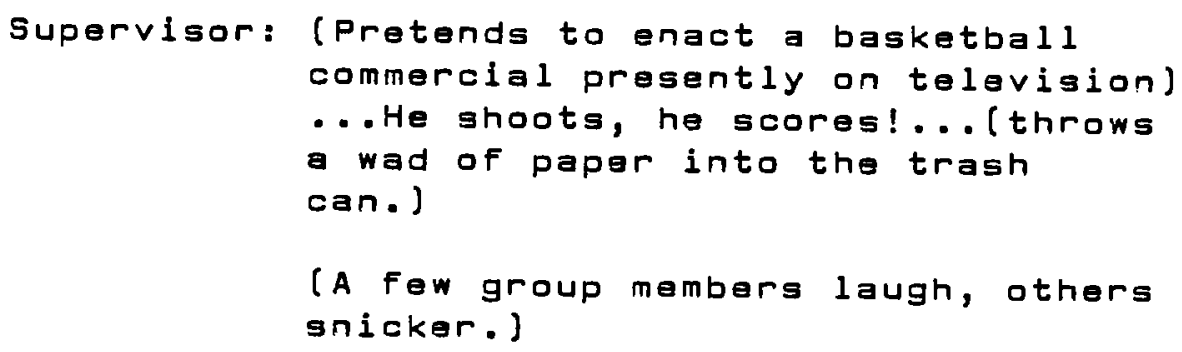

Aside from persons in the group who initially performed for the benefit of the researcher, other group members were observed "catching themselves" from stating humorous remarks or actually retracting half-stated jokes lall of which targeted the clientele). It appeared that such behavior (at least in part) was a realization by certain group members that while one's supervisor may appreciate the joke, a newcomer may not. Since these rotractions occurred only during initial observations, their disappearance was considered to be an informal index of the researcher's perceived status-- viz., that he was no longer considered to be an outsider, but now was a part of the in-group. 


\section{Statemennt of Hypotheses}

As implied in the discusgion of the research questions, a good deal of the research conducted in this study was exploratory in nature and was not specifically concerned with statistical "hypothesis testing." The typological framework presented earlier (Figure 3.) was derived both from previous studiss and exploratory observations conducted at the outset of the present study. The framework thus suggests the generally expected types of humor emergent within the conditions given.

Hypothesis I: The use of ridicule, sarcasm and invective as a form of humor will more frequently occur in the back regions of treatment work.

This hypothesis, while seemingly commonsensical, is derived from Goffman's work on team performance and "face-work." Essentially, the underlying assertion is that such remarks are discrepant with the impression of professionalism fostered by the performance of group members while in the staff conference.

Hypothesis II: The frequency with which a member of the group is the target of "person-focused" humor will be an inverse function of his/her status within frontstage settings. 
The hypothesis was adopted from Traylor's (1972) study but qualified by the region of interaction within the workplace. The expected finding lindeed, one strongly substantiated in Traylor's study) is that members of higher status within the group will less frequently be made the focus of others' jokes than members of lower status. Two related variables of concern in this present study are the perceived logitimacy of top status holders (i.e., managerial personnel), and the interactional setting and how these variables together may influence the hierachical patterns of person-focused humor as suggested by Lundberg (1969) and Traylor $(1972)$

Hypothesis III: When the focus of humorous remarks is of superordinate status, humor/jokes will occur more frequently in the back ragion.

Hypothesis III is directed at testing another commonsensical assumption; viz., that fearing sanctions, subordinates guard their humorous remarks of superordinates by communicating them only while in a "defensible space."

Presentation of the data for all of the hypotheses, and the qualitative observations in general, are discussed in the following chapter. 


\section{PRESENTATION OF THE DATA: FINDINGS}

\section{Functional Logitimacy of Managerial Personnel}

The forms and patterns of humor which emerged during the staff conferences and on-line, or at the pub, displayed distinct differences between the two treatment teams. As has been repeatedly suggested in this study, the divergent patterns were to a large degree associated with the interpersonal relations between staff members. Such relations were, in fact, evidenced in the initial interviews with program managers while discussing the research project. The following was a form of managerial humor recorded during the very firgt interview with the program manager of Team $A$.

S: We aren't sending kids over to 7-day anymore. Five-day families deal with their problems or they aren't $\mathbf{5 - d a y}$ families.

R: So, how long did it take for that to change? The old method was actually a "system."

S: I'll show you how that happened--close the door.

(R)esearcher gets up from his seat and closes the door, suspecting that he is about to gain some privileged information. Behind the door $1 \mathrm{~s}$ an $8 \times 12$ inch cartoon of a King sitting an his thrane. The King is striking a kneeling subject over the head with a club. The caption below reads, "He's invoking executive privilege again."

R: (glances back to $s$ who is chuckling).

S: Just a matter of "proper management!"

In the qualitative observations made during both staff 
conferences and on-line, other team members communicated similar carlcaturas of the supervisor's use of office-albelt with a decidedly different moral valuation. That is, while subordinate role-occupants saw the office of the program manager as legitimate, they perceived the office holder as functionally illegitimate. This perception was evidenced upon several occasions when the manager was not present (i.e., whon members were in the "back regian"):

Bi: One message...family workers will train CCWs to lead educational groups.

Bz: ...something he thought up this morning while he was throwing up... (supervisor was 111)

(The treatment team was occupied with developing therapeutic and educational programs to teach kids "how to survive the treatment process")

Ba: If we aren't careful then he'll [supervisor] take control and do it, which sounds like something we're not comfortable with.

Bc: I find myself feeling sorry for the guy's family. He definitely needs some group to be apart of...to have conversation with.

Bj: Well I wish heid find another group to converse with.

Bz: He's like Darth Vader when he comes into a family meeting. Just his presence is like this ominous force...

Such vilification assumed a variety of communicative forms-- humor being one of the major ones. By contrast, 
members of Team B assessed the functional legitimacy of their program manager in more favorable terms. Generally, all of the workers stated that they "really 1 ike the new supervisor." As one worker stated:

This supervisor is very humanitarian. Another expresed similar feelings:

I guess I used to foel a little bit self-conscious. I guess that was because of our last supervisor who really made us feel intimldated. [Our supervisor] really doesn't make us feel that way.

And, on one of the survey forms a team member, after marking "seldom" after the item, "s/He rules with an iron/hand," wrote:

It always has a velvet glove on it.

As indicated by Hollowman (1968) and Peabody (1962), it is the kind of role enactment by particular persons while in office which helps transform the power they derive from their office into personal authority at the level of workgroup relations. Implicit in this legitimation process is the kind of social relationship found between superordinate and subordinate role-occupants. Hollowman (1968) pointed out that managerial relationships, characterized by democratic participation and personal influences of managerial personnel, promote less social distance land greater legitimacy of the superordinate) then those characterized by 
autocratic roles.

The differences in perceptions of managerial relations for each treatment groups was also evidenced in the Supervisory Evaluation Questionnaire distributed to both groups. Group members rated the program manager of their own team on twenty-five different items which were then used to compare the respective differences. While several problems (mentioned in the previous chapter) requiro skeptical evaluation of the results, the questionaire is, in fact, a confirmation of the observational data already collected. As indicated by the results of students t-test (see Appendix F), the program manager of Team $B$ was rated high on almost all of the items, while the manager of Team A was ratad low. These differences appear to exemplify divergent types of managerial style: one defined as legitimate by participants, the other defined as illagitimate.

\section{Frontstage Hümor}

Virtually all of the humor emerging in the staff conference could be classified as "person-focused" in the sense that dialogue almost always centered around the social service profession...that is, it was "people oriented."

In general, a greater number of humorous remarks, however, were observed in the front stage than the backstage. The primary reason for this difference was that despite the numerous issues to be discussed in the staff conference, 
staff members were free from the task domands which often engulfed them while on-line. The types of remarks and frequency with which particular persans or groups were the focus in conference humor varied considerably between teams (see Table I).

TABLE I

FRONTSTAGE HUMOR DISTRIBUTION

Team A Team 9

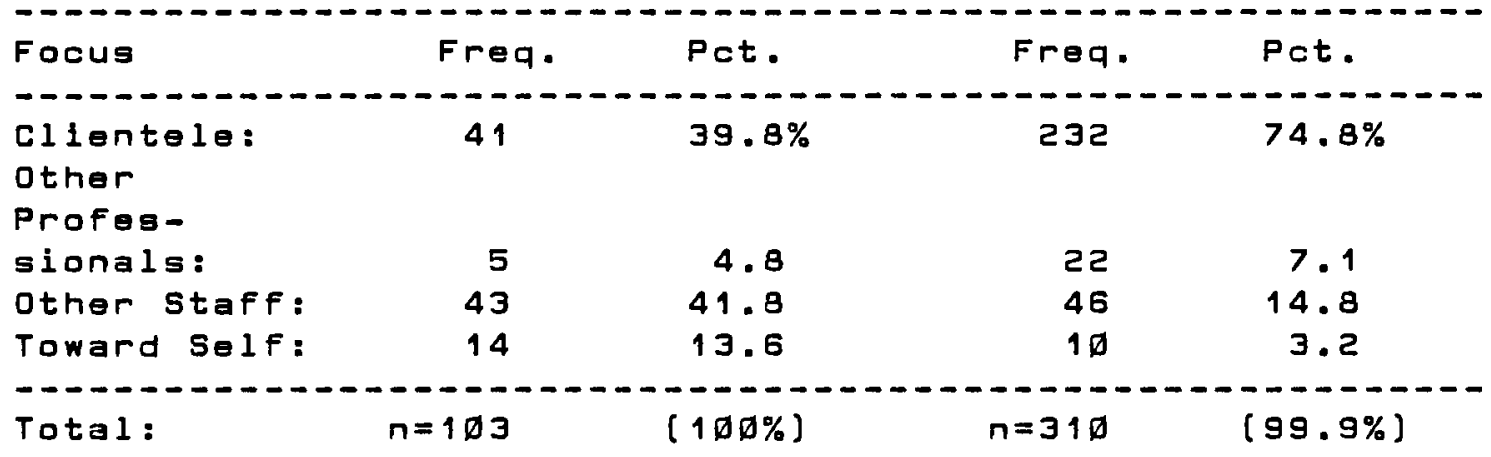

As evidenced in Table I, Team g had a greater percentage of humorous remarks made about the clisntele (primarily the children, but also parents and other relatives of the child). The types of remarks ranged from numerous stories about particular children to sarcastic remarks regarding more difficult clientele. The larger volume of humaraus remarks in Team B, however, may be attributed to factors other than the sheer wittiness of respective group members. First, the total number of staff members of Toam $B$ exceeded of Team A by two persons leverything else being equal, Team a thus had 
greater potential for a larger volume of communicative exchange). Second, the amount of humor within each team also appears to be related to managerlal style of the supervisor who presided over the meetings. Stories, and other tidbits of organizational folklore, however, had to meet demands for brevity if they ware to be told. That is, such story-telling itself had to be structured according to the time-constraints of the conference. This constraint, however inhibiting, did not keep members from interjecting such talss as the one below:

It was hysterical...we had a kid once who spoke funny. Everyone thought he had a speech impediment, but it was just that he was from the East. People would ask if he had the problem... we'd say "No, he's just from Brooklyn."

Often, such story telling was licensed by the occasion of the case-presentation, when treatment workers would be asked to elaborate on particular treatment issues. The occasion always provided the potential for particular participants to frame the elaboration in humorous form and thus provide entertainment for the group las illustrated below ):

LouAnn: (Presenting case material of child to CSD worker) He gives affection freely ...except to Mark. (Group laughs-- Inside joke).

Mark: (To CSD worker) Do I look like the kid's dad or something? He would call 


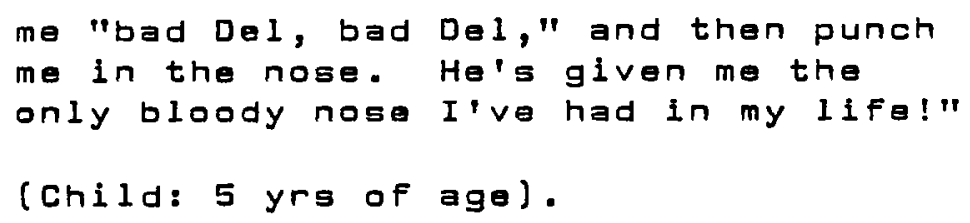

While the presence of CSD workers (Children's Services Divisionl and other professionals formalized the setting and manifested a frontstage performance by the team, their leaving revealed the social transformation of the setting into a back region. This transformation was marked, in part, by the types of humorous remarks present in each, and appears to conform to Hypothesis I:

Hypothesis I: The use of ridicule, sarcasm and invectives as a form of humor will more frequentiy occur in the back region.

Hypothesis I appeared to be subgtantiated for the toam performance in both regions but only partially for individual performances. Table II demonstrates the frequency of occurence of these forms of humor for both Team A and Team B, while CSD and othar professionals were present and while they were not. 
TABLE II

INVECTIVE, RIDICULE AND SARCASTIC HUMOR

Taam A Team B

\begin{tabular}{|c|c|c|c|c|}
\hline Types of Humor & $\begin{array}{l}\text { Team } \\
\text { lack }\end{array}$ & $\begin{array}{r}\text { Parfarmance } \\
\text { Front }\end{array}$ & $\begin{array}{l}\text { Team } \\
\text { Back }\end{array}$ & $\begin{array}{r}\text { Performance } \\
\text { Front }\end{array}$ \\
\hline $\begin{array}{l}\text { Invectives/ } \\
\text { Invel }\end{array}$ & & ----- & & ----- \\
\hline $\begin{array}{l}\text { Profanities: } \\
\text { Ridicule/ }\end{array}$ & 4 & $\emptyset$ & 1 & $\emptyset$ \\
\hline Sarcasm: & 11 & $\emptyset$ & 11 & $\emptyset$ \\
\hline
\end{tabular}

The use of invectives/profanities was relatively infrequent in the staff conferences of both treatment teams compared to backstage communications. In fact, the only humorous remarks observed during frontstage team perfomances were made about the clientele. This held true especially when the presence of outsiders formalized the setting. That is, some of the usual conference jokes and banter would have been perceived by outside professionals as discrepant with the definition of the situation (1.e. "wo ara all professionalg"). Part of the reason was that these same professional functionarias either represented the social groupings being humorously critiqued or were themselves the target of staff member's quips. of the remarks made about other professionals, several were directed towards the resident nurse by members of Team 8 . One remark followed a 


\begin{abstract}
"Special Award" sent to team members who had recently been infected with "ring worm" by one of the children.

The award sent by the regident nurse read:
\end{abstract}

\title{
FIRST SPECIAL SERVICE AWARD OF 1985
}

To those staff who extended EMPATHY above and beyond the usual expectations.

These staff can be recognized by wearing of a special badge which connotes a rare

understanding of discomfort and isalation.

(The "special badge" drawn on the award was, of course, a "ring worm").

After the four awards had been distributed by the supervisor land several group members were groaning at the reminder of their affliction) the group broke into numerous chuckles when one warker pithily stated:

I'm gonna give [nurse] a Smart-Ass Award!

Compared to conversation "backstage" in the local pub (i.e., the "greenroom" setting), the types of profane humor used in the staff conferences were relatively mild. While particular staff members were never observed to be the target of humorous remarks during the frontstage performance of the team, such humor took several different forms in the backstage setting. The patterns of person-focused humor within staff conferences between the two different teams revealed quite divergent findings. of particular interest is the pattern of person-focused humor as it was affected by 
status dimensions (see TABLE III).

TABLE III

PERSON-FOCUSEO HUMOR: STAFF CONFERENCES

(No. of Jokes Received Per Group)

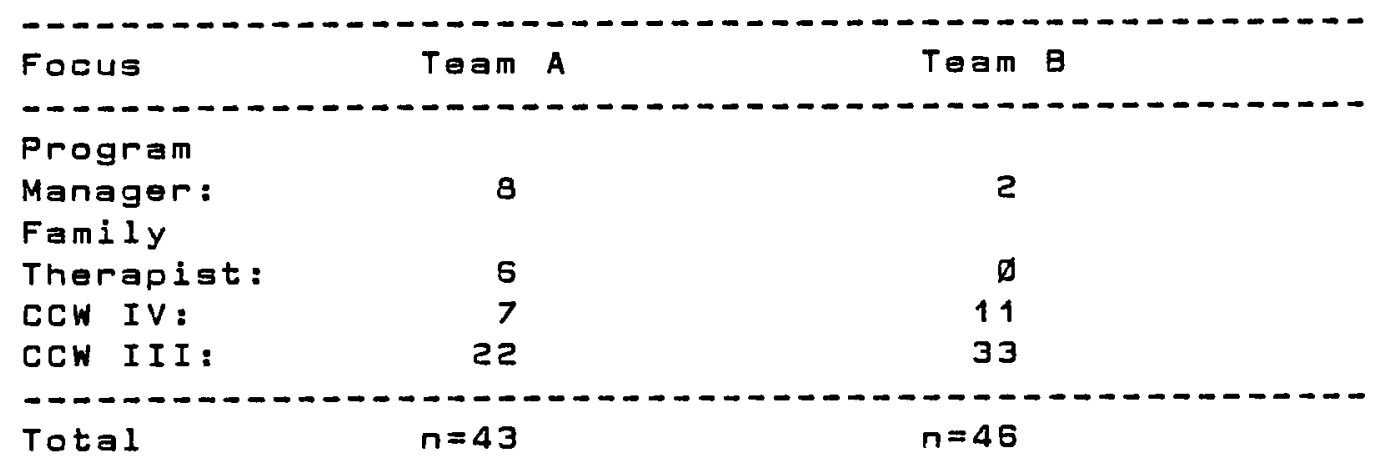

One of the hypothesis presented earlier (Hypothesis II) was that the frequency with which a member of the group is the target of person-focused humor will be an inverse function of his/her status within formal or frontstage settings. To test this hypothesis, a nonparametric correlation was computed between the status of group members and the amount of person-focused humor they received (see TABLE IV J.

The statug rankings were a composite of the ordinal rankings members received on level of education, formal authority, level of salary (or length of employment) and esteem scores. The status rankings, and ordinal rankings for person-focused humor achieved for each group were then used for an intergroup comparison. 
TABLE IV

STATUS AND PERSON-FOCUSED HUMOR RANKINGS

Team $B$

Team A

\begin{tabular}{|c|c|c|c|c|c|}
\hline \multicolumn{2}{|c|}{ Member Status } & PFH.Rank & Membar & status & PFH.Rank \\
\hline \multicolumn{6}{|c|}{ 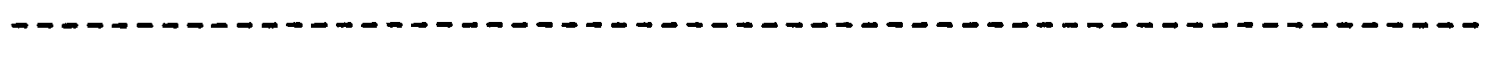 } \\
\hline supervisor & 1 & 1 & supervisor & 1 & 9 \\
\hline Pricl11a & 2 & 6.5 & Elite & 2 & 7 \\
\hline Phil & 3.5 & 9.0 & Susan & 3 & 7 \\
\hline Fletch & 3.5 & 2.5 & Denise & 4 & 10 \\
\hline Cindy & $5 . \emptyset$ & 8 & Jag & 5 & 1.5 \\
\hline Sandy & 6.0 & 4.5 & Louann & 6 & 7 \\
\hline Dot & $8 . \emptyset$ & 4.5 & Maggie & 7 & 5 \\
\hline Henry & $8 . \emptyset$ & 2.5 & $5 a 11 y$ & 8 & 4 \\
\hline \multirow{3}{*}{ Lucilie } & $8 . \emptyset$ & 6.5 & Fred & 9 & 3 \\
\hline & & & Mark & $1 \varnothing$ & 1.5 \\
\hline & & & June & $x$ & $x$ \\
\hline$N=9$ & & & $N=1 \emptyset$ & 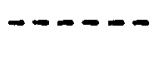 & \\
\hline Spearmans & Rho & $0.1 \emptyset$ & & & -.71 \\
\hline
\end{tabular}

While TABLE IV does, in fact, appear to roveal

hierarchically patterned humor for Team B but not for Team A, such an interpretation must be a guarded one. "June," a member of Team $a$ was rated so low on all of the different status indices that inclusion of her person-focused humor (P.F.H.) ranking would have been misleading. The observational data, in fact, reveal that June was totally excluded from any of the humorous exchange. Rather than regarding this exclusion as an indication of deep group reverence for June, the exact opposite was true. That is, ahe was excluded from joking and humorous play because ahe was perceived as incapable of doing good childcare work-thus her extremely low status with other group members. 
Indeed, more general observations during the staff conferences of Team $\theta$ revealed that exchanges of any kind involving June were almost solely with the program manager; interaction with other group members did not take place or was minimal.

One of the difficulties in analyzing the ordinal data for Team A is that a clear status structure did not appear. While the findings might suggest that status differances for Team A were "smaller" than those within Team $B$, the rankings still reflect the formal relations between group members. The top ordinal rank for Team A was the supervisor, while the next two postions were both family workers, followed by the two level IV childcare workers; the rest of the ordinal positions were level III childcare workers.

One of the more interesting findings was how both the construction and distribution of person-focused humor symbolically reflected status differentials perceived by team members within tho two groups. Displayed in TABLE IV, the pattern of person-focused humor in the staff conferences of Team $B$ assumed a hierarchical form lwith team members of high status being made the focus less than members of lower status). This generaliy substantiated the hypothesis presented earliar:

Hypothesis II: The frequency with which a member of the group is the target of person-focused humor will be an inverse function of his/her status within formal 
or frontstage settings.

The hypothesis seemed to be substantiated only where superordinates were seen to have functional authority $\{i . e .$, were seen as legltimate because of both their technical competence and human relation skills). The nanparametric correlation between status and person-focused humor received for Team B was-.71. It might thus be suggested that at the symbolic level, where the suparardinates held functional legitimacy, the group evidenced a discernable group structure. For Team A, however, where the top office-holder was perceived as functionally illegitimate, the exchange of humorous remarks seem to symbolize the lack of a definite status structure which might otherwise be expected to accompany organizational roles.

Not only did the perceived legitimacy/illegitimacy of top office-holders accompany differences in the number of times the program manager was the focus of other's humorous remarks, it also appeared to be directly related to the types of humor constructed. In the two occasions where the program manager of Team $B$ (legitimate) was the focus, the humorous exchange was actually initiated by the manager. The exchanges generally followed the format recorded during one such eplsode in a staff conference:

$$
\begin{aligned}
& \text { Supervisor: (Attempts to explain the need for } \\
& \text { workersexplaining to children the } \\
& \text { cauge-effect nature of negative } \\
& \text { behavior: 1.e., how it reduces }
\end{aligned}
$$




\begin{abstract}
their opportunities to have fun within a "token economy."

Supervisor has trouble explaining--is stumbling over words--finally gets through).

Supervisor: (Looks around) Did I do okay?

(Group laughs heartily).

Sally: I'd give it a "C+".

Fred: I think we got it...

Two other types of humor las indicated earlier in Figure 3), mimicry and private communications, were also observed within staff conferences. These communications represent forms of "coded" humor used by participants in safe-guarding the content of the communication from the scrutiny-- and potential sanctioning-- of superordinates.
\end{abstract}

TABLE $V$

CODED HUMOR WITHIN STAFF CONFERENCES

Form
Private
Communications:
Mimicry:
Total:

Although the major form of person-focused humor in both groups tended to be open communications, a number of private communications were observed within the conferences of both 
teams. The method employed to find out what the participants were talking about-- or secretly laughing about las relevant to this study)-- was to seek them out after the conference and inquire. While often times the particlpants would not disclose the precise content of the communication, they would, at least, ldentify the focus of the humor and the general remarks made.

Private communications were observed in both staff conferences. The communications where humor was shared, differed significantly in content. All of the communications represent dyadic, and sometimes triadic Interaction, and were either spoken so softly as to be barely audible, or were transacted in the form of note-passing. of the private humorous communications observed in the staff conferences of Team B, three were concerned with the in-conference performance of other staff members and the other two were a form of humorous play communicated through notes. One of the notes retrieved included the following (nonsensical) mesagges within a triad during the conference.

Bz: When are your vialin classes?

aj: Can [ ] have a cookie?

Bz: Definitely NO!

Be: Who named you Yoda?

Bz: The head wasshole. [sic] 
such humorous interaction represented, if only briefly, a "time out" from the usual routine of the conference. Within Team A all of the private (humorous) communications focused on superordinates in the group: these remarks generally ridiculed the functional performances of superordinates within their occupational roles ( 3 of the remarks ridiculed the supervisor while 3 ramarks ridiculed a level IV childcare workerl.

Another form of "coded humorit within the confarence was ninicry. William Willeford, analyzing the historical significance of jesters and fools within the King's court discussed the use of mimicry as an early form of humor:

Things were no longer what they seemed. The bauble, an object suddenly alive and human could satirize a third person, even the king with the fool defending him while the bauble persuasively argued that he was a fool. The fool could also address the bauble as though it were a person and treat it with respect even though the reduction of that person to a bauble had already made a fool of him (1969:34).

The use of mimicry as a form of humor within staff conferences, though seldam used, likewise mocked superordinates. Members of Team B utilized mimicry upon several occasions to mock the intonation and speech impediments of several of the clients. Team A, however, used mimicry to humorously--and nonverbally--characterize other team members (specifically, the ones whom they saw as being 
functionally illegitimate). Of the five silent renditions observed with the staff conferences of Team A, three mocked the actions of the supervisor. The proceedings of these occasions usually followed the format presented below (transcribed verbatim from field notes):

(R)'s notes: end of meeting; Bz mimics supervisor as both head towards the door, with Bz following. Supervisor speaking with family worker while Bz lip-sinks the conversation with exaggerated facial geatures; moving eye-brows up and down. Other on-line staff laughing. Supervisor miffed; looks to gee what the laughing is about. No idea. Walks out of [conference] room.

While such humorous performances in the front region were shielded from informal sanctioning by use of a specific form of presentation (specifically a clandestine one), humorous presentations in the back region were not. Back regions were thus represented by differences in physical locale, as well as differences in the normative expectations governing prasentationg of self. What was silently acted out in the staff conference became open for humorous critique on-line and sardonic at the "revival meetings."

A careful survey of the data reveals that variations in forms of humor within both of the treatment teams demonstrate of the conceptual framework offered earlier (sea Figure 3 ). These patterns, while illustrating the framework in terms of their frequency of occurrence, also typify the general 
definition of managerial relations between superordinates and subordinates as offered by the participants. The types of humor provided by participants along these lines, as well as more general ethnographic data of humor and group life, are examined in the following section.

\section{Backstage Humor}

The units, while representing a locale shielded from the observations of visitors who frequently tourad tha agency, were not completely protected from "territorial invasion;" that is, from the intrusion of outsiders (Cavan 1966). The occasional unannounced visits of case workers, other agency superordinates, or the supervisor, instantaneously required that the region be socially transformed into a frontstage, and necessitated the construction of a personal front congruent with the demands of the new performance. Such social transformations were demonstrated in the event where outsiders had walked onto the unit unannounced during a "physical restraint." The episodes, usually bellicose, typically consisted of workers attempting to physically control an assaultive and verbally abusive child. One such episode occurred directly outside of the the conference room door during one staff meeting, with the child yelling very loudly:

Leave me alone God damn it! Fucker, let go of 
my legs!

While such the episodes are a routine part of treatment work, they also represent situations which threaten the observer's sense that everything is under control and "normal." The occurrence of physical restraints in a unit which the outsider had just entared demanded that the performances sustain a non-thraatening definition of the situation-- specifically that "nothing unusual is happening" (Emerson 1970:2ø2-221). One of the ways in which workers foster this definition was exemplified in the statement of one worker, who said:

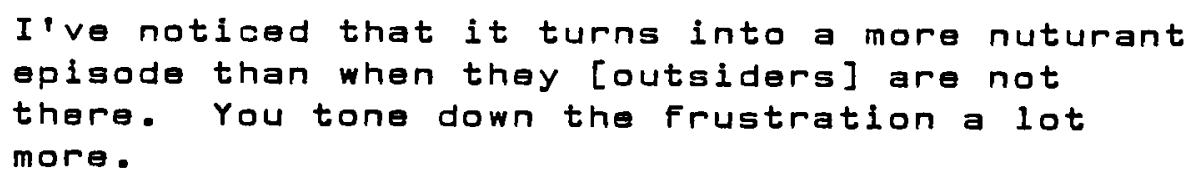

This is to point out that while work on the unit represented a back region for adult conversations (relativa to the staff conferencel it too could be quickly transformed into a frontstage when the presence of significant superordinates so demanded.

Compared to the total number of humorous remarks and joking that were present in the staff conferences, joking in the back region (on-line work) was considerably less frequent (see TABLe VI). 
TABLE VI

BACKSTAGE HUMOR DISTRIBUTION (On-Lina)

\begin{tabular}{|c|c|c|c|c|c|c|c|c|}
\hline & & Team & A & & & Team & & \\
\hline--- & & Freq. & Pior & & -- & $\begin{array}{l}\text { Freq. } \\
\text { l by }\end{array}$ & $\begin{array}{l}\text { Pot } \\
\text { gior }\end{array}$ & ---0 \\
\hline Focus & $F r$ & tstage & Ba & stage & Fror & tstage & Ba & kstage \\
\hline---------- & -- & ---- & -- & 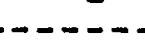 & - & 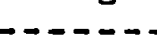 & - & \\
\hline $\begin{array}{l}\text { Clientele } \\
\text { other Pro- }\end{array}$ & 41 & $39.8 \%$ & 5 & $8 \%$ & 232 & $74.4 \%$ & 18 & $32.7 \%$ \\
\hline fessionals & 5 & 4.8 & $\emptyset$ & $\emptyset$ & 22 & 7.1 & 8 & 14.5 \\
\hline other staff & 43 & 41.8 & 53 & 84 & 46 & 14.8 & 21 & 38.2 \\
\hline Toward Self & 14 & 13.6 & 5 & 8 & $1 \varnothing$ & 3.2 & 8 & 14.5 \\
\hline rotal: & & $\emptyset \emptyset \%)$ & 63 & & & $99.9 \%$ & 55 & $(99.9)$ \\
\hline
\end{tabular}

The primary reason for this reduced humorous interaction in the back region was that the task-demands of on-line work often did not afford staff enough time to joke. Almost all of the time spent on-line involved dealing with the clientele. This meant that team members actively structured the shift by programming activities for the children as well as dealing with a wide range of issues and problems. Second, when not directly dealing with the children, workers had numerous other responsibilities which they needed to perform. These included such tasks as making phone calls to case workers and parents as well as dealing with other professionals from the children's schools, otc. Third, the time spent on break, or after the children had gone to bed, was usually dedicated to writing reports about specific behavioral problems of the different children during that 
shift. The breaks then, while providing a respite for workerg from confrontations and other problematic interactions with the clients, represented work-dutios of a different kind. It was generally during these breaks, howaver, that most of the on-line data were gathered. (In an attempt to systamatize observation of humor on-line, observation times were scheduled for equal amounts of time during both the morning and evening shifts-- these time blocks were intantionally scheduled in such a way so as to include the usual work-breaks.) The breaks varied in length and number depending upon which shift one was working. The morning shift generally afforded team members more time to complete all of the peripheral duties while the children were in school. The p.m. shift was spent almost entirely with the children and seemed to contain the largest volume of interaction between staff and clients. The differences in the volume of interaction between the two shifts generally fits the description of daily routings within a psychiatric hospital prosented by cummings and Perruci (1966), except that school, as opposed to work, was the central activity of the clients during the day.

Also evident in the data is the significant difference between the percentage of remarks made about the clientele in the staff conferences and thase made on-line. This suggests a pragmatic intent: jokes about the clientele offered as humor in the staff conference would be something other than 
humor if communicated directly to the clientele. That is, the clients would have been befuddled or provoked by the remarks, but not necessarily amused.

An interesting though not uncommon sharing of humor between staff members eventuated from the jokes told to staff by the children; this appeared as a "subcultural borrowing" of sorts. While joke-sharing between staff and children was a common occurrence, the original content seemed to be framed with an adult-specific meaning when staff told the jokes among themselvas. This was evidenced by the fact that members who had already heard the jokes from the children, generally seemed more amused when jokes were retold within the context of adult-adult interaction than adult-child interaction. Notably, some of the jokes seemed to escape any commonsensical interpretation at all (they could be appreciated, however, because they were understood to be absurd). One of the more popular riddles circulated is presented below:

Q: Why did the chicken cross the road?

A: To get to the other side.

Q: Why did the punk-rocker cross the road?

A: Because he had a chicken stapled to his earlobe.

Another routine form of play, among members of one team in particular, was the sharing of comics, caricatures and humorous stories of both the job and the institutional order 
of the organization. One cartoon shared by a team member pictorially displayed a mouse whose head was pinned down in a mousetrap, being sexually exploited by a perpetrator whose accomplices were waiting in line (to take advantage of the first mouse's misfortune). The caption read, "When you're down and out, everyone wants to scraw you."

As previously mentioned, a frequent form of entertainment was the distribution of humorous 1 iterature which critiqued the profession and the organization. One such piece of literature was acquired during observation while on-line:

\section{To Al1 shifts:}

In order to assure that we perform at the highest level possible, it is our policy to keep all employees well trained through our Special High Intensity Training program (S.H.I.T.). We are giving our employees much more S.H.I.T. than any other organization in the country.

If you feel that you do not receive your share of S.H.I.T. on the job, please see your supervisor. You will be placed on the top of the S.H.I.T. list for special attention.

All of our lead workers and unit supervisors are particularly qualified to see that your get all the S.H.I.T. you can handle at your own speed.

If you consider yourself to be trained enough already, you may be interested in helping us to train others. We can add you to our Basic Understanding Lectura List Special High Intensity Training, (B.U.L.L.S.H.I.T.) program. If you have any further questions, please address them to our Head of Training Special High Intensity Training (H.O.T.S.H.I.T.) 
program, at the main office.

Thank you

lother comic literature, which humorously portrays a problem common to childcare work, was circulated among one of the treatment teams and is presented in appendix B.J

While jokes and riddles were shared between staff on-Iine, so were humorous remarks about other team members. That is, person-focused humor still remained one of the dominant forms of humor (see TABLE VII).

The distribution of person-focused humor seemed to only partially conform to Hypothesis III:

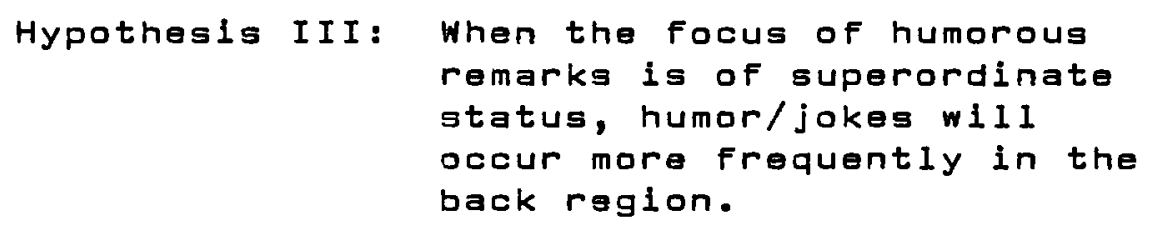

While remarks made about the program managers generally seemed greater in frequency in the back region, such findings are rather misleading if close attention is not payed to the distribution between teams. Specifically, while the frequency of remarks about the program manager of Team $B$ did not seem to vary significantly between regiong, the frequency of remarks about the program manager of Team A lseen as functionally illegtimate) did. Humor directed at other high status staff members (e.g., family therapists), however, was 
greater in frequency during the staff conference than during on-line work.

TABLE VII

PERSON-FOCUSED HUMOR: ON-LINE

Team A

Team $\mathrm{B}$

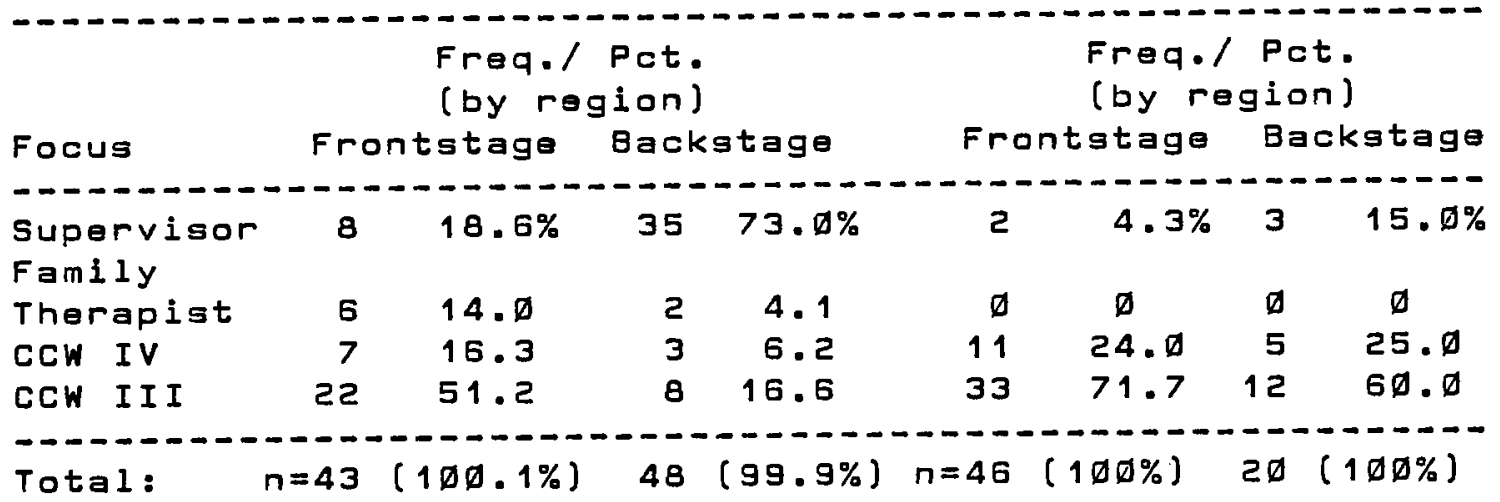

Most of the humorous remarks tenderad about other on-line staff members and/or family therapists, ratained a "hail-follow met-well" quality to them, exhibiting different degrees of camaraderie. Jokes directed at superordinates and the agency, however, were of a qualitatively different nature. Such humor tended to be for the sole purpose of ridiculing the focus of the remark. The only humor of which superordinates of Team $B$ were the focus consisted of remarks made about the program manager and, upon occasion lat the pub), one of the level IV childcare workers. Humaraus ridicule directed at the program manager of Team 8 was observed only once, and occurred in ths back ragion. The remarks appeared to be directed at a situation where the 
manager had walked on to the unit and had given a child information which countermanded the present directions given by the on-line workers. As one worker gtated, "I could have just wrung [supervisor's] neck." several other comments guggested that workers could help gcreen the manager from subsequent poor decisions by "not letting her on the unit." (These comments were observed during the earliar weeks of the research: no such comments about the supgrvisor of Team $B$ were observed thereafter.) Humorous remarks directed at a lead childcare worker concerned the amount of unauthorized time the worker spent off the unit leaving other team members feeling somewhat isolated. As Peabody (1962) suggested, it is both elements of personal competence and human relation skills which lead to one's functional authorlty among other group members. Both elements were deemed to be waning during the situations in which both the manager and the lead childcare worker were humorously critiqued. While humorous ridicule focused on the gituational illegitimacy of superordinates in Team B, humorous ridicule within Team A seemed to be directed towards superordinates defined as "routinely illegitimate." That is, lack of personal competence and skills in human relations was perceived as routinized in the performance of these superordinates. This perceived lack of functional legitimacy was evidenced in several convergations observed during a break from on one of the staff conferences (the joking between team members during 
ane of these is presented below):

(R): It sounds like there's a lot of change going on...

Bj: "Der Fuehrer" has already changed things.

Bz: Yeah, he's like a baboon sent in to organize everything.

(R): Is this a typical staff meeting today?

Bz: Not quite, they're usually more like a war.

Bk: Well, back to hell...

(Team members begin walking back to the conference room

Bj: Have you ever noticed some of his raal

inapropriate type of jokes?

Bk: Some of them are real sick!

Bj: Especially the one's about the farm animals.

The definition of the personal competence of the program manager of Team A (that of a "baboon") and the type of managarial ralations held with subordinatga (authoritarian--"Der Fuehrer") was evidenced in several other communications. In general, humorous ridicule within the back region of on-line work-- where the program manager was the focus-- was greater in frequency than in the front region [sea table VIII.) 
TABLE VIII

HUMOROUS RIDICULE: DISTRIBUTION BY REGION

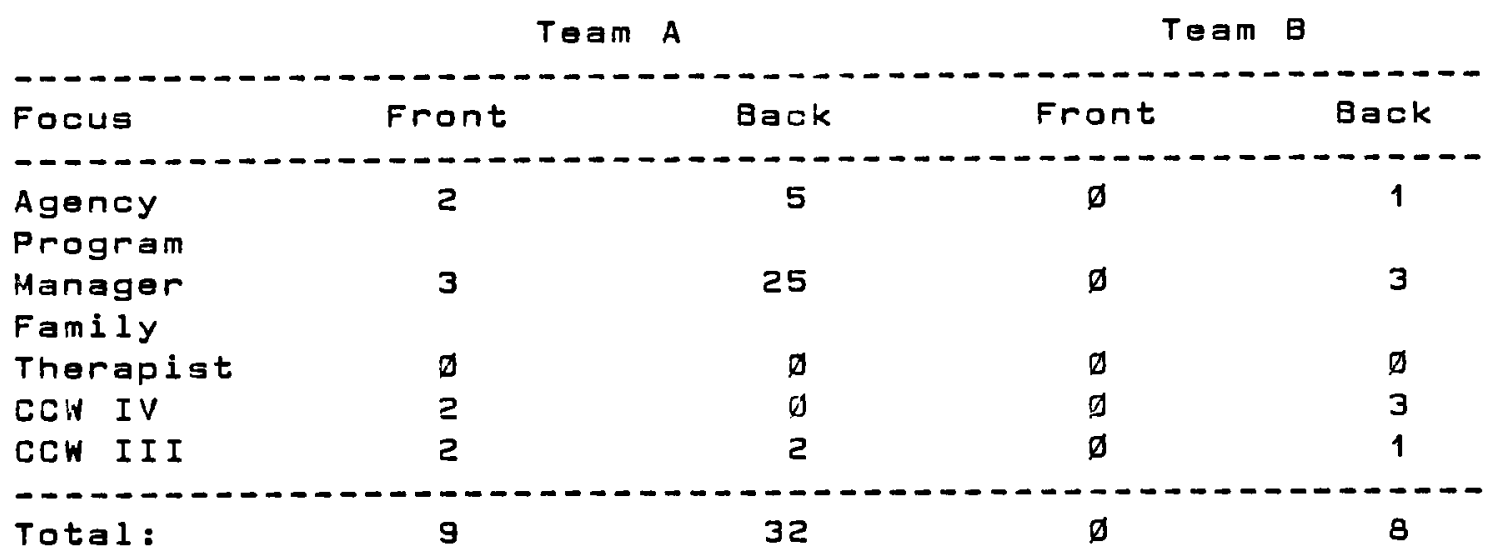

While humorous caricatures were symbolically constructed within the back region of on-line work, invectives and profanations as a form of humor typically emergad in the "greenroom" setting of the local pub li.e., during the "revival meetings"). Such communications, though present in on-line work, were less frequent and guarded from the perception of the clisnts; whose presence las previously mentioned) demanded that team members give a frontstage parfarmance of a different sort. The presence of profanation, sarcasm and ridicule are represented as forms of backstage humor by their distribution on-line, at the pub and, by their virtual disappearance in the front region of the staff conference. The pattern of this distribution displays the conceptual framework of parson-focused humor presented earlier in this study (figure 3 ), and is also in 
conformity with Hypothesis I offered earlier.

One of the Initial expectations not supported by the findings is that person-focused humor would retain a hierarchial pattern even in the back region. That is, it was thought that the functional legitimacy of superordinates might have some kind of lasting or "residual" effects upon subordinatas even in the absence of the formar. Once removed from the purview of other functionaries witinin tha staff conference, however, hierarchial patterns of person-focused humor became amorphous (the nonparametric correlation betwen person-focused humor in the back region and status, was. $\oslash 2$ for Team A and. 22 for Toam B). The findings indicated, moreover, that a frequent focus of backstage humor was, in fact, the program manager. For Team $A, 73 \%$ of the humorous remarks made "backstage" were directed at the program manager, while only $15 \%$ of the jokes within Team 8 did so.

\section{"Greeenrooming:" Humor at the Revival Meetings}

The joking and humorous play observed between staff members of the treatment teams within this study assumed a wide variety of forms. One of the indigenous themes among participants of both workgroups was the "revival mesting." While denizens were observed to ask each other, "Are you going to the revival meeting tonight?" the newcomer to such scenes was lod to believe that he was "obviously" witnessing a commitment to a religious service. The revival meating, 
however, reforred to an occasional gathering at a local pub where workerg "revived" themselves and shared in general conversation. The humorous metaphor of the revival meating provided participants "in the know" with a symbolic reference which served two primary functions: (1) it allowed participants to communicate with each other and organize the after-work activity in front of the "olients" (the children--for whom staff members were expected to "role-model"), and (2) staff members wero provided with an occasion to symbolically construct esoteric humor: several of the participants had acquired identities commensurate with this extra-curricular activity. One participant who usually organizad the occassions was refarred to as "the reverend;" upon his absence another worker temporarily assumed the responsibility of "substitute reverend," providing the "parishioners" with the necessary information-- viz., time and name of the meeting place.

Compared to perforinacas given on-line for the audience of children, the "revival meetings" at the pub proved to be a "private retreat" (Cavan 1966) devoid of either clientale or managerial personnel. The revival meetings thus represented not only stapping back stage, but stapping into the "greenroom." While the revival meetings provided license to vent the usual occupational frustrations, they also were times when team members involved themselves in "role distancing." That is, team members "effectively expressed 
pointed separateness between the individual and his [her] role" (Goffman 1375:124). Team members frequently stated how "sorry" they felt for particular children, empatinizing with the powerlessness of the clientale in the face of broader institutional forses. Such timas appagrad to sarve two primary purposes: the occasions allowed team members to taka an attitude towards the clients of "kids will be kids" rather than regarding them as the combatants they previously had dealt with during their shift; and, the occasions permittad workers to cognitively separate themselves from the lass pleasant aspects of their role. Specifically, workers came to redefine themselves more as parental figures than as behavioral technicians.

While humor at the revival meetings assumed a variety of forms, a form comparatively nonaxistant in on-line work and the staff conference was one consisting of profanation and invective. While the use of this locutionary mode would have previously been discrepant with the performance of "professionalism" carried off in the staff conferance (or on-linel, the formality of conferance talk would have likewise been discrepant with the purpose of the revival meeting. Indeed, the use of conference formality would itself have seemed profane given the social context of the pub. As Edmund Leach suggested, "It is always the situation rather than the lexicon which decides whather or not any particular expression is or is not a profanity and the 
gravity of that profanity" (Leach 1980:219).

The focus of profane humor at the pub tended to be both staff and clientele as well as other administrative officials. The selection of targets for the profanation, however, was not arbitrary; rather, the selection of particular targets was deemed a matter of "retalitory equity" (Zillman and Bryant 1974). That is, the target or focus was implicitly defined as a person deserving of the remark. Thus, the locutionary mode used to tell humorous stories of problematic children usually entailed the use of the defamatory pronouns such as "little fucker," or "little shit," while reference to superordinates usually entailed more sophistication. This sophistication was best exemplified in one observation where a lead worker (whose own functional authority was seen as waning because of both the sexist jokes he told and his untimely disappearances during on-line workJ was the central focus during one joke-teling session at the pub. One joke that the lead worker had initially communicated to otherg was used as a "set up" for his own eventual profanation:

$P z$ : Have you heard $X^{i} s$ joke?

$P \mathbf{j}$ : what joke?

Pz: You know...the duct tape...

$P$ j. W-h-a-t?

(Group chuckling)

Pz: Why do you wrap duct tape around guinea 


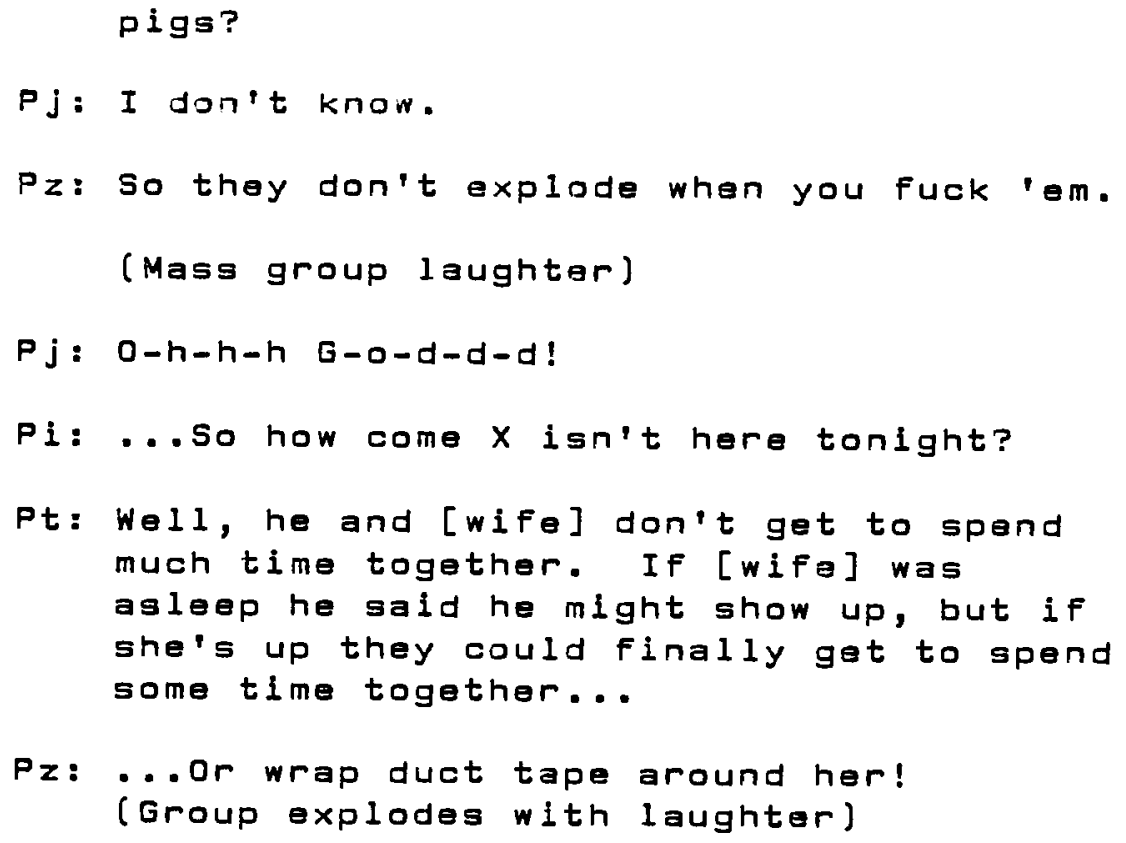

Such profanation "has the weak general sense of the vulgar language of abuse, but there is also a strong sense where it equates with blasphemy" (Leach 1980:214). While the inclusion of a specific focus (person) in the joke-telling was not always the original intent for telling them, neither was the joke-telling a ritualized event in the revival meeting. In contrast to the ritualized profanation represented in, for example, "playing the dozeng" (Abrahams 1962), humorous profanation at the pub tended to be an impromtu activity. The activity, however, was not the dominant form of humor at the pub; the usual form and focus of humor tended to be the exchange of staries about the cliantele.

The exchange of stories about the clientele (both present and past) was, in part, a perpetuation of tho 
organizational folklore of the agency. In a paper on "Occupational Justifications for Alcoholism," Jones stated:

Entering, and prasticing an occupation is more than a process of learning and executing the technical demands of the work involved in that occupation. Occupations contain within the collective definition a body of folklore, or beliefs about the practitioners of that occupation (198ø:3).

The telling of humorous stories of clients and staff was thus part of an ongoing socialization process about "what it is to be a childcare worker." Although the stories were a part of the discussion and humor accompanying general banter at the revival meetings, childcare workers alone were not responsible for the disseminating the knowledge. other personnel such as agency receptionists, though not in attendance at the pub, were adept at passing along agency folklore. One story, which enjayed repeated telling by receptionists and over-night staff was told to the researcher several times:

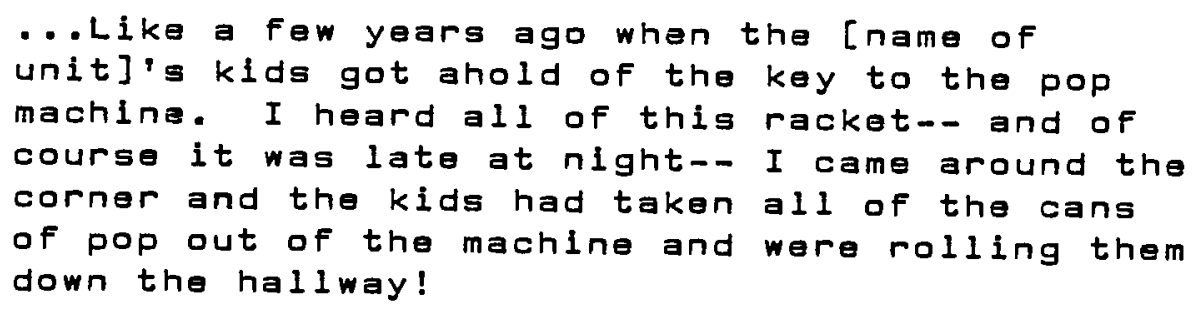

Workers from each of the treatment team likewise recounted, upon occasion, pranks and feats performed by particular children who had previously been involved in the treatment program. One such story Included a hyperactive 
child who was dashing about the unit. The child had climbed up on a blackboard suspended from the wall as the program manager entered the unit. The program manager, who had specifically come to deliver an address to both staff and children, was greeted by the chlld with "Well Barry, you old son-of-a-bitch." According to the worker telling the story, the childcare staff members present were "caught" between the normative demands to reprimand the child for "inappropriate behavior," and wanting to laugh heartily at the whole situation.

The revival meetings, although representing a forum of discussion for a vast array of diffarant topics of interest, displayed no particular patterns of joking between the participants. Indeed, while the absence of suparordingtes allowed the participants to freely disclose their feelings towards administrative personnel and the agency in general, participants were just as likely to exchange remarks about other childcare workers. The exchanges thus represented a form of "locker room talk" with participants engaging in typical organizational gossip as well as conversations about personal habits and personal interests. 


\section{CONCLUSION}

The initial theoretical questions which guided this research concerned how specific interactional settings within the organization mediated variations in the emergence of certain forms of humor; and how patterns of person-focused humor were influenced by both the status-position and the functional authority (legitimacy) of role-occupants.

One of the interesting findings of this research concerned how participants socially transform tha same setting into either a front region or a back region. In attempting to foster particular definitions of the situation le.g., "we are professionals," or "this is a irevival meeting," not work") participants symbolically constructed different kinds of humor commensurate with the occasion.

As evidenced in the data presented on humar in the front region, interpersonal profanation, invective and opan ridicule as forms of humor were absent in performances given in the front region of the staff conference (i.e., while professional functionaries from outside the group were present). Even when outsiders were not present in the staff conference, humorous ridicule and invective apparad to be reservad for the clientale (lowest status group) only. Humorous remarks which were directed at other group members (in a nondisparaging way) during the staff conference varied between the two treatment teams. For Team B, person-focused 
humor was distributed hierarchically with top status-holders being made the focus (or "butt") generally less than low-status holders. While other research (Lundberg 1969; Traylor 1972) has revealed similar findings, these studies did not indicate the specific social conditions which produced such pattarns. As suggested within this present study, hierarchical patterns of person-focused humor do not simply display the fact that some participants have higher status than others because of the office they hold within the organization. Rather, such patterns of humor arise because of a specific phenomenological eloment: viz., that organizational suparordinates are defined as "functionally legitimate" to different degrees by other group members. That is, person-focused humor as a mode of communication symbolically portrays the role-relationship between office-holders as it is percelved and DEFINED BY THE PARTICIPANTS. While person-focused humor assumed a hierarchical form for Team B, distribution of person-focused humor among members of Team A was devoid of any particular pattern. That is, both the forms and distribution of humor found in the staff conferences of Team A did not adhere to any particular status structure...the implication being that there was no clearly defined status structure given the condition of managerial relations. The shared definition of superordinates as functionally illegitimate (because of deficiencies in human ralation 
skills and technical competence, as perceived by others) produced other kinds of humor in the staff conference. Not only were these same superordinates more frequently the focus of other's humor, but humorous communications which ridiculed the superordinates took a coded form. This is not to suggest that all "coded" humor was far the purpose of ridiculing others: as the qualitative observations of humor in the staff conferences of Team B revealed, such activities also constituted a form of entertainment. The private communications and humorous mimicry within the staff meetings of Team A ware, however, a social commentary mocking superordinate group members (subordinates, of course, could be openly critiqued) in such a way that any sanctions could be avoided.

While "coded humor" (ridiculing superordinates) appeared to escape "official" detection in the front region, and thus maintained the personal fronts of specific perfarmers, open ridicule (in the form of humor) in the back region suggested that the need for these conventions had been dropped. Even the superordinates observed to have considerable functional authority were the target of others' humor within the back region. For top managerial personnel le.g., program managers], becoming the target did not represent an arbitrary pastime of the on-line staff. The episodeg, instead, contained a pragmatic motive-- the ridiculing of the behavior of superordinates who had breached certain normative 
expectations in the role-relationship with subordinates. Where humorous comments were directed at ather team members on-line, the comments usually were good natured and engaged in as a type of leisure activity; although superordinates did not necessarily share the same good fortune. Hidden from the view of an audience of officiaries, it is thus not suprising to find that deference to superordinates, symbolically portrayed by means of humorous exchange patterns in the staff conference, could be temporarily abandoned. By temporarily discarding the earlier social conventions of status present during the conference, participants came to socially construct a different type of role-ralationship: viz, one that appeared to approach status equity. Such humor seemed to serve several functions for the subordinate members. While the humor provided an avenue by which frustrationg could be "vented," it also represented a potential for vindication from the usual type of managerial relations present within the team. That is, by sharing in the humorous ridicule of superordinates, team members cognitively mitigated social boundaries in the role-relationships between managerial and on-line personnel.

\section{Problems and Implications for Future Research}

Besides problems encountered with the data collection (mentioned earlier in chapter IV), several theoretical problems concerning both the relativity of stage settings and 
status dimensions, as they influanced humor, are in need of further explication.

One of the major questions only partly answered in this research was, "What social conditions must exist for settings to be socially transformed from back regions to front ragions and vice versa?" As discovared during the research, cognizance of a particular audience to whom the performar feels some obligation (i.e., whose scrutiny is of some importancel produced front stage performances; this was true for the team when outsiders were present in the staff conference as it was for indlvidual performers working on-ilne when the program manager walked onto the unit. This transformation was accompanied by the appearance and disappearance of certain forms of humor. A theoretical concern worthy of sociological investigation, in the light of such findings, are the kinds of social conditions which would lead to the maintenance of the setting as a back region even when these other outside offlciaries are present. That is, are there particular areas of work defined as "home territory," whera workers may "...strike out propriety claims and create an order of activity indigenous to a particular establishment; to be defended if necessary againgt the invasion of others?" (Cavan 1966:2ø5-2Ø6). Such places as the worker's lunch room, or other like settings, may well be considered a home territory of sorts. Whether the symbolic designation of such space also manifests certain normative 
expectations, which licenses subordinates to enact a back region performance even in the presence of potential scrutiny, ramains to be seen. This is to question, of course, what kinds of counter-norms governing the use of humor, as well as other behaviors, coexist within the daily life of organizations.

In observations made by some of the resaarcher's gtudents about their own jobs lpolice work, secretarial work and others) during the period of this research, the joking which went on at their own place of work seemed generally to resemble the patterns found here. One use of humor in all of these reglons, which is outside of the scope of this study, is how humor may be used in "remedial interchanges;" that is, how humor may be used as a corrective measure in regard to a "virtual offense?" [Goffman 1971:120).

Finally, the major portion of this study has been concerned with how humor used among group members varies in accordance with the perceived legitimacy of superordinates. Perhaps just as interesting a concern is the part which humor plays in sustaining claims of legitimacy--i.e., in warding off counter definitions of reality. 


\section{REFERENCES}

Abrahams, Roger D.

$198 \emptyset$ "Playing the Dozens." Journal of

American Folklore 75:209-220. Rpt. in Alan

Dundes (ed.), Mothar Wit from the Laughing Barrel. New York: Garland Pub..

Apte, Mahader L.

1983 "Humor Research, Methodology, and Theory

in Anthropology." In Paul McGhee and Jeffery $H$.

Goldstein (eds.), Handbook of Humor Research:

Vol. I. New York: Springer-Verlag.

Barron, Milton L.

195ø "A Content Analysis of Intergraup Humor."

American Sociological Reviow 15:88-93.

Bateson, Gregory

1955 "A Theory of Play and Fantasy." Psy-

chiatric Research Reports 2:39-51.

Berger, Arthur Asa

1976 "Anatomy of a Joke." Journal of

Communication 26:113-115.

Berger, Peter L.

1961 The precarious Vision. Garden City,

New York: Doubleday Co..

197ð A Rumor of Angels: Modern Society and the Rediscovery of the Supernatural. Garden City, New York:

Anchor Books.

Berger, Peter $L$. and Thomas Luckmann

1967 The Social Construction of Reality. Garden City,

New York: Doubleday-Anchor Press.

Bergson, Henri

1956 "Laughter." In Wylie Sypher (ed.), Comedy. Garden City, New York: Doubleday-Anchor.

Bogardus, Emory 5 .

1945 "Sociology of the Cartoon." Sociology and Social

Research 3ø:139-144.

Bradney, Pamela

1957 "The Joking Relationship in Industry."

Human Relations 10:179-187.

Brown, Roger and Marguerite Ford

1967 "Address in American English." Journal of Abnormal and Social Paychology 62:375-385.

Burling, Temple, Edith M. Lentz and Robert N. Wilson

1956 The Give and Take in Hospitals. New York: G.P. Putnam's Sons.

Burns, Tom

1953 "Friends, Enemies and Polite Fiction."

American Sociological Review 18:654-662.

Campbel1, Donald $T$.

1956 Leadership and Its Effect Upon the Group. Columbus, Ohio: Ohio State University Press.

Caudill, William

1958 The Psychiatric Hospital as a 5 mall society. 
Cambridge, Mass.: Harvard University Press.

Cavan, Sherry

1966 Liquor License. Chicago: Aldine Pub..

Ceccio, Joseph

1978 Medicine in Literatura. New York: Longmen Ino..

C1 imo, Sugan

1985 "Belly Laughs Can Be Serious Medicine For Stress."

Pp.1ด-11 in The Business Journal Magazine (Fab. 7).

Coser, Lewis

1956 The Functions of Social Conflict. New York:

The Free Press.

Coser, Rose Laub

1959 "Some Social functiong of Laughter: A Study of Humor in a Hospital Setting." Human Relations 12:171-182.

1960 "Laughter Among Colleagues: A Study of the Social

Functions of Humor Among the Staff of a Mental

Hospital." Psychiatry 23:81-95.

Cousins, Norman

1976 "Anatomy of an Illness." The New England Journal

of Medicine 295:1485-1563.

Cummings, Carolyn and Robert Perrucei

1966 "Social Distance and Status Protection in a Psychiatric Hospital." The Sociological Quarterly $7: 423-434$.

Davies, Christio

1982 "Ethnic Jokes, Moral Values and Social Boundaries." British Journal of Sociology 33:383-403.

Davis, Murray $S$.

1979 "Sociology Through Humor." Symbolic Intaraction 2: $210-224$.

Difazio, William

1984 "Hiring Hall Community on the Brooklyn Waterfront." In Vernon Boggs, Gerald Handel and Sylvia F. Fava (eds.), The Apple Sliced: Sociological Studies of New Yark City. South Hadley, Mass.: Bergin and Garvey.

Douglas, Mary

1968 "The Social Control of Cognition: Some Factors in Joke Perception." Man 3:361-376.

Duncan, Hugh Daziel

1953 Language and Literature in Society. Chicago:

University of Chicago Press.

1962 Communication and Social Order. New York: The Bedminster Press.

Durkheim, Emile

1965 The Elementary Forms of the Religious Life. New York: The Free Prass.

Dworkin, Earl S. and Jay S. Efran

1967 "The Angered: Their Susceptability to Varieties of Humor." Journal of Personality and social Psychology $6: 233-236$. 
Emerson, Joan

1970 "Nothing Unusual is Happening." Pp. 2Ø8-222

in Tamotsu Shibutani (ed.), Human Nature and Collective Behavior: Papers in Honor of Herbert Blumer. Englowood Cliffs, N.J.: Prentice Hall.

1975 "Behavior in Private Places: Sustaining Definitions of Reality in Gynecological Examinations." Pp. 329343 in 0 . Brisset, and $C$. Edgley (eds.), Lifo as Theater: A Dramaturgical Sourcebook. Chicago: Aldine Pub..

Fine, Gary Alan

1977 "Humor in Situ: The Role of Humor in 5 mall Group Culture." Pp. 315-318 in Antony J. Chapman and Hugh Foot (eds.), Its a Funny Thing Humour. Oxford: Pergamon Press.

Fleischman, Edwin A.

1953 "The Description of Supervisory Behavior." Journal of Applied Psychology, 37:1-6.

Frankl, Victor

1957 The Dootor and the Soul. Trans. Richard and Clara Winston. New York: Alfred H. Knopf.

Froud, sigmund

1938 The Basic Writings of Sigmund Freud. A.A. Brill (ed.), New York: Random House.

1905 Jokes and Their Relation to the Unconscious. Vienna: Deuticke, 1905.

Garfinkel, Harold

1967 Studies in Ethnomethodology. Englewood Cliffs, N.J.: Prentice-Hall.

Goffman, Erving

1952 "On Cooling the Mark Out: Some Aspects of Adaptation to Failure." Psychiatry: Journal for the Study of Interpersonal Process 15:451-463.

1959 The Presentation of Self in Everyday Life. Garden City, New York: Anchor Books.

1971 Relations in Public: Micro Studies of the Public Order. New York: Basic Books.

1975 "Pole Distance." PP. 122-131 in D. Brisset and C. Edgly (eds.), Lifo as Theater: A Dramaturgical Sourcebook. Chicago: Aldine Pub..

Goodchilds, Jacqueline $D$.

1959 "Effects of Being Witty in the structure of a 5 mall Group." Sociometry 22:251-272.

Goodrich, Anne T., Jules Henry and D. Wells Goodrich

1954 "Laughter in Psychiatric Staff Conferences: A Sociopsychiatric Analysis." American Journal of Orthopaychiatry 24:175-184.

Gogs, Mary E. W.

1959 Physicians in Bureaucracy: A Case-study of Professional Pressures on Organizational Roles. Columbia University: Unpublished PH.D. Dissertation. 
Gouldner, AIvin W.

1954 Patterns of Industrial Bureaucracy. New York:

The Free Press.

Gross, Edward

1970 "Work, Organization and Stress." Pp. 55-98 in

Sol Levine and Norman A. Scotch (eds.), Social Stress. Chicago: Aldine Pub..

Hammond, Peter $B$.

1964 "Mossi Joking." Ethnology 3:26ø-27Ø.

Handelman, Don and Bruce Kapferer

1972 "Forms of Joking Activity: A Comparative Approach." American Anthropologist 74:484-517.

Handelman, Don

1976 "Re-thinking 'Banana Time': Symbolic Integration in a Work Setting." Urban Life 4:433-447.

Hertzlar, Joyce 0 .

197ø Laughter: A Socio-scientific Analysis. New York: Exposition Prass.

Hollowman, Charles R.

1968 "Leadership and Headship: There is a Difference." Personnel Administration 31:38-44.

Homan, Roger

1981 "Crisis in the Definition of Reality." Sociology $15: 21 \emptyset-224$.

Homans, George C.

195ø The Human Group. New York: Hancourt, Brace and Company.

Ice, Jackson Lee

1973 "Notes Toward a Theology of Humor." Religion in Life $42: 388-4 \emptyset \emptyset$.

Jacobson, S. and G.L. Hermann

1966 "Interpersonal Dynamics of Hospitalized Depressed Patients. Home Visits." Journal of Marriage and the Family 28:94-1ø2.

Jones, Joseph F.

198 "Occupational Justifications for Alcoholism." A paper presented at the Pacific Sociological Association Conference (April).

1962 "Differentials in the Conference in Two Types of Organizational Sub-5ystems." Unpublished Masters Thesis, University of Washington.

Kallen, M. Horace

1968 Liberty, Laughter and Tears: Reflections on the Relations of Comedy and Tragedy to Human Freadom. Dekalb: Northern University Press.

Kapferer, Bruce

1969 "Norms and the Manipulation of Relationships in a Work Contaxt." Pp. 182-216 in J. Clyde Mitchall (ed.), Social Networks in Urban Situations. Manchester: University of Manchester press. 
Kaplan, Howard B. and Ina H. Boyd

1965 "The Social Functions of Humor on an Open Psychiatric Ward." The Psychiatric Quarterly 39:5ø5-515.

Kluckhohn, Clyde

1949 Mirror for Man. New York: MeGraw-Hill.

Koestler, Arthur

1949 Insight and outlook: An Inquiry into the Common

Foundations of Science, Art and Social Ethics. New

York: The MacMillan Company.

Laforge, Rolfe and Robert Suczek

1957 "The Interpersonal Adjective Check List." Pp. 455463 in Timothy Leary (ed.), Interpersonal Diagnosis of Personality: A Functional Theory and Methodology For Personality Evaluation. New York: The Ronald Press.

Laach, Edmund

1980 "Profanity in Context." Pp. 214-228 in Jeremy

Cherfas and Roger Lewin (eds.), Not Work Alone: A Cross- Cultural View of Activities Superfluous to Survival. Beverly Hills: Sage Pub..

Leak, Gary K.

1974 "Effects of Hostility Arousal and Aggressive Behavior on Catharsis and Humor Preference." Journal of Personality and social Psychology 30:736-740.

Lundberg, Craig C.

1969 "Person-focused Joking: Pattern and Function." Human Organization 28:22-28.

MacAndraw, Craig and Robert B. Edgerton

1969 Drunken Comportment: A Social Explanation. Chicago: Aldine Pub..

Maluccio, Anthony $N$. and Wilma D. Marlow

1972 "Residential Treatment of Emotionally Disturbed Children." The Social Science Review 46:23ø-25ø.

Martingau, William A.

1967 "A Model for a Theory of the Functions of Humor." Research Reports in Social Science 1:51-64.

McGhee, Paul E.

1979 Humor: Its Origin and Development. San Francisco: W.H. Freeman and Co.

Mechanic, David

1962 "Sources of Powar of Lower Participants in Complex Organizations." Administrative Science Quarterly 7 : $349-364$.

Mindess, Harvey

1971 Laughter and Liboration. L.A.: Nash Pub.. Morreall, John

1983 Taking Laughter Seriously. Albany: Stata University of New Yark.

obrdlik, Antonian J.

1942 "Gallowe Humor-A Sociological Phenomenon." American Journal of Sociology 47:7ø9-716. 
D'Quinn, Karen and Joel Aronoff

1981 "Humor as a Technique of Social Influence." Social Psychology Quarterly 44:349-357.

Palola, Ernest G. and Joseph F. Jones

1965 "Contrasts in Organizational Features and RoleStraing Between Psychiatric and Padiatric Wards." Journal of Health and Human Behavior 6:141-147.

Parsons, Talcott

1961 "An Outline of the social system." In T. Parsons, E. Shils, K.D. Naegele, and J.R. Pittg (eds.), Theories of Society. New York: The Free Press.

Peabody, Robert $L$.

1962 "Perceptiong of Organizational Authority: A Comparative Analysis." Administrative Sclence Quarterly $6: 463-482$.

Perrucci, Robert

1974 Circle of Madness: On Being Insane and Institutionalized in America. Englewood Cliffs, N.J: PrenticeHall.

Pettigraw, Andrew $M$.

1983 "On Studying Organizational Culture." Pp.87-1Dz in John Van Maanen (od.), Qualitative Methodology. Beverly Hills: Sage Pub..

Pfeffer, Jefferey

1981 Power in Organizations. Marshfield, Mass.: Pitman. Prus, Robert

1980 "Sociologist as Hugtler: The Dynamics of Acquiring Information." Pp. 132-144 in William B. Shaffir, Robert A. Stebbing and Allan Turowetz (eds.), Field Experience: Qualitative Approaches to Social

Research. New york: St. Martin's Press.

Radcliffe-Brown, A.R.

1952 Structure and Function in Primitive society.

London: Lowe and Brydone.

Read, Kenneth E

1980 Other Voices: The Style of a Male Homosexual Tavern. Novato, Ca.: Chandler and Sharp.

Richards, Suzanne

1985 "The Laugh Clinic: Saminars on Humor Helpg Make Life a Little Easier." The Oregonian, Morning Ed., Feb. 18, (Sec. C, P. 1).

Ridgeway, Cocilia L., Joseph Berger and Leroy Smith 1985 "Nonverbal Cues and Status: An Expoctation States Approach." American Journal of Sociology $9 \emptyset: 955-978$.

Rossel, Robert D

1981 "Chaos and Control: Attampts to Regulate the Use of Humor in Self-Analytic and Therapy Groups." Small Group Behavior 12:195-219.

Roy, Donald $F$ 1959 "Banana Time: Job Satisfaction and Informal Inter- 
action." Human Organization 18:158-168.

Sapir, Edward

1954 "Conceptual Categorias in Primitive Languages."

Pp. 128-135 in Dell Hymes (ed.), Language in

Culture and Society. New york: Harper and Row.

Scheff, Thomas $J$.

1979 Catharsis in Healing, Ritual and Drama. Berkeley: University of California Press.

Scheler, Max

1958 Philosophical Perspectives. Trans. Oscar A. Haac. Beacon Hill, Boston: Beacon Hill Press.

Schmid, J. Jr., J.E. Morsh and H.M. Detter

1967 "Analysis of Job Satisfaction: A.S. Scale."

Pp. 439-44Ø in Marvin Shaw and Jack M. Wright

[eds.), Scales for the Measurement of Attitudes.

New York: McGraw-Hill.

Schutz, Alfred

1962 Collected Papers Vol. I: The Problem of Social

Reality. Maurice Natanson (ed.). The Hague,

Netherlands: Martinus Nijhoff.

Scogin, Forrest R. Jr. and Howard R. Pollio

1980 "Targeting and the Humorous Episode in Group

Process." Human Relations 33:831-852.

Scott, John R.

1974 "Practical Jokes of the Newfoundland Seal Fishery."

Southern Folklore Quarterly 38:275-283.

Stephengon, Richard

1951 "Conflict and Control Functions of Humor."

American Journal of Sociology 56:569-574.

Stogdill, Ralph M. and Carroll L. Shartle

1955 Methods in the study of Administrative Leadership.

Columbus, Ohia: Ohio State University Press.

Sykes, A.J.M.

1965 "Joking Relationships in an Industrial Satting."

Amarican Anthropologist 68:188-193.

Traylor, Gary

1972 "Joking in a Bush Camp." Human Relations 26:

$479-486$.

Uliian, Joseph Alan

1976 "Joking at Work." Journal of Communication 26 : $129-133$.

Van Order Smith, Natalis and W. Edgar Vinackle

1951 "Reactions to Humorous Stimuli of Diffarent

Generationg of Japanese, Chinese and Caucasians

in Hawail." The Journal of Soclal Psychology 34: 59-96.

Weber, Max

1947 The Theory of Social and Economic Organization.

Trans. A.M. Henderson and Talcott Parsons. New

York: Oxford University Press. 


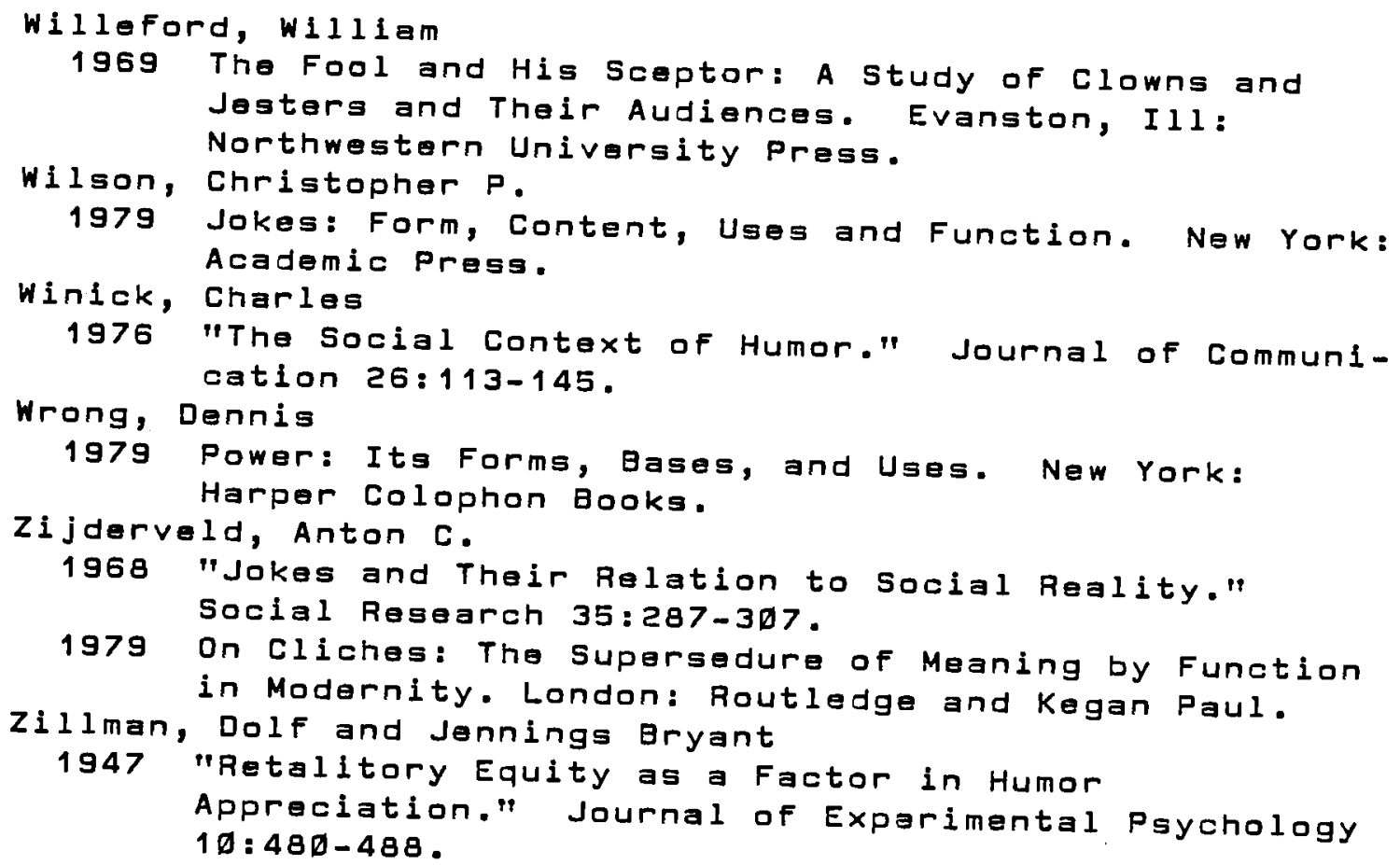


Dne form of "shared sentiment" or collective representation found within this study pertained to the different "units" (children's living quartars) for which both supervisors and staff were responsible. The units had been given names by the children and served as a source of identity for both kids and staff. Names such as "Bears" Unit" or Lions" Unit" were typically employed by staff as referents for both "where" they worked within the agency, and the "kinds" of kids (ar "cases") they dealt with [names have been changed]. The staff, unless they were rotation workers ("rotating" from unit to unit, wherever their halp was needed), were hired anto a particular unit and commonly referred to themselves as "Baars" staff," or "Lions" staff." The name of the unit also served as a collective representation for the children, who frequently engaged in inter-unit games-- this representation was often manipulated by workers in an attempt to increase the solidarity and cooperation between the children of one particular unit. 


\section{APPENDIX B}

\section{IMPORTANT NOTICE}

In keeping with our excellent school health policies, we find it necessary to update our information on an uncomfortable, but seldom fatal condition, that of HEADLICE.

You might suspect an infestation of headlice when:

* a child's hat cames off by itself.

* a child's hair is waving in the breeze, only there is no breeze.

* after running your fingers through a child's hair, you find your inch long fingernails have been bitten off.

* you hear tiny volces singing, "For She's a Jolly Good fellow" coming from the earphone you have just wiped off with alcohol.

* you notice Johnny'g hair, which was parted on the laft is now parting itself on the right or in the middle.

* a child gets his comb out of his pocket by opening the pocket and calling "Here Boy!"

* you notice that Suzle's animal barretts have arranged themselves into a circus parade.

* you pat a child on the head and a tiny voice yells "keep your hands to yourself."

* you notice insect-eating birds frequently on a child's head.

* a child's hair stands on end when he/she passes under a "No Pest Strip."

* an angry buzzing sound is heard when a child's hair is disturbed.

* frogs and toads are frequently seen with their tongues entangled in a child's hair.

* a child shows more than a 5-6 pound weight loss after beling sprayed with insect fogger.

STEPS TO TAKE:

1. Instruct infected students to use the pronoun "we" 
instead of "I".

2. Suggest more appropriata synonyms when a student refers to a teacher as being "crabby."

3. Consult the "Ortho Garden Book" for shampoos available.

4. Do not allow students to become emotianally attached to small pets that they might find an other kid's scalps or shoulders. In particular, discourage the use of pet names such as "spot."

5. UNDER NO CIRCUMSTANCES allow the child to come closer than $2 \emptyset$ feet to an electric bug zapper to prevent child from being sucked in and electracuted. 
APPENDIX C

A notation scheme for recording humorous interaction was adopted from Craig C. Lundberg (1969). The scheme utilizes four main categories previosly defined in chapter 4 . They are: initiator, recipient, focus and audience. The notation scheme is presented below:

1. Small letters indicate persons la.g., in recording exchanges of humorous remarks made about a specific child, where the child's name is irrelevant for tracking future exchanges, we could use the letter "b").

2. Capital letters indicate groups le.g., we could use the letter "B" to denote the group of which child "b" is a part). Different membarg of a group are signifiad by use of the same letter with primes. Three mambers, then, would be designated as b', b'', b'", etc..

3. Arrows, >, indicate who initiated the humorous communication and who is the recipient of the communication. Thus, if c communicated a joke or other humorous remark to $D$, the exchange would be coded $C>0$.

4. Parentheses ( ) enclose the focus or "butt" of the humorous remark. If the focus is not present the focus is 
coded with an underline; e.g. (a).

The audience was coded using small or capital letters which appeared immediately after the parentheses. Before the direction was coded the actual communication was recorded verbatim. The following example is presented as it appeared in the researcher's coding sheet. Note that for the most part the first and last initials of the team members were used-- the use of letters were usually utilized where children were referred so that strict confidentiality would be insured. (Actual initials of person's names have been changed).

\section{CODE SHEET}

Team: A

Setting: On-line

remarks:

Present: $B L, T M, N G$,

(R)esearcher

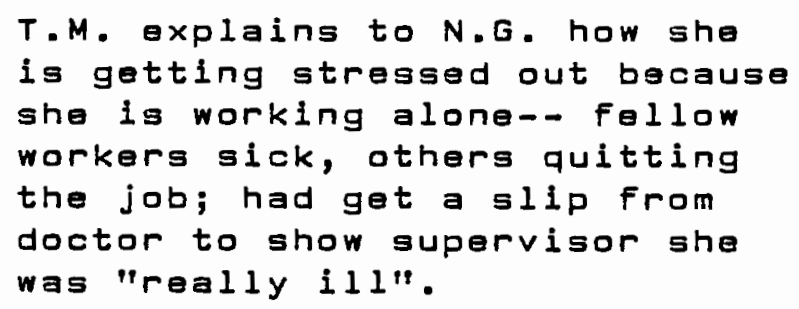

Initiator>Recipient(Focus) Audience

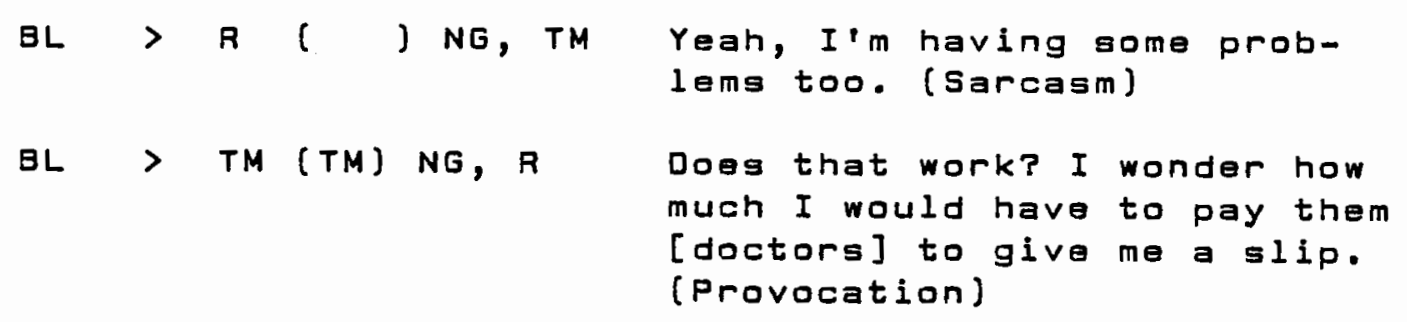




\section{APPENOIX D}

Esteom rankings included group members rating each other using an instrument developed by Laforge and Suzcek. The fifteen item scale constitutes a total score range of 15 to 6ø. The lower the score achleved, the more esteem afforded one by other group members. After respondents were scored they were then ordinally ranked 1 to $n$ ldepending upon the size of the groupl, the person receiving the lowest score (mast esteem) ranked 1, next lowest score ranked 2 , and so on.

After each group member had been ranked, his/her rank was added to the ranking achieved on the other status items to determine their overall occupational status-rank within the group. This status-rank was then correlated with the number of times they were the focus of other's jokes, humorous remarks, atc. (Spearman's rho was used).

The instrument was scored and evaluated in accordance with the method prescribed by Laforge and suczek who claimed that: "An intensity dimension has been built into the check list such that each of the sixteen variables is represented by a four point scale" (1957:455).

One of the variables from the check list was omitted from the survey form: the item seamed to be concerned with personal assertiveness but, as phrased, appeared to also Include issues of "obedience" (see Laforge and suczek P. 456, 
$T M>B L\{B L\} N G, R$

With the kind of problems you've got, you don't need a doctor, you need a psychiatrist!

Notice that in BL's opening remark the focus is unclear: while BL refers to himself, the remark's sarcastic form implicitly suggests that it is actually TM who is being "set up" (mimicked) and thus the true focus. In tha closing communication, TM is the initiator, communicating to BL who is the recipient; $N G$ and $R$ (the researcher) are the audience, Iistaning to the humorous exchange.

In the nonparametric correlation of status with person-focused humor received, the scheme facilitated aasy tabulation of frequency for group members who were the focus. The same format was found to be very useful during staff conferences: a list of all members present during the meeting was recorded, which thus meant that the audience category on the code shert could be amitted. 
item IJ. Previous comments regarding the deficiency of the Interpersonal Adjective Check List seem to be at adds, however, with the claim of validity proffered by its inventors... who state... "During the three year period of revision, the check list has been administered to several thousand subjects in a variety of ways" (1957:458). (The test-retest reliability correlation for the items was.73). The questionaire used in the present study is presented below.

\author{
EVALUATION
}

This questionaire is being used in conjunction with other data collected on the use of humor in work-groups. Participation in responding to this questionairo is totally voluntary. Collection of this information is for the sole purpose of fulfilling a partial requirement towards an advanced degree from the soclology department at portland State University. Collection of this data does not represent any official endorsement, interest or policy-enactment by this agency.

All sources of personal identification are STRICTLY CONFIDENTIAL and are ABSOLUTELY NOT for any type of public use whatsoever. Please do not put your name on this form.

Please fill out the following:

male:

$$
\text { official job title: }
$$

female:

how long with this agency:

Please circle the number of the adjective(s) which you feel best represents/characterizes the individual being rated. circle only the number, not the words. If you have additional comments you wish to make please feel free to use the back side of the questionaire. Thank you in advance for your participation, it is greatly appreciated.

(Please fill out ane evaluation for each member of the group ). 


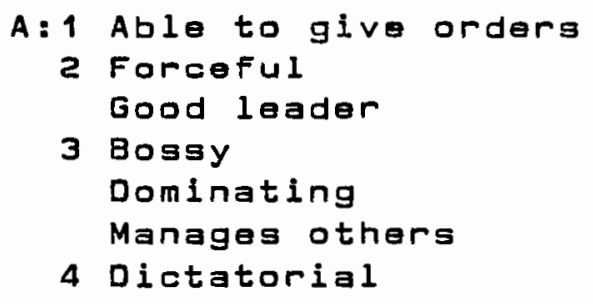

C:1 Able to take care of self

2 Can be indifferent to others Businesslike Likes to compete with others

3 Thinks only of himself Shrewd and calculating Selfish

4 Cold and unferling

E: 1 Can be frank and honest

2 Critical of others Irritable Straightforward and direct

3 outspoken often unfriendly Frequently angry

4 hard-hearted

G:1 Able to doubt others

2 Frequently dissappointed Hard to Imprass Touchy

3 Jealous Slow to forgive a wrong Stubborn

4 Distrusts averybody
B:1 Self-raspecting

2 Independent

Self-confident

Self-reliant and assertive

3 Boastful

Proud and selfsatisfled

Somewhat snobbish

4 Egotistical and conceited

D: 1 Can be strict if necessary

2 Firm but just

Hardbollad when necessary

stern but fair

3 Impatient with others' mistakes

Self-seaking

Sarcastic

4 Cruel and unkind

F: 1 Can complain if necessary

2 Often gloomy

Resents being bossed Skeptical

3 Bittar

Complaining

Resentful

4 Robols against everything

H: 1 Able to criticize self

2 Apologetic

Easily embarrassed

Lacks selfconfidence

3 Self-punishing

Shy

Timid

4 Always ashamed of self 
J: 1 Grateful

2 Admiros and imitates others often helped by others Very respectful to authority

3 Dopendent Wants to be lead Hardly ever talks back 4 Clinging vine

L: 1 Cooperative

2 Eager to get along with others

Always pleasant and agraeable

3 Too easily influanced by friends

Will confide in anyone Wants averyone's love

4 Agrees with everyone

N: 1 Considarate

2 Encourages othars Kind and reassuring

Tender and soft-hearted

3 Forgives anything

Oversympathatic

Too lenient with others

4 Tries to comfort everyone
K:1 Appreciative

2 Very anxious to be approved of

Accepts advice readily

Trusting and eager to please

3 Lets others make decisions

Easily fooled

Likes to be taken care of

4 Will beliave anyone

M: 1 Friendly

2 Affectionate and understanding

sociable and neighborIy

Warm

3 Fond of everyone

Likes everybody

Friendly all the time

4 Loves everyone

$0: 1$ Helpful

2 Big-hearted and unsalfish

Enjoys taking care of others

Gives freely of self

3 Generous to a fault Dvarprotective of others

Too willing to give to others

4 spoils people with kindness

$P: 1$ Well thought of

2 Makes a good impression

often admired

Respected by others

3 Always giving advice

Acts important

Tries to be successful

4 Expects everyone to admire him 
The Supervisory Evaluation Questionaire was constructed using items from four different scales. Items $1,2,8$, and 14 on the survey were adopted from a scale by 5 togdill and Shartle (1955), while items 3 and 11 were taken from a scale by Schmid, Morsh And Detter (1967). Of the remaining items, $4,5,6,7,9,10,18$, and 25 ware from Flaischman's (1953) study, while items $12,13,15,17$, and 21 were taken from Campbeli's scale (1956). Items 16, 19,20 and 23 were constructed independently. While many of these items appeared on all of the scales, the wording was slightly different on some-- the items used here were the ones considered most clearly worded.

The measures of reliability reported for the respective scales from which the items were extracted were:

Schmid, Morsh and Detter; as measured by the Kuder-Richardson formula $2 \emptyset=.9 \emptyset$.

Stogdill and Shartle; correlation between two independent groups $=.46$. Their conclusion was that "the raters were not in close agreament in their perception of the effectiveness of the subjects being rated" (1955:65).

Campbell; no levela of reliability reported. Fleischman; intercorrelations .71 to .88 for repeated tests.

The reader should be aware that these reported levels of reliability represent the total scale of which the items were a part. These measures do not represent levels of reliability for the independent items as used in the 
Supervisory Evaluation Questionnaira. The utility of the survey, howevar, is in representing the differences, itam for Item, of the perception of managerial personnel between groups.

The actual coding of the survey utilized a Likert format with items 1 through 25 coded on a five point scale (presented in Appendix F). A factor analysis of the items did not reveal a clear factor structure; rather, all of the items appeared to load rather high on three different factors which, far all practical purposes, were indiscernible except for one. Item 21, "s/he engages in friendly jokes and comments during group meetings," had a loading of .91 an Factar III while the rest of the items had a correlation of less than. 50 (still a moderate correlation).

\section{SUPERVISORY EVALUATION QUESTIONAIRE}

This questionalre is being used in conjunction with other data collected on the use of humor in work-groups. Participantion in responding to this questionaire is totaliy voluntary. Collection of this information is for the sole purpose of fulfilling partial credit towards an advanced degree in sociology from Portland State University. Callection of this data does not represent any official endorsement, interest or policy-enactment by this agency.

All sources of personal identification are strictly confidential and are absolutaly not for any type of public use whatsoever. Please DO NOT put your name on this form.

Please fill out the following:

male: official job title:

female: how long with this agency:

\section{DIRECTIONS:}

Note: The term, "group," as emplayed in the following itams, 
refers to a department, division or other unit of organization which is supervised by the person being described. The term "members," refers to all parsonnal in the unit of organization which is supervised by the person being described.

1. READ each item carefuliy.

2. THINK about how frequently the leader engages in the behavior described by the item.

3. READ the five answers provided after the itam and decide which of the five most nearly expresses the frequency with which the leader engages in the behavior.

4. CIRCLE the letter of the answer you have selected.

II.

1. The supervisor of this unit encourages members to work as a team.

A.always B.often C.occasionally D.seldom E.never

2. The supervisor of this unit makes it pleasant to be a member of the group.
A. always
B.often
C.occasionally
D.seldom
E. never

3. The supervisor of this group is a person I like to have conversation with.
A. always
B.often
C. occasionally
D.seldom E.never

4. S/He is friendly and can be easily approached.
A. always
B. often
c.occasionaliy
D.seldom
E.never

5. S/He tries to promote high morale among those under him/her.

A.always B.often C.occasionally D.seldom E.never

6. S/He treats all his/her workers as equals.
A.always B.often
C. occasionally
D. seldom
E.never

7. $5 /$ He insists that averything be done his/her way.
A. always
$B$. often
C.occasionally
D.seldom
E.never

8. S/He establishes cordial relations with subordinates. A.always B.often C.occasionally D.geldom E.never

9. S/He treats people under him/her without considering their feolings.
A.always
B. oftan
C.occasionally
D.seldam
E.never

10. S/He sees that workers are rewarded for a job well done.
A. always
B.oftan
C. occasionally
D.seldam
E.never 
11. S/He ignores the opinions of those who disagrea with him/her.
A.always
B.often
C.occasionally
D. seldom
E. never

12. S/He oriticlzes a specific act rather than a particular individual.
A.always
B.often
C.occasionaliy
D. seldom
E.never

13. S/He changes the duties of members without first talking it over with them.
A.always
B.often
c.occasionally
D. seldom
E. never

14 S/He looks out for the personal welfare of individual members.
A.always
B. often
C.occasionally
D.seldom E.never

15. S/He expressas appraciation when a worker doas a good job.
A. al ways
B.often
C.occasionally
Q.seldom E.never

16. S/He promotes communication by helping to problemsolve conflicts between workers.
A. oftan
C. occasionally
B.fairly often
D.once in awhile
E. very seldom

17. S/He acts without consulting the group.
A. often
C.occasionally
B.fairly often
D.once in awhila
E.very seldom

18. S/He offers new approaches to problems.
A. oftan
C. occasionally
B. fairly often
D.once in awhile
E. very seldom

19. S/He makes himself/herself avaliable to help workers with personal problems.
A. often
C.occasionally
B.fairly often
D.once in awhile
E.very seldom

20. S/He displays a good working knowledge of this program.
A. often
B. fairly often

C.occasionally

D.once in awhile

E.very seldom

21. S/He engages in friendly jokes and comments during group meetings.
A.often
B.fairly often
C. occasionally
D.once in awhile
E.very seldom 
22. S/He is able to utilize past experiance in the field.
A. often
C.occasionally
B.falrly often
D. once in awhile
E.very seldom

23. S/He displays a good working knowledge of the field.
A. oftan
C. occasionally
B.falrly often
0.once in awhile
E.very seldom

24. S/He makes helpful suggestions about wark problems.
A. often
C. occasionally
B.fairly often
D.once in awhile
E.very seldom

25. S/He rules with an iran hand.
A.always
B. often
C. occasionally
D.seldam
E. never

Please feel free to use the back side of the page for any comments you might have. 


\section{STURENT'S T-TEST ON SUPERVISORY}

EVALUATION QUESTIONNAIRE

\begin{tabular}{|c|c|c|c|c|c|}
\hline & NO. OF & & STANDARD & $T$ & DEGREES \\
\hline TEM & CASES & MEAN & DEVIATION & VALUE & OF FREEDOM \\
\hline
\end{tabular}

1. The supervisor of this unit encourages members to work as a team.

5 always 4 often 3 occasionally 2 seldom 1 never

$\begin{array}{lllllll}\text { Team } & A & 5 & 3.33 & .516 & -2.48 & 9 \\ \text { Team } & B & 5 & 4.40 & .894 & \end{array}$

2. The supervisor of this unit makes it pleasant to be a member of the graup.

5 always 4 often 3 occasionally 2 seldom 1 never

$\begin{array}{llllll}\text { Team A } & 6 & 2 . \emptyset \emptyset & .894 & -5.21 & 9 \\ \text { Team B } & 5 & 4.40 & .548 & \end{array}$

3. The supervisor of this group is a person I like to have conversation with.

5 always 4 often 3 occasionally 2 seldom 1 never

$\begin{array}{rrrrrr}\text { Team } A & 6 & 1.66 & 1.033 & -5.30 & 9 \\ \text { Team B } & 5 & 4.40 & .548 & \end{array}$

4. S/He is friendly and can be easily approached. 5 always 4 often 3 occasionaliy 2 seldam 1 never

$\begin{array}{lllllll}\text { Team } & A & 6 & 2.33 & .816 & -5.27 & 9 \\ \text { Team } B & 5 & 4.60 & .548 & \end{array}$




\begin{tabular}{lllll} 
& NO. OF & STANDARD & $T$ & DEGREES \\
ITEM & CASES & MEAN & DEVIATION & VALUE \\
\hline
\end{tabular}

5. S/He tries to promote high morale among those under him/her.

5 always 4 often 3 occasionally 2 seldom 1 never

$\begin{array}{lllllll}\text { Team } & A & 6 & 2.16 & .408 & -7.76 & 9 \\ \text { Team B } & 5 & 4.40 & .548 & \end{array}$

6. S/He treats all his/her workers as equals.

5 always 4 often 3 occasionally 2 seldom 1 never

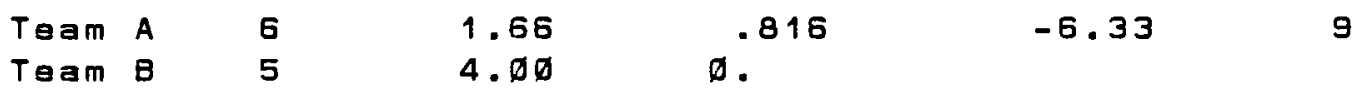

7. S/He insists that everything be done his/her way. 1 always 2 often 3 occasianally 4 seldom 5 never

$\begin{array}{rrrrrr}\text { Team A } & 5 & 2.00 & 1.095 & -2.58 & 9 \\ \text { Team B } & 5 & 3.40 & .548 & \end{array}$

8. S/He establishes cordial relations with subordinates. 5 always 4 often 3 occasionally 2 seldom 1 never

$\begin{array}{lllllll}\text { Team A } & 6 & 2.16 & .753 & -5.22 & 8 \\ \text { Team B } & 4 & 4.5 \emptyset & .577 & \end{array}$

9. S/He treats people under him/her without considering their feelings.

1 always 2 often 3 occagionally 4 seldom 5 never

$\begin{array}{lllllll}\text { Team } & A & 6 & 2.5 \emptyset & .548 & -5.73 & 9 \\ \text { Team B } & 5 & 4.4 \emptyset & .548 & \end{array}$


NO. OF

CASES

STANDARD

$T$

DEGREES

I TEM

MEAN

DEVIATION

VALUE OF FREEDOM

10. S/He sees that workers are rewarded for a job well done.

5 always 4 often 3 occasionally 2 seldom 1 never

$\begin{array}{llllll}\text { Team } A & 6 & 2.66 & 1 . \emptyset 33 & -2.86 & 9 \\ \text { Team } B & 5 & 4.0 \emptyset & \emptyset . & & \end{array}$

11. S/He ignores the opinions of those who disagree with him/her.

1 always 2 often 3 occasionally 4 seldom 5 never

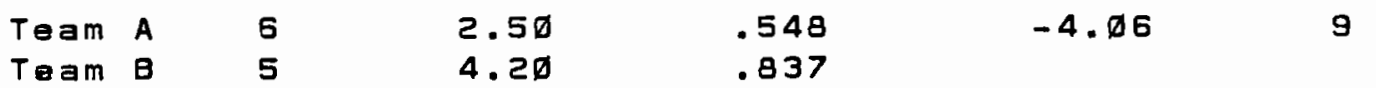

12. S/He criticizes a specific act rather than a particular individual.

5 always 4 often 3 occasionally 2 seldom 1 never

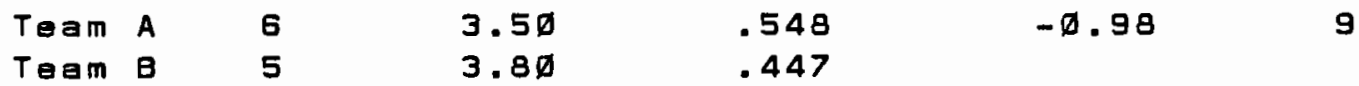

13. S/He changes the duties of members without first talking it over with them.

1 always 2 often 3 occasionally 4 seldom 5 never

$\begin{array}{llllll}\text { Team A } & 6 & 2.33 & .816 & -7.24 & 9 \\ \text { Team B } & 5 & 5.00 & \emptyset . & \end{array}$

14. S/He looks out for the personal welfare of individual members.

5 always 4 often 3 occasionally 2 seldom 1 never

$\begin{array}{llrrrr}\text { Team A } & 6 & 2.5 \emptyset & 1 . \emptyset 49 & -3.36 & 9 \\ \text { Team B } & 5 & 4.2 \emptyset & .447 & \end{array}$




$\begin{array}{lllll} & \text { NOEF } & \text { STANDARD } & \text { T } & \text { DEGREES } \\ \text { ITEM } & \text { CASES MEAN } & \text { DEVIATION } & \text { VALUE OF FREEDOM }\end{array}$

15. S/He expresses appreciation when a worker does a good job.

5 always 4 often 3 occasianally 2 seldom 1 never

Team A 6

2.16

.753

$-5.28$

9

Team $B$

4.20

.447

16. S/He promotes communication by helping to problemsolve conflicts between workers.
5 often
4 fairly often
3 occasionally
2 once in awhile
1 very seldom

$\begin{array}{llllll}\text { Team } A & 6 & 1.33 & .516 & -7.14 & 9 \\ \text { Team B } & 5 & 4.40 & .894 & \end{array}$

17. S/He acts without consulting the group.
1 often
3 occasionally
2 fairly often
4 once in awhile
5 very seldom

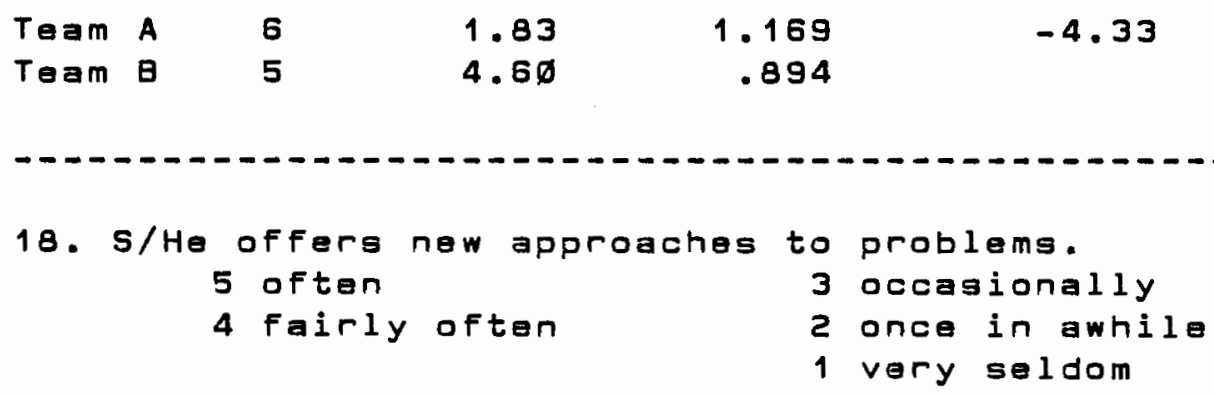

$\begin{array}{rrrrrr}\text { Team A } & 6 & 2.5 \varnothing & 1.049 & -4.54 \\ \text { Team B } & 5 & 4.8 \varnothing & .447 & \end{array}$

9 


\begin{tabular}{|c|c|c|c|c|c|}
\hline & $\mathbf{N}$ & & STANDARD & $T$ & DEGREES \\
\hline EN & CASES & MEAN & DEVIATION & VALUE & OF FREEOOM \\
\hline
\end{tabular}

19. S/He makes himself/hergelf available to help workers with personal problems.
5 often
4 fairly often
3 occasionally
2 once in awhils
1 very seldom

$\begin{array}{rrrrrr}\text { Team A } & 6 & 1.50 & 1.225 & -4.02 & 9 \\ \text { Team B } & 5 & 4.00 & .707 & \end{array}$

2ø. s/He displays a good working knowledge of this program. 5 often

4 fairly often

3 occasionally

2 ance in awhile

1 very seldom

$\begin{array}{rrrrrr}\text { Team } A & 6 & 2.50 & 1.378 & -2.88 & 9 \\ \text { Team B } & 5 & 4.40 & .548 & & \end{array}$

21. S/He engages in friendly jokes and comments during group meetings.

$\begin{array}{ll}5 \text { often } & 3 \text { occasionally } \\ 4 \text { fairly often } & 2 \text { once in awhile } \\ & 1 \text { very seldom }\end{array}$

Toam A 6

2.65

Team $B \quad 5$

3.80

1.033

$-1.97$

9

.837
22. 5/He is able to utilize past experiance in the field.
5 oftan
4 fairly often
3 occasionally
2 once in awhile
1 very seldom

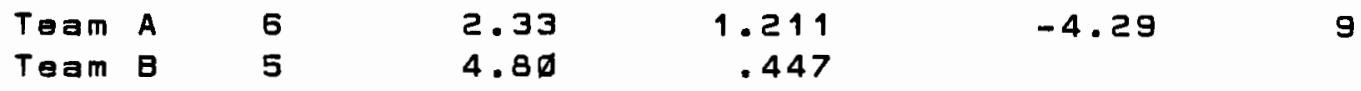




\begin{tabular}{|c|c|c|c|c|c|}
\hline & NO. OF & & STANDARD & $T$ & DEGREES \\
\hline EM & CASES & MEAN & DEVIATION & VALUE & OF FREEDOM \\
\hline
\end{tabular}

23. S/He displays a good working knowledge of the field.

$$
\begin{array}{ll}
5 \text { often } & 3 \text { occasionaliy } \\
4 \text { fairly often } & 2 \text { once in awhile } \\
& 1 \text { very seldom }
\end{array}
$$

$\begin{array}{lllllll}\text { Team } & A & 6 & 2.33 & .816 & -6.61 & 9 \\ \text { Team } B & 5 & 4.8 \rrbracket & .447 & \end{array}$

24. S/He makes helpful suggestions about work problems.

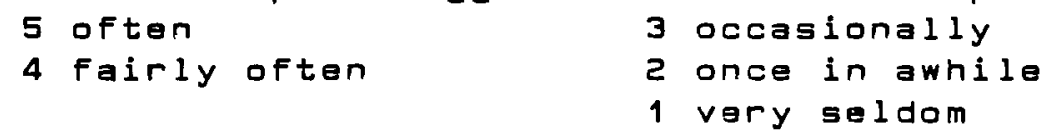

Team A 6

Team $B \quad 5$

$$
2.66
$$

$4.8 \emptyset$

9

25. S/He rules with an iron hand.
1 always
2 often
3 occasionally
4 seldom
5 never

$T$ eam $A$

Team $B$

1.56

.816

$-5 . \emptyset 1$

9 